\title{
THE BEGINNING OF CULTURAL MEMORY PRODUCTION IN CHINA AND THE MEMORY POLICY OF THE ZHOU ROYAL HOUSE DURING THE WESTERN ZHOU PERIOD
}

\author{
Maria Khayutina*
}

\begin{abstract}
This article explores how the memory of the conquest of Shang and the rise of the first Zhou kings was transmitted during the early centuries of the Zhou dynasty, specifically as it was reflected in inscriptions on excavated bronze vessels and bells from the Western Zhou period (ca. mid-eleventh to early eighth century B.C.E.). Approaching these inscribed objects and their texts from the perspective of the theories of social memory and cultural memory reveals that commemorating the foundational past of the dynasty became part of an intentional policy of the Zhou royal house as early as the first half of the tenth century B.C.E. It demonstrates that by the mid-tenth century в.C.E., a stable narrative emphasizing Kings Wen 文 and $\mathrm{Wu}$ 武 as the founding fathers of the Zhou dynasty was established at the expense of King Cheng 成, whose role was gradually downplayed following the general logic of lineage organization, according to which the commemoration of the earliest common ancestors serves as the foundation of corporate integrity in a network of patrilineally related families. It shows that most of
\end{abstract}

*Maria Khayutina, 夏玉婷, Ludwig-Maximilians-University (LMU) of Munich; email: Maria.Khayutina@lmu.de

This work has been a part of my research project Kinship, Marriage and Politics in the Light of Ritual Bronze Inscriptions from 11-8 c. BCE supported by the Deutsche Forschungsgemeinschaft (2014-2018, grant Nr. KH 286/3-1, 2). I reworked the manuscript during my stay as a guest fellow at the International Consortium for Research in the Humanities "Fate, Freedom and Prognostication" at the University of Erlangen-Nuremberg during 2018-2019 and presented the second draft at the conference Rethinking Early Chinese Historiography, organized by Yuri Pines and Martin Kern in Jerusalem on May 12-16, 2019. I am grateful to Edward Shaughnessy, Erica Brindley, Dirk Meyer, Ondřej Škrabal, Armin Selbitschka, Shing Müller, Yuri Pines, Kai Vogelsang, Lothar von Falkenhausen, and one anonymous reviewer for their critical remarks at various stages of this work. I am also indebted to Frank Saunders for the proof-reading of the final version. All remaining errors are my responsibility.

(C) The Society for the Study of Early China and Cambridge University Press 2021. This is an Open Access article, distributed under the terms of the Creative Commons Attribution

licence (http://creativecommons.org/licenses/by/4.0/), which permits unrestricted re-use, distribution, and reproduction in any medium, provided the original work is properly cited. 
the men who included such commemorations in inscriptions indeed belonged to the royal patrilineal network, wherein they occupied the highest positions. It further exemplifies that the royal house cultivated the memory of the first kings using various media, including rituals, utensils, royal speeches, and inscriptions. From the analysis of such inscriptions, we can infer that that the foundational memory of the Zhou dynasty was usually reactivated in the context of political negotiations, some of which included addressing lineage outsiders. Finally, it shows that both the royal house and other metropolitan lineages modified the foundational narrative according to their current needs. This article thus contributes both to tracing the roots of the early Chinese historiographic tradition and to understanding memory production in a society as an ongoing process of negotiations and adaptations.

The Zhou conquest of Shang (mid-eleventh century B.C.E.) is one of the most frequented lieux de mémoire (sites of memory) of the Chinese tradition. ${ }^{1}$ Form the point of view of traditional historiography, the conquest marks the beginning of the Zhou dynasty (1046/1045-256 B.C.E.) - the last and greatest of the "Three Dynasties" (Xia, Shang and Zhou) that ruled the "Under-Heaven" (tian xia 天下) before the foundation of the first centralized empire in 221 B.C.E. The memory of the conquest and the first Zhou kings became central to the early literary texts whose final versions are known today as parts of the Shi jing 詩經 (The Classic of Poetry, or Poetry) and the Shang shu 尚書 (Exalted Documents, or Documents) Classics. Transmitted texts and excavated manuscripts alike reflect that during the Eastern Zhou period (770third century B.C.E.), the ruling and intellectual elites of various early Chinese polities widely shared this memory. Upon the canonization of the Classics during the Han Empire (202 B.C.E.-220 C.E.), this memory became one of the foundations of the imperial narrative of the past for many centuries to come. But how was this memory transmitted during the first centuries of the Zhou dynasty, before the Classics had been produced and spread widely? Coming to terms with this question is important both for tracing the early roots of the early Chinese historiographic tradition and for understanding memory production as a process of constant negotiations and adaptations to the present needs of a given society.

1. "A lieu de memoire is any significant entity, whether material or nonmaterial in nature, which by dint of human will or the work of time has become a symbolic element of the memorial heritage of any community" (Pierre Nora, Realms of Memory: The Construction of the French Past, English Language edition edited and with a foreword by Lawrence D. Kritzman. Translated by Arthur Goldhammer (New York: Columbia University Press, 1996), xvii; cf. Pierre Nora, Les Lieux de mémoire (Paris: Gallimard, 1984-1992). 
The earliest mentions of the conquest of Shang and/or the first Zhou kings can be found in inscriptions on excavated bronze vessels and bells. Chinese Bronze Age elites used such objects for feasts and ancestral sacrifices, as dowry or wedding presents, and as burial goods. Focusing on the inscriptions from around the mid-eleventh to the early eighth century B.C.E., defined in current historiography as the Western Zhou period, I address the following questions to these texts:

- How was the conquest commemorated by its eyewitnesses?

- When did the commemoration of the conquest and the first kings become a part of an intentional memory policy?

- Who cultivated this memory?

- What present situations involved the acts of evoking the past?

- Which changes in the Zhou foundational narrative occurred during the period under consideration?

In the following, I demonstrate that a stable narrative emphasizing Kings Wen 文 and $\mathrm{Wu}$ 武 as a pair of founding fathers of the Zhou was established by the mid-tenth century B.C.E. at the cost of downplaying the role of King Cheng 成, despite the fact that the conquest of Shang was accomplished during his reign. I argue that the reason for focusing on Kings Wen and Wu and downplaying King Cheng's role was in the Zhou kinship cum political organization, in which commemoration of the earliest common progenitors served as a basis of corporate integrity in a network of patrilineally related lineages. I show that the royal house cultivated the memory of the first kings using various media, including rituals, utensils, royal speeches, and inscriptions, and that this memory was usually reactivated in the context of political negotiations, and was by no means part of routine, bureaucratic discourse. I show examples of the ways this memory was transmitted within metropolitan lineages and how it was modified according to the current needs of the royal house and other aristocratic families.

\section{The Conquest of Shang and the Western Zhou Chronology}

The conquest was a gradual process rather than a single event. According to transmitted tradition, King Wen ("Adorned") received the Heavenly Mandate to overturn the decadent Shang dynasty, but he died before being able to achieve his goal. ${ }^{2}$ His son King Wu ("Martial") conquered

2. The posthumous title "Wen" is often translated as "Civil" as a counterpart to Wu, "Martial," the title of his successor. Translations "Civilized" and "Cultivated" 
Shang four years later for the first time. He installed there a surviving Shang prince as a nominal ruler under supervision of his three brothers. After King Wu's death four years after the conquest, the puppet Shang ruler and the three treacherous supervisors raised a rebellion. It was suppressed during the reign of the second king, Cheng ("Accomplished"), wherein another brother of King Wu, Zhou gong 周公 (usually translated as "Duke," but more accurately rendered as "Patriarch") Dan 旦, played the leading role. This time Shang was re-conquered and destroyed. This was the second and the final conquest of Shang. ${ }^{3}$ The conquest then extended further to the east, reaching the territories of the former Shang allies in western Shandong 山東 and leading to the foundation of $\mathrm{Lu}$ 魯. 4

As the Zhou conquest of Shang marks the beginning of the Zhou dynasty, from a modern perspective, it is essential to know its date. However, people cared less about dates at the time of the conquest, as it was sufficient to remember what happened and where it took place. Hence, records of exact dates of events seldom appear in early

are also often seen, but they project Eastern Zhou, Han, and modern concepts back to the archaic past. The translation "Adorned" is adopted here based on the meaning of wen as "pattern, decorum," following David Schaberg, A Patterned Past: Form and Thought in Early Chinese Historiography (Cambridge, MA: Harvard University Asia Center, 2001), although Schaberg translates the title "Wen" as "Patterned" (see pp. 57-86). Alternatively, Lothar von Falkenhausen, "The Concept of Wen in the Ancient Chinese Ancestral Cult," Chinese Literature: Essays, Articles, Reviews 18 (1996), 1-22 suggests the translation "Accomplished," but this word better suits to translate the title of King Cheng.

3. Chen Mengjia 陳夢家, “Xi Zhou tongqi duandai (yi)” 西周銅器斷代(一), Kaogu xuebao 1955.1, 137-75, at 160; Li Feng, Landscape and Power in Early China: The Crisis and Fall of the Western Zhou, 1045-771 BC (Cambridge: Cambridge University Press, 2006), 65 .

4. Lu, where Zhou gong was awarded a domain, became the pioneer of Chinese historiography by introducing systematic record-keeping in 722 в.C.E. Whether $\mathrm{Lu}$ only adopted the practice already established at the royal court, and whether some other polities similarly compiled annals is unclear, since whatever historical court records were destroyed by the Qin (221-207 B.C.E.) as a part of its invading imperial memory policy. As Qin's own annals, to Sima Qian's great disappointment, were unsystematic and lacked date records, it is obvious that Eastern Zhou polities had no single standard of record-keeping, and it may be not purely accidental that Lu's records became so prominent. Whether or not Lu's native Confucius (551-479 B.C.E.) personally edited the Spring and Autumn annals of Lu, he certainly contributed to the spread of the Lu vision of the past. Teaching the ancient Shang shu and Shi jing to his disciples, he stylized Zhou gong to an ideal sage minister and indispensable aid to King Cheng, representing the latter as immature and seeking protection. Thus, $\mathrm{Lu}$, originally a colony on a far eastern periphery of the Zhou realm, left a deep imprint on the traditional narrative about the beginning of the Zhou dynasty. One should keep this in mind when deliberating on the historical roles of King Cheng and Zhou gong. 
inscriptions. ${ }^{5}$ Although events dating becomes common at the end of the reign of King $\mathrm{Mu}$ 穆 (the 5th king) and during the reign of King Gong 共 (the 6th king), it declines during the reigns that followed, only to gain popularity again during the second half of the ninth century B.C.E. ${ }^{6}$ It is not before 841 B.C.E. that the chronology of Zhou kings' reigns is clearly established. 7 Based on various references in Warring States period texts and divergent assumptions about the Zhou calendar, scholars have proposed around thirty different dates for the conquest. ${ }^{8}$ Currently, two dates, 1045 B.C.E. or 1046 B.C.E., have become widely used, but neither of these is secure. ${ }^{9}$ The dates of individual reigns are equally controversial (see Table 1). ${ }^{10}$ Therefore, in the following discussion I will provide exact dates only for the kings whose chronologies can be plausibly reconstructed, but I will also use sequential numbers for these whose dates are still uncertain.

5. Maria Khayutina, "The Royal Year-Count of the Western Zhou Dynasty (1045771 BC) and its Use(r)s: A Sociological Perspective," in Time and Ritual in Early China, ed. Xiobing Wang-Riese and Thomas O. Höllmann (Wiesbaden: Harrassowitz, 2009), 125-51.

6. For inscriptions and the question of the length of the reigns of Kings $\mathrm{Mu}$ and Gong, see Edward L. Shaughnessy, Sources of Western Zhou History: Inscribed Bronze Vessels (Berkeley: California University Press, 1991), 248-56; Maria Khayutina, "The Tombs of the Rulers of Peng and Relationships between Zhou and Northern Non-Zhou Lineages (Until the Early Ninth Century B.C.)," in Imprints of Kinship: Studies of Recently Discovered Bronze Inscriptions from Ancient China, ed. Edward L. Shaughnessy (Hong Kong: The Chinese University Press, 2016), 71-132, at 81.

7. Ebbs and flows in record-keeping practice can be observed in the example of the chronological tables in the Appendix: although dates, albeit incomplete, occasionally appear already in inscriptions from the reign of King Zhao, there are no dated inscriptions from the first twenty years of King $\mathrm{Mu}$. Towards the end of the latter reign full date notations suddenly become widespread.

8. Zhu Fenghan 朱鳳瀚 and Zhang Rongming 張榮明, eds., Xi Zhou zhu wang nian dai yan jiu 西周諸王年代研究 (Guiyang: Guizhou renmin, 1998).

9. Compare Edward L. Shaughnessy, Sources of Western Zhou History, 235 to David W. Pankenier, "The Cosmo-Political Background of Heaven's Mandate," Early China 20 (1995), 121-76, 130; See also Xia Shang Zhou duandai gongcheng zhuanjiazu, ed., Xia Shang Zhou duan dai gong cheng 1996/2000 nian jieduan chengguo baogao: Jian ben 夏商周 斷代工程1996/2000年階段成果報告: 簡本 (Beijing: Shijie tushu, 2000), 49.

10. This question is not going to be resolved in a near future. The situation is currently getting more complicated because of both new archaeological discoveries and the publication of vessels from private collections. On one hand, inscriptions from places outside of the royal domain are being used to challenge earlier reconstructions of the royal chronology without even questioning whether their writers used the royal calendar. Questions regarding the authenticity of privately owned bronzes are generally avoided. Nevertheless, even if the royal chronology can be adjusted, groups of inscriptions attributed to certain reigns that are interconnected by their content, paleography, and vessels' appearance, and that feature dates compatible within a single calendar should remain constant. 
TABLE I Variants of Zhou periodization and chronology

\begin{tabular}{|c|c|c|c|c|c|c|c|}
\hline \multicolumn{3}{|c|}{ Archaeological periods } & \multicolumn{2}{|l|}{ Kings } & \multicolumn{3}{|c|}{ Proposed reign dates (B.C.E.) } \\
\hline $\begin{array}{l}\text { Chen Mengjia } \\
1955\end{array}$ & $\begin{array}{l}\text { Zhu } \\
2009\end{array}$ & Fenghan & Number & $\begin{array}{l}\text { Posthumous } \\
\text { title }\end{array}$ & $\begin{array}{l}\text { Shaughnessy } \\
1991\end{array}$ & $\begin{array}{l}\text { Xia-Shang- } \\
\text { Zhou } 2000\end{array}$ & $\begin{array}{l}\text { Tentatively assumed } \\
\text { in this article }\end{array}$ \\
\hline \multirow[t]{4}{*}{ Early } & & \multirow[t]{2}{*}{1} & 1 & Wu武 & $1049 / 45^{-1043}$ & $1046-1043$ & $1046 / 5-1043$ \\
\hline & & & 2 & Cheng 成 & $1042 / 35-1006$ & $1042-1021$ & 1042-? \\
\hline & & \multirow[t]{2}{*}{2} & 3 & Kang 康 & $1005 / 03-978$ & 1020-996 & $?$ \\
\hline & & & 4 & Zhao 昭 & $977 / 75-957$ & $995-977$ & $?-957$ \\
\hline \multirow[t]{5}{*}{ Middle } & & \multirow[t]{2}{*}{3} & 5 & $\mathrm{Mu}$ 穆 & $956-918$ & $976-923$ & $956-923$ \\
\hline & & & 6 & Gong 共 & $917 / 15-900$ & $922-900$ & $922-900$ \\
\hline & & \multirow[t]{3}{*}{4} & 7 & Yih 懿 & $899 / 97-873$ & $899-892$ & 899-? \\
\hline & & & 8 & Xiao 孝 & $872-866$ & $891-885$ & $?$ \\
\hline & & & 9 & Yi 夷 & $865-858$ & $884-878$ & $?$ \\
\hline \multirow[t]{4}{*}{ Late } & & \multirow[t]{2}{*}{5} & 10 & $\mathrm{Li}$ 厲 & $857-842$ & $877-841$ & $?-841$ \\
\hline & & & 11 & Gonghe 共和 & $841-828$ & $841-828$ & $841-828$ \\
\hline & & \multirow[t]{2}{*}{6} & 12 & Xuan 宣 & $827 / 25-782$ & $827-782$ & $827-782$ \\
\hline & & & 13 & You 幽 & $781-771$ & $781-771$ & $781-771$ \\
\hline
\end{tabular}


Table 1 further shows the conventional subdivision of the Western Zhou period into three subperiods of four or five reigns. This scheme, developed by archaeologists and later adopted by historians, is arbitrary and crude, because it lumps together changes in material culture and historical phenomena that ought to be considered separately. Many archaeologists and bronze specialists use a six-part periodization, subdividing each of the periods in two parts. ${ }^{11}$ This sometimes enables us to establish a finer chronology of bronze vessels and bells and their inscriptions. It is now the turn of historians, who use inscriptions as sources, to develop a more chronologically informed approach to the Western Zhou social processes and changes. ${ }^{12}$ In my discussion, I will pay a considerable attention to the issue of various bronzes' dating, including revisions of the dates of several important inscriptions in the Appendix.

\section{Bronze Inscriptions and Western Zhou Social Memory}

During the twentieth century, bronze inscriptions became recognized as important sources for the study of the social and political history of the Western Zhou period. ${ }^{13}$ Although some inscriptions may contain historically relevant information, inscribed bronzes have been more broadly understood as media of religious communication between the living and the ancestors to whom they were often dedicated. ${ }^{14}$ However, often enough, bronze objects were equally explicitly dedicated to the living, as well as to posterity. Hence, Wang Ming-ke has proposed interpreting their functions in Zhou society in light of the theory of social memory. ${ }^{15}$

11. See Zhu Fenghan 朱鳳瀚, Zhongguo qingtongqi zonglun 中國青銅器綜論 (Shanghai: Guji, 2009).

12. For a recent attempt to provide a four-partite historical periodization based on art-historical periodization of inscribed bronzes, see Matsui Yoshinori 松井嘉德, "Western Zhou History in the Collective Memory of the People of the Western Zhou: An Interpretation of the Inscription of the 'Lai pan,'" Toyoshi kenkyu 66 (2008), 664-712, at 661-64, based on Hayashi Minao 林已奈夫, In Shū seidōki sōran 1: In Shū jidai seidōki no kenky ū 殷周青銅器綜覧一: 殷周時代青銅器の研究 (Tōkyō: Yoshikawa Kōbunkan, 1984). Although I principally agree that the Western Zhou period should be subdivided into at least four periods, I disagree with Matsui's specific suggestions.

13. Edward L. Shaughnessy, Sources of Western Zhou History.

14. Lothar von Falkenhausen, "Issues in Western Zhou Studies," Early China 18 (1993), 139-226.

15. Wang Ming-ke, "Western Zhou Remembering and Forgetting," Journal of East Asian Archaeology 1 (1999), 231-50. 
In the 1920s, Maurice Halbwachs demonstrated that human memory functions within a collective framework. Individual memories are shaped through communication within a group that collectively produces its representations of a common past. As memory is always selective, different groups of people - families, social classes, or religious groups-produce different collective memories, which in turn give rise to different social identities and different modes of behavior. Since humans' sense of reality is inseparable from present life, the image of the past within a social group is shaped by its current needs. The agents who manage the memory can use it to pursue their goals, which can be of political nature.$^{16}$ Eric Hobsbawm further showed that societies "invent traditions" responding to political changes, while Benedict Anderson discussed how modern nations are being constructed as "imagined communities" within the political boundaries of national states. Therein, deliberate strategies of both remembering and forgetting serve to maintain the common national identity. ${ }^{17}$ Based on this theoretical background, Wang Ming-ke has suggested looking at inscribed bronzes as "containers of social memories." 18

Attempting to reveal what kind of identities and what social organization inscribed memories might support, Wang identifies "the ancestors' contribution to the Zhou conquest of Shang" as one important theme. Pointing out that most inscriptions referring to it derive from the Zhou metropolitan region in the Wei 渭 River valley in Shaanxi 陝西, he supposes that the group that shared such memories consisted of members of old polities of this region that had their roots in pre-dynastic Zhou time and had been Zhou allies in the conquest campaign. Cultivating matrimonial relationships between the old families, retelling the story of the conquest in ceremonies by current kings, and inscribing the conquest's memories on bronze vessels supported the in-group feeling in their "confederacy." Wang supposes that other families, whose ancestors did not participate in the conquest, commemorated it too as they were "willing to remember some crucial events that tied [them] more closely to the Zhou royal family and the allies in the Zhou conquest." 19

16. Maurice Halbwachs, La mémoire collective: Ouvrage posthume publié par Mme Jeanne Alexandre née Halbwachs (Paris: Presses Universitaires de France, 1950); Francis J. Ditter, The Collective Memory, trans. Maurice Halbwachs (New York: Harper \& Row, 1980).

17. Eric Hobsbawm, "Introduction: Inventing Traditions," in The Invention of Tradition, ed. Eric J. Hobsbawm and Terence O. Ranger (Cambridge: Cambridge University Press, 1983), 1-14; Benedict R. Anderson, Imagined Communities: Reflections on the Origin and Spread of Nationalism (London: Verso, 1991).

18. Wang Ming-ke, "Western Zhou Remembering and Forgetting," 231-32.

19. Wang Ming-ke, "Western Zhou Remembering and Forgetting," 235-38. 
In the next step, Wang moves towards transmitted literature from the Warring States to the Han period. He exemplifies that some memories of the Western Zhou period had been altered, while many facts had been forgotten. He identifies this as reflections of "cultural amnesia" and, predictably, suggests that the latter had been caused by the relocation of the Zhou court in 771 B.C.E. The latter event both caused the loss of material memory carriers (bronze vessels), and triggered political processes that generated new social needs, which, according to Halbwachs and Hobsbawm, required new images of the past. The authors of the later periods reinvented their distant past, as this was better suited to their aim of constructing their huaxia 華夏 cultural and political identity. ${ }^{20}$

Wang makes an important contribution inasmuch he recognizes the agency of lineages in social and political processes-from the conquest itself up to the collective production of the conquest's memory. Wang's study fosters an interactive understanding of the Zhou society and fits the current trend of viewing archaic polities as stages of "collective action" involving various forms of top-down and bottom-up transactions and negotiations. ${ }^{21}$ However, looking at the whole Western Zhou period as a single block of cultural reality while comparing it to the opposite end of the long Zhou epoch, Wang misses an opportunity to reveal changes, including the reshaping and selective forgetting of earlier narratives, that occurred in the memory culture of the metropolitan elites already during the mid-eleventh to early eighth century B.C.E.

Just a few years after the publication of Wang's pioneering, but, unfortunately, not widely known study, an archaeological sensation provided a new opportunity to ponder the process of memory formation in Western Zhou society and the functions of bronze inscriptions in this process. A hoard of twenty-seven bronze vessels was discovered in Yangiiacun 楊家村 in Meixian 眉縣 county, just south of the ancient Zhou Plain, which was the main ritual, political, and administrative center of the Western Zhou kings. ${ }^{22}$ Most of the vessels were commissioned by a member of the Shan 單 lineage whose personal name was transcribed into modern characters either as Lai 逨 or Qiu 述 (the latter transcription

20. Wang Ming-ke, "Western Zhou Remembering and Forgetting," 239-47.

21. Blanton Richard and Fargher Lane, eds., Collective Action in the Formation of PreModern States (New York: Springer, 2008).

22. For the status of Zhouyuan 周原 (the Zhou Plain), also referred to as Qi Zhou 岐周 (Zhou under the Mount Qi) in the system of royal residences, see Maria Khayutina, "Royal Hospitality and Geopolitical Constitution of the Western Zhou Polity (1046/5-771 BC)," T'oung Pao 96 (2010), 1-77, at 60-73. 
will be followed in this study). ${ }^{23}$ The ding cauldrons were dated to the forty-second and forty-third years of King Xuan's reign (786 and 785 B.C.E.). A 372 -character-long inscription on a pan basin recorded the commissioner's pedigree from the time of the conquest of Shang interlinked with the line of the Zhou royal house that all Qiu's ancestors mentioned in the inscription faithfully served. ${ }^{24}$ The Qiu pan became immediately famous for being the first material proof of the Zhou kings' list recorded in the "Zhou ben ji" 周本紀 chapter of Sima Qian 司馬遷's (145-90 в.C.E.) Shi ji 史記. At the same time, the Qiu pan corroborated the observation based on a similar but earlier record of pedigree aligned with the history of the royal house, the Shi Qiang pan 史牆盤, dating around 900 B.C.E. and excavated in 1976, that the Western Zhou official historical narrative only slightly differed from the transmitted history. ${ }^{25}$ In any case, both pan and some other inscriptions could be now treated as evidence of a high historical consciousness within the Western Zhou nobility, which, in turn, could be examined from a socioanthropological perspective. For instance, Lothar von Falkenhausen has diagnosed "the strategic importance of talking about the past as one way of furthering particular lineage interests vis-a-vis the royal government in a highly public context." ${ }^{26}$ Considering a discrepancy between the representation of the history of the Shan lineage recorded in the Qiu pan and the data about this lineage in much later-Tang (618906) - transmitted sources, as well as pointing out some irregularities in the list of Qiu's ancestors, Falkenhausen has supposed "that the author, or authors, of the Qiu-pan inscription manipulated historical memory." Matsui Yoshinori went even so far as to define the Qiu pan (or, in his transcription, the Lai pan) as tsukura reta rekishi 作られた歴史 ("made up history," or "invented history") "designed to underscore

23. Shaanxi sheng kaogu yanjiusuo, Baoji shi kaogu gongzuodui lianhe kaogudui, and Meixian wenhuaguan, "Shaanxi Meixian Yangjiacun Xi Zhou qingtongqi jiaocang" 陝西眉縣楊家村西周青銅器窝藏, Kaogu yu wenwu 2003.3, 3-12; Shaanxi sheng kaogu yanjiusuo, Baoji shi kaogu gongzuodui Yangjiacun lianhe kaogudui and Meixian wenhuaguan, "Shaanxi Meixian Yangjiacun Xi Zou qingtongqi jiaocang fajue jianbao" 陝西眉縣楊家村西周青銅器窝藏發掘簡報, Wenwu 2003.6, 4-42.

24. For the identification of the Qiu pan as a record of pedigree rather than a lineage's genealogy, see David Sena, "Arraying the Ancestors in Ancient China: Narratives of Lineage History in the 'Scribe Qiang' and 'Qiu' Bronzes," Asia Major (3rd Ser.) 25 (2012), 63-81, at 79 .

25. One difference is in the perception of King Zhao as a victorious king in the inscriptions and the one who lost a war in transmitted texts.

26. Lothar von Falkenhausen, "The Inscribed Bronzes from Yangjiacun: New Evidence on Social Structure and Historical Consciousness in Late Western Zhou China (c. 8oo BC)," Proceedings of the British Academy 139 (2005), 239-93, at 277. 
the achievements of the family, and created with Lai's power as the backdrop." Matsui suggests that:

the royal genealogy inserted into the inscription of the "Lai pan" was an important tool, providing a sense of reality to such an "invented history," and acting as a validating site in the "collective memory" of the dynastic foundation. ${ }^{27}$

Although the English version of Matsui's article repeatedly speaks about "collective memory," making the reader anticipate some socioanthropological insights, it does not specify what this "collective" actually is. The Japanese original only mentions "Shū hito-tachi ni kioku" 周人たちに記憶 (Zhou people's memory). ${ }^{28}$ Neither version, as is indeed the case for hundreds of other papers working with the concept of "Zhou people/people of Zhou," attempts to define it as a sociopolitical entity. Still, it is possible to deduce that when Matsui speaks of ke 家 / "families," he means aristocratic lineages, and he regards these as active participants in the memory-production process. Although Falkenhausen does not thematize "collective" or "social" memory in his works, his views are quite close to these of Wang Ming-ke and Matsui, as he assumes that aristocratic lineages kept their own archives and engaged themselves in reconstructing their own history. ${ }^{29}$

In a recent contribution to a volume on historical consciousness in the ancient world, I attempted to provide both a sociologically and chronologically sensitive view of the Zhou collective memory formation, comparing bronze inscriptions from the Western and Eastern Zhou periods that refer to the conquest of Shang and the first Zhou kings. I pointed out that during the Western Zhou, such inscriptions were usually commissioned by people who-like Qiu/Lai-belonged to metropolitan Ji 姬-surnamed lineages related to the royal house by patrilineal kinship. A few lineage outsiders, who equally evoked these memories, were close associates or important political partners of the current kings, while some of them were also affiliated with the Ji clan by affinal ties. ${ }^{30}$ Commemorations of the conquest and the first kings

27. Matsui Yoshinori, "Western Zhou History in the Collective Memory," 667.

28. Matsui Yoshinori, "Kioku sa reru Seishû shi—Rai ban mei no kaidoku" 記憶さ れる西周史——速盤銘の解讀, Toyoshi kenkyu 2005.3, 457-89, 473.

29. See Falkenhausen, "Issues in Western Zhou Studies," 163; Falkenhausen, "The Inscribed Bronzes from Yangjiacun," 254, 272-74.

30. Affinity is a kinship relationship established through marriage. See, for example, Rubie S. Watson, Inequality among Brothers: Class and Kinship in South China (Cambridge: Cambridge University Press, 1985), 117-136; Maria Khayutina, "Marital Alliances and Affinal Relatives (sheng 侽 and hungou 婚購) in the Society and Politics of Zhou China in the Light of Bronze Inscriptions," Early China 37 (2014), 39-99. 
were usually embedded in royal speeches addressed at the vessel's commissioner. Considering that metropolitan elites would be unlikely to invent royal speeches-not necessarily because of the possible court censorship, but because of mutual control within the elite-I suggest that the right to reproduce such speech with an allusion to the memory of the Zhou foundational past signified a high distinction of specific addressees and emphasized their close relationship with the royal house. Thus, in contrast to Wang Ming-ke's assumption that old aristocratic lineages deliberately commemorated the conquest and the first kings to preserve their membership in the Zhou "confederacy," or to Matsui's hypothesis that insignificant families that accidentally rose to nobility and power invented family histories linking them to the dynasty's founding heroes, I suggest that these inscriptions reflect a targeted memory policy of the royal house. This policy aimed to approximate certain members of the elite and to maintain hierarchy within a network of agnatically and affinally related elite families, instead of attempting to forge a broadly accessible collective memory for a "Zhou nation." I further point out that Western Zhou inscriptions referring to the deep past reflect genealogical rather than historical consciousness and demonstrate that inscriptions from the Spring and Autumn period equally reflect the transmission of the Zhou foundational memory along genealogical lines. ${ }^{31}$

Regarding the social functions of the memory of the distant Zhou past in bronze inscriptions, neither Wang nor myself have discussed in detail the specific content of commemorative references, nor have we analyzed the means (apart from the inscriptions themselves) by which this memory was constructed. Falkenhausen and other authors focusing specifically on the Qiu pan or Shi Qiang pan have compared these with transmitted history. Matsui, moreover, has attempted to check whether the memory of the royal line underwent changes during the Western Zhou period. As a result, he has primarily revealed differences from the Eastern Zhou and later transmitted texts. The present article will attempt to reveal whether there was a single narrative of the dynasty's beginning from its inception, whether different narratives coexisted, or whether there was a master narrative that changed over time. It will pay attention to the context of commemorative practices as well as to the aspects of mediality, such as the interplay of oral and written communication, and the use of images in the memory transmission. To meet these goals, I will

31. Maria Khayutina, "Reflections and Uses of the Past in Chinese Bronze Inscriptions from the Eleventh to Fifth Centuries BC: The Memory of the Conquest of Shang and the First Kings of Zhou," in Historical Consciousness and the Use of the Past in the Ancient World, ed. John Baines, Henriette van der Blom, Yi Samuel Chen and Tim Rood (Sheffield: Equinox, 2019), 157-80. 
make use of some analytic tools developed by Jan and Aleida Assmann in the framework of their theory of cultural memory.

\section{Western Zhou Cultural Memory and Bronze Inscriptions}

Jan and Aleida Assmann's theory of cultural memory relies on Halbwachs' theory of collective memory, stressing the qualitative difference between two "memory frameworks": "communicative memory" versus "cultural memory." Communicative memory is "biographical" and "factual." It is located within the generation that experienced certain historical events as adults and was able to transmit the memory of these events to descendants. This primarily happens through everyday interaction and storytelling, though it also occurs using different other media such as writing or images. The main social framework through which communicative memory is transmitted is usually the family, although this can also be a neighborhood, a professional group, or other network. While eyewitnesses rely on their own remembering, and storytellers and listeners may change roles, the content and the interpretations of events within the communicative framework may vary and change over time. The horizon of the communicative memory may extend up to three or four generations, or eighty to a hundred years into the past..$^{22}$ It is not tied to fixed events, and it continuously shifts as elder generations pass away and the memories of younger generations come to the foreground. 33

At the core of cultural memory are the events of the distant past, regarded as foundational for the community. The temporal horizon of cultural memory, tied to these events, does not shift over time. Maintaining the foundational memory serves to stabilize and convey the community's self-image, and to facilitate the concretion of identity,

32. The extent of the communicative horizon certainly depends on contemporary life expectancy. The data about the age of persons buried in the early Spring and Autumn period's graves at the Shangma cemetery reveal that only roughly 15 percent of males lived beyond the age of 55; cf. Lothar von Falkenhausen, The Chinese Society in the Age of Confucius (1000-250 BC): The Archaeological Evidence (Los Angeles: Cotsen Institute of Archaeology Press, 2006), 136. This means that the horizon of the communicative memory in the Zhou China extended to ca. eighty years.

33. Cf. Jan Assmann, trans. John Czaplicka, "Collective Memory and Cultural Identity," New German Critique 65 (1995), 123-33; Jan Assmann, Cultural Memory and Early Civilization: Writing, Remembrance, and Political Imagination (Cambridge: Cambridge University Press, 2011); Aleida Assmann and Dietrich Harth, eds., Kultur als Lebenswelt und Monument (Frankfurt am Main: Fischer-Taschenbuch, 1991); Aleida Assmann, Erinnerungsräume: Formen und Wandlungen des kulturellen Gedächtnisses (Munich: Beck, 1999); Astrid Erll, Memory in Culture (Houndmills: Palgrave Macmillan, 2011). 
by which social groups distinguish "us" from "them." Cultural memory, maintained through figures of memory, always depends upon a specialized practice of cultivation, including cultural formation (texts, rites, monuments) and institutional communication (recitation, observance). Here, we can see that Jan Assmann's figures of memory are similar to Nora's lieux de mémoire. 34 The production of stable figures of memory can take place long before the invention of writing. Thus, "the distinction between communicative memory and cultural memory is not identical with the distinction between oral and written language." The cultivation of the cultural memory involves organization, including the "institutional buttressing of communication," e.g., through formalization of the communicative situation in ceremony and the specialization of the bearers of memory (priests, archivists). However, although cultural memory "is fixed in immovable figures of memory and stores of knowledge," it always reconstructs the past in relation to the present situation. Thus, the "every contemporary context relates to these [figures of memory] differently, sometimes by appropriation, sometimes by criticism, sometimes by preservation or by transformation." 35

Martin Kern has employed the theory of cultural memory for his analysis of religious practices and representations reflected in the Classics. He identifies the ritual songs in the Shi jing and the speeches attributed to early kings in the Shang shu as expressions through which the foundational past was imagined and commemorated by later generations, especially in the context of ancestral sacrifice, which was as much a religious as a political institution of the Zhou elite. In the same work, Kern addresses bronze inscriptions, treating them as a background against which the received literature can be studied. For instance, he expects that comparisons with inscriptions may reveal when certain elements of the foundational narrative have been established and, accordingly, when the related parts of the Shang shu and Shi jing came into being. Drawing on recent phonological and lexicological studies, he undertakes a quantitative evaluation of the use of some key concepts (such as the "Heavenly Mandate" or "Son of Heaven") in inscriptions, chronologically attributed to the early, middle, and late Western Zhou periods. He observes that the commemoration of the king-founders Wen and $\mathrm{Wu}$ and the claim that they had received their right to rule directly from Heaven "take on particular urgency only toward the end of the Western Zhou, some 200 years after the death of King Wu." Kern

34. Jan Assmann, "Collective Memory and Cultural Identity," 129; Pierre Nora, Realms of Memory, xvii.

35. Jan Assmann, "Collective Memory and Cultural Identity," 130-31. 
suggests that the production of an "increasingly coherent and solidified imagination of the beginnings of the dynasty and its original legitimacy" might have been a "response to the gradual political and military decline of the dynasty over its last century," by which he means the ninth to early eighth century в.C.E. Pointing at disparities between the language of the inscriptions and that of the Classics, he concludes that even the core parts of the Classics, traditionally regarded as originating from the very beginning of the Zhou dynasty, were either partially updated, or entirely created during the late Western Zhou or early Eastern Zhou period. ${ }^{36}$

Kern's work supports, though slightly modifies, the observations previously made by Vassili Kryukov and Kai Vogelsang, who equally compared selected Shang shu and Shi jing texts with bronze inscriptions, aiming to reveal their chronological correlations. ${ }^{37}$ Kryukov proposed that the earliest parts of the Shang shu derive from the eighth to seventh century в.С.E. ${ }^{38}$ while Vogelsang suggests shifting the burden of proof on those who claim that they date from the early Western Zhou. ${ }^{39}$ Vogelsang identifies numerous discrepancies between the language of the inscriptions and the Shang shu..$^{\circ} \mathrm{He}$ also mentions that two inscriptions displaying the greatest number of parallels with the royal speeches in the Classics, the $\mathrm{Da}$ Yu ding 大孟鼎 (JC2837) and the Mao gong ding 毛公鼎 (JC2841), discovered during the nineteenth century, may be forgeries. ${ }^{41}$ As both of them indeed represent conspicuous examples of inscriptions commemorating the Zhou foundational past, I will briefly dwell on the debate about their authenticity.

36. Martin Kern, "Bronze Inscriptions, the Shangshu, and the Shijing: The Evolution of the Ancestral Sacrifice during the Western Zhou," in Early Chinese Religion, Part One: Shang Through Han (1250 BC to 220 AD), ed. John Lagerwey and Marc Kalinowski (Leiden: Brill, 2009), 143-200, at 145-51.

37. Vassili Kryukov, Ritualnaya kommunikatsiya $v$ drevnem Kitae (Moscow: Institut Vostokovedeniya RAN, 1997); Vassili Kryukov, Tekst i Ritual: Opyt interpretatsii dreonekitayskoy epigrafiki epokhi In-Chzhou (Moscow: Pamyatniki istorcheskoj mysli, 2000); Kai Vogelsang, "Inscriptions and Proclamations: On the Authenticity of the 'gao' Chapters in the Book of Documents," The Bulletin of the Museum of Far Eastern Antiquities 74 (2002), 138-209.

38. Kryukov, Tekst i Ritual, 322.

39. Kai Vogelsang, "Inscriptions and Proclamations," 196.

40. For criticism, see Sarah Allan, “On Shu 書 (Documents) and the origin of the Shang shu 尚書 (Ancient Documents) in light of recently discovered bamboo slip manuscripts," Bulletin of the School of Oriental and African Studies 75 (2012), 547-57, at 549.

41. Kai Vogelsang, "Inscriptions and Proclamations," 146, with further references in n. 39. The JC numbers correspond to Zhongguo kexue yanjiuyuan kaogu yanjiusuo, ed., Yin Zhou jinwen jicheng 殷周金文集成 (Beijing: Zhonghua shuju, 1984-1994). 
Suspicions about both inscribed vessels were raised by Zhang Zhidong 張之洞 (1837-1909). ${ }^{42}$ Zhang doubted that a genuine inscription may share any language with a transmitted text-in this case the "Jiu gao" 酒誥 chapter of the Shang shu. Most of Zhang's arguments against the $D a$ Yu ding cannot be followed, especially after more than a century of documented discoveries of - still not so numerous-bronze inscriptions that share their language and ideas with this inscription. 43 Indeed, other inscriptions—as Vogelsang and Kern demonstrate-date from the middle and late Western Zhou periods, and Zhang's opinion that such complex content and expressions are unlikely to appear in a very early inscription is reasonable. 44 As I will demonstrate below, the problem of the $D a$ Yu ding is not that it may be a fake, but that it has been dated too early. 45 In any case, there were no further attempts to discredit the authenticity of this vessel. However, the Mao gong ding, a midto-late ninth century B.C.E. cauldron with the so far lengthiest known inscription of the Western Zhou period (479 characters), ${ }^{46}$ was declared a forgery in an influential publication by Noel Barnard during the mid1960s. 47 Among other things, Barnard regarded as suspicious that the

42. Zhang Zhidong was a classically educated Qing official, military expert, and reformer, but a layman in the field of epigraphy. Rong Geng 容庚 (1894-1983) quoted Zhang's deliberations to exemplify that "to take a fake for an original, is like being blind, but to take an original for a fake, is also a sort of being mad; this is the case of Zhang Zhidong" (以偽為真, 有如盲韾, 以真為偽, 亦類風狂, 張之洞是也). See Rong Geng 容庚, Shang Zhou yiqi tongkao 商周彝器通考 (Peiping: Harvard-Yenching Institute, 1941), 213; repr. in Rong Geng 容庚, Shang Zhou yiqi tongkao 商周彝器通考 (Shanghai: Renmin, 2008), 171.

43. He also doubted that an unknown person called Yu could receive an announcement similar to the "Jiu gao" from a Zhou king because we know that the "real Jiu gao" was issued to King Wu's brother Kang shu. Besides, he argued that the story of King Wen's receiving of the Heavenly Mandate was invented by Han dynasty Confucians. See Rong Geng, Shang Zhou yigi tongkao, 171-73.

44. Zhang's judgement was related to the opinion of his contemporaries who did not know about the Xiao Yu ding and dated the Da Yu ding to the reign of King Cheng.

45. This is equally valid for the current assumption that it dates from the reign of King Kang.

46. Although this extraordinary length may already appear suspicious to some readers, it is just one hundred characters longer than the Qiu pan (372 characters) and is ca. 70 characters shorter than the early Spring and Autumn period's Shu Yi zhong 叔尸鐘 (JC272-281) from the peripheral Qi polity in present-day Shandong.

47. Noel Barnard, "Chou China: A Review of the Third Volume of Cheng Te-k'un's Archaeology in China," Monumenta Serica 1965.24, 307-459, at 395-408. Barnard used this publication to substantiate his theory of "characters constancy," previously criticized by Cheng Te-k'un, according to which the characters repeatedly used in one inscription always manifest the same structure. Barnard first criticized the Mao gong ding for its poor casting quality, untypical appearance features, and use of some unusual terminology, and used it to demonstrate that "characters inconstancy" observable in 
Mao gong ding shared some wording with the "Wen hou zhi ming" 衛侯之命 chapter of the Shang shu and with other previously published inscriptions..$^{8}$ Since the early 1970s, several scholars published studies that rehabilitated this vessel and its inscription. ${ }^{49}$ More recent studies considering the materials excavated after mid-1970s dispelled many suspicions expressed by Barnard and provided further evidence against his underlying theory of "characters constancy." 50 This is not a suitable place for a detailed review of these studies, but I would just like to recall that Barnard wrote his review in 1965, before the major finds of bronze inscriptions, such as the Zhuangbai or Yangjiacun hoards, were made. Even the He zun 㤑尊 (JC6014), equally displaying impressive parallels with the wording of the Classics, discussed below in the present article, was not yet published. New discoveries have demonstrated that inscriptions frequently operate with stock phrases, and the use of similar expressions in two inscriptions does not suggest that one of them should be a forgery. On the other hand, many expressions and graphical forms that looked odd and had no counterparts in other inscriptions known by the 1960s have been attested on vessels excavated only later.

the structure of the particle wei 唯 in this inscription is a criterion of forgery. Five years later, Cheng Te-k'un attempted to prove that character inconstancy was in general typical for Chinese writing and, at the same time, to rehabilitate the Mao gong ding; see Cheng Te-k'un, "The Inconstancy of Character Structure in Chinese Writing," Journal of Chinese Studies 6 (1971), 137-72.

48. Barnard, "Chou China: A Review," 403.

49. See Chang Kuang-Yüan 張光遠, “Xi Zhou zhong qi Mao gong ding-bolun Aozhou Bana boshi wuwei zhi shuo" 西周重器毛公鼎——駁論澳洲巴納博士㟇偽之說, Gugong jikan 1972.2, 1-69; Chang Kuang-Yüan and John Marney, "The Mao Kung Ting-A Major Bronze Vessel of The Western Chou Period: A Rebuttal of Dr. Noel Barnard's Theories," Monumenta Serica 31 (1974-1975), 446-74; Kwong-yue Cheung 張光裕, Weizuo xian Qin yiqi mingwen shuyao 偽作先秦彞器銘文疏要 (Hong Kong: Hong Kong Book Shop, 1974), 374-93. Zhang Shixian's 張世賢 X-ray examination of a group of vessels from the Palace Museum confirmed that the Mao gong ding displays technological features typical for the late Western Zhou period. See Zhang Shixian 張世賢, “Cong Shang Zhou qintongqi neibu tezheng shilun Mao gong ding de zhenwei wenti" 從商周銅器的內部特徵試論毛公鼎的真偽問題, Gugong jikan 1982.4, 55-96.

50. Chu Kwok-fan 朱國藩, “Cong cihui yunyong jiaodu tantao Mao gong ding mingwen de zhenwei wenti" 從詞彙運用角度探討毛公鼎銘文的真偽問題, Zhongyang yanjiuyuan lishi yuyan yanjiusuo jikan 2000.6, 459-507; for further evidence for "characters' inconstancy," see Li Feng, "Ancient Reproductions and Calligraphic Variations: Studies of Western Zhou Bronzes with 'Identical' Inscriptions," Early China 22 (1997), 1-41; Matthias L. Richter, "Suggestions Concerning the Transcription of Chinese Manuscript Texts-A Research Note," International Research on Bamboo and Silk Documents: Newsletter 3 (2003), 1-12, at 2. See also Imre Galambos, Orthography of Early Chinese Writing: Evidence from Newly Excavated Manuscripts (Budapest: Balassi, 2006), 21-24, for the assessment of Barnard's and Cheng's polemics. 
If such prototypes were not known earlier, how could the artisans of the nineteenth century use them for forging the Mao gong ding?

By defending the $\mathrm{Da}$ Yu ding and the Mao gong ding, as well as other "non-standard" objects excavated before the advance of modern archaeology, I do not intend to rule out the problem of forgery in general. This problem was and is addressed by Chinese specialists, who have already sorted out hundreds of (often genuine) objects with fake carved inscriptions that were held in the imperial and private collections until the mid-twentieth century. It was indeed not accidental that many such inscriptions contained some pieces of the foundational narrative, as this increased their market value. I am confident that the inscriptions included into the Yin Zhou jinwen jicheng 殷周金文集成， published during the 1980-1990s by the Institute of Archaeology of the Chinese Academy of Sciences based on the preliminary work by Chen Mengjia 陳夢家, can be safely used. On the other hand, I am concerned about the growth of the black market of bronzes during recent decades. The dispersion of hundreds of looted objects among private collections across China not only leads to the loss of precious archaeological data, but also makes them available as models for new forgeries, which can be produced now with much more expert knowledge than was accessible to artisans from Song to Qing. I thus think that unprovenanced objects from recent private collections should be assessed with great caution, especially when they refer to the Zhou foundational memory. I will address the issues of provenance and reliability of individual bronzes in respective footnotes.

Whereas the quantitative approach clearly demonstrates the exclusive character of inscriptions referring to the Zhou fundamental past, it is all the more astonishing that these very inscriptions are often treated as representative. In a recent work on the politics of the past in Early China, Vincent Leung takes Western Zhou epigraphy as a point of departure for a study that mainly focuses on Eastern Zhou and Western Han literature. Leung explicitly avoids engaging in the debate about memory and attributes all references to the past to the realm of "history," pointing out that "in the Western Zhou, all history must be family history," and "the past was essentially delimited to the genealogical field." 51 It is not so clear whether he admits that different families had different notions of the past. Comparing three lengthy inscriptions mentioning the conquest and the first kings, which belong to the best-known and most frequently cited Western Zhou texts (including the already mentioned $\mathrm{Da} \mathrm{Yu}$

51. Vincent Leung, The Politics of the Past in Early China (Cambridge: California University Press, 2019), 28. 
ding), Leung defines them as "typical," and even goes so far to state that "a majority of the inscriptions describe similar official exchanges between the Zhou king and his subject" and that they "almost always begin with the present-day Zhou king recounting the virtues of King Wen, and sometimes those of King Wu." 52 In fact, no more than 11 percent of all published Western Zhou inscriptions mention a king, while it is also arguable whether every meeting with the reigning king, regardless of circumstances and purpose, can be understood as an "official exchange." Only a tiny portion of inscriptions recording any interactions with the king includes references to the first kings, and only half of the inscriptions that mention them do so in connection to the Zhou foundational past. I therefore compiled a list of all (just two dozen) relevant cases, including the information about the dates, the contexts of references and the identity of commissioners (see Table 9 in the Appendix). 53

Scholars who expect bronze inscriptions to reflect certain "common" Zhou representations, assume that Zhou society was thoroughly standardized. As a result, they regard unique features either as suspicious or as generalizable pars pro toto examples, thus underestimating the complexity of early Chinese social reality and eventually making misleading observations. Inscriptions are not just random "philological entities" delivering pieces of information on various social phenomena. ${ }^{54}$ They are intrinsically related to specific people who belonged to different social groups that could assume different perspectives on both the present and past. Taking into account the identity of inscriptions' commissioners is necessary to understanding the social setting of various discourses. 55 Such differentiated readings reveal that even within the Zhou metropolitan society, some groups participated in the discourse about the Zhou foundational past, while others had only

52. Leung, The Politics of the Past in Early China, 28, states that Li Feng "also noted the ubiquity of this invocation of the founding rulers in the bronze inscriptions throughout this late Bronze Age dynasty" in Li Feng, Bureaucracy and the State in Early China: Governing the Western Zhou (Cambridge: Cambridge University Press, 2008), 294-99. I was not able to find such statement in Li Feng's work, even if he often uses the word "numerous" while referring to three or four relevant examples.

53. This number bases on a search in the Academia Sinica, Digital Archives of Bronze Images and Inscriptions 殷周金文及青銅器資料庫. www.ihp.sinica.edu.tw/ bronze/ (hereafter Academia Sinica online database). If one would count only individual texts, eliminating duplicates reproduced in inscriptions on several vessels or bells commissioned by high-ranked and wealthy persons, this percentage may drop by a half.

54. For the criticism of approaching inscriptions as "philological entities," see Falkenhausen, "Issues in Western Zhou Studies," 147.

55. Khayutina, "The Royal Year-Count," 149-51. 
limited access to it. ${ }^{6}$ The fact that some key concepts (e.g., the Heavenly Mandate) appear in inscriptions very seldom is most likely because they make part of an exclusive discourse. Nevertheless, like everywhere in the world, the privileged groups who participated in exclusive discourses likely had a greater impact on the formation of the early Chinese cultural memory than these who produced a mass of similarly looking appointment inscriptions that barely mention anything beyond assignments of offices and lists of gifts. Thus, establishing the identity of the vessels' commissioners, including their lineage affiliation and relationships with the royal house, is relevant both for reconstructing the social composition of the Zhou elite and for understanding how different discourses were embedded in the social structure.

In the following, I will discuss in detail several inscriptions, treating them not as representative, but as outstanding, unique evidence of the process of early Chinese cultural memory production, and trying to reveal who participated in this process.

\section{The Conquest of Shang in Inscriptions of Contemporaries}

Inscriptions from the first post-conquest decades are generally similar to inscriptions from the late Shang period. ${ }^{7}$ They are normally very short and consist only of ancestral titles, names, or family signs..$^{8}$ Inscriptions with event notations are extremely rare, and these usually derive from the closest surroundings of the royal house.59 They equally only very seldom include direct speech. ${ }^{60}$ Several inscriptions from the reign of King Cheng (the second king, r. 104 B.C.E.2-?) or slightly later mention the

56. Khayutina, "Reflections and Uses of the Past," $172-73$.

57. I exclude from this group the He zun, usually attributed to the reign of King Cheng, but which I date to the reign of King Zhao. This inscription will be discussed in the next section. For the revision of its date, see the Appendix.

58. Olivier Venture, Étude d'un emploi rituel de l'écrit dans la Chine archaïque (XIIIeVIIIe siècle avant notre ère) (Ph.D. dissertation, University of Paris 7, 2002), 277. See, e.g., early inscribed vessels from early Zhou cemeteries in Feng and Qian Rivers valleys in Zhongguo shehui kexueyuan, ed., Zhangjiapo Xi-Zhou mudi 張家坡西周墓地 (Beijing: Zhongguo dabaike quanshu, 1999), 132-67; Wang Guangyong 王光永, “Shaanxi Baoji Daijiawan chutu Shang Zhou qingtongqi diaocha baogao" 陝西寶雞戴家灣出土商周青 銅器調查報告, Kaogu yu wenwu 1991.1, 3-22.

59. See, especially, Tian Wang gui 天亡篮 (JC4261), excavated on the Zhou Plain, with a 77-character long description of a ritual performed by King Wu (cf. Appendix, Table 2).

6o. Among the inscriptions that can be unambiguously dated to the reign of King Cheng, only the identical Ke he 克盉 and Ke lei 克罍 (YHB1367, 1368) quote a royal speech, in which the king announces his decision to make Ke the ruler of Yan 燕. For more details on this inscription, see the Appendix with further references. The YHB numbers correspond to Zhong Bosheng 鍾柏生 and Chen Zhaorong 陈照容, eds., Xin 
conquest of Shang. The most famous of them is the Li gui 利篮 (JC4131), counting 32 characters. It was excavated from a hoard in an insignificant place in the middle part of the Wei valley together with several vessels of a later date. Li participated in King Wu's campaign against the Shang (Wu wang zheng Shang 武王征商), while the king personally rewarded him for his achievements, possibly as a diviner. The Mei situ Yi gui 沫司徒疑篮 (JC4059), counting 24 characters, was excavated from a cemetery of Wei 衛, a Zhou colony established about $120 \mathrm{~km}$ from the ruins of the Shang royal center. Its commissioner commemorated that the king (plausibly King Cheng), who "pierced and struck the Shang Settlement” (ci fa Shang yi 束 (刺) 伐商邑), appointed Kang shu 康叔 (King Wu's brother) and himself to perform outpost service ( $b i$ 鄙) in Wei. The unprovenanced Xiaochen Shan zhi 小臣單觶 (JC6512), counting 21 characters, commemorates that the king (similarly King Cheng) stayed in Cheng shi 成追 (師) (Accomplished Encampment), probably corresponding to Chengzhou 成周 (Accomplished Zhou), after having “conquered Shang" (ke Shang 克商), and that the Zhou gong 周公 awarded the commissioner. The commissioners of these three vessels were contemporaries of, or, at least in one case, participants in the conquest of Shang. They had personal contact with Kings Wu or Cheng, or with King Wu's brothers, Zhou gong and Kang shu. Their memory of the conquest was factual and based on their own experiences. The same is true for most of the early inscriptions that mention temple names of the kings Wen, $\mathrm{Wu}$, and Cheng. Their commissioners commemorated their own interactions with these kings or mentioned ancestral sacrifices that the reigning king performed in the first Kings' honor thereby serving as a pretext for the royal gift-giving (see Nos. 1-11 in Table 9 in the Appendix).

Early inscriptions referring to the conquest of Shang can be compared to other contemporary inscriptions commemorating donations in connection with military campaigns. For instance, Xiaochen Shan zhi reads:

The King, after having conquered Shang, was in Cheng shi. Zhou gong granted xiaochen (Minor Servant) Shan ten strings of cowries. [Shan] used [this occasion] to make a treasured venerated ritual vessel (Xiaochen Shan zhi, JC6512).

王後涯克商, 在成追 (師), 周公易 (賜) 小臣單貝十朋, 用作寶尊彝。

shou Yin Zhou qing tong qi ming wen ji qi ying hui bian 新收殷周青銅器銘文暨器影彙編 (Taipei: Yiwen, 2006). 
An inscription excavated in 1896 in vicinity of Longkou 龍口 in Shandong province commemorates another campaign:

In the year when gong the Grand Protector fought the insurgent Yi [people], in the eleventh month, day geng-shen (57), the gong was in the Zhou* Encampment, the gong granted Lü ten strings of cowries. ${ }^{61}$ Lü used [this occasion] to make a venerated ritual vessel for his father (Lü ding, JC2728).

唯公大保來伐反尸 (夷) 年, 在十又一月庚申, 公在㖹追 (師), 公易 （賜）旅貝十朋，旅用作父尊彝。

Awards and appointments received from the king or other superiors could be relevant for both a person's status during his life and the honors paid to him during his funeral. Because of their impact on the status of persons and their families, donations became a subject of inscriptions already during the late Shang period. Other events were mentioned in inscriptions insofar they served as pretexts for donations and as reference points for the commissioners' own biographies. ${ }^{62}$ From a larger perspective, memories about donations received by family founders could become foundational for generations of their descendants, so long as they were able to inherit related privileges and to derive from them long-lasting benefits. In this case, events from the deep past could become fixed points in the memory of lineages and could facilitate the concretion of their identities as in-groups. However, such memories would not necessarily be shared between different lineages or contribute to production of a common "Zhou" identity in the lineage network. Different excavation contexts of the inscribed vessels reveal that commissioners and their immediate descendants made different choices regarding the vessels' potential as containers of social memories. They could opt to display the vessel with an important commemoration in an ancestral temple so as to preserve it for later generations, as this probably happened to the $\mathrm{Li}$ $g u i$, or they could bury it in a tomb and make it disappear, as happened to the Mei situ Yi gui.

Independently of the benefits that later generations could gain from keeping commemorative bronzes, it is also clear that the commissioners of the three bronzes considered in this section mentioned the conquest of Shang as an event in their own biographies, and did not emphasize

61. Numbers in brackets after the day-names correspond to the number of these days in the sixty-day cycle. Note that this Zhou 盆 is unrelated to Zhou 周, which is the name of the dynasty.

62. Cf. Kryukov, Ritualnaya kommunikatsiya, 98. 
its significance in any particular way as compared to other events that preceded royal donations. Further conquests, such as that over the Yi in Shandong mentioned in the Lü ding, could be more relevant for their contemporaries settling as colonists in this area. With every new success and award, the memory could potentially shift to a new reference point. Such inscriptions therefore cannot be regarded as reflections of the cultural memory of the Zhou dynasty.

The small number of mentions of the conquest in inscriptions commissioned by contemporaries is noteworthy. Possibly, as long as the generation that experienced the conquest was still alive and passed the memories down within the communicative framework of families or of kin-based military units orally, the need to convey these memories to a durable medium was not yet largely recognized. Another reason may be that, during this early time, bronze vessels could be more strictly associated with ancestral worship in which the ancestors could be regarded as further detached from the human world than they would be in periods to come. Hence, worldly affairs would be less likely to be reported to the ancestors. Yet another banal reason could be that most of the contemporary Zhou elites were nearly illiterate. ${ }^{63}$ Hence, they did not expect their ancestors to have the ability to read and did not think about transmitting their memories to their descendants in writing. The royal house and other major Ji-surnamed lineages worshipped Kings Wen, $\mathrm{Wu}$, and, later, Cheng as ancestors. ${ }^{64}$ They probably commemorated the conquest as a part of their ancestors' biographies but did not make this explicit in their inscriptions. ${ }^{65}$ There also could be other communicative settings in which the members of different families exchanged memories about this common past. However, these practices stay invisible in early Zhou epigraphy.

63. By "nearly," I mean that they were possibly able to write their names and to recognize the names of ancestors in inscriptions on vessels, as bronzes with such inscriptions dated to the late Shang and early Zhou periods have been found in the Zhou heartland in Shaanxi. This could be important for the appropriate use in rituals. However, they might not be able to write and read more complex narrative texts, although the spread of inscriptions in the form " $X$ made sacrificial vessel for $Y^{\prime \prime}$ during the early Zhou period shows that the basic reading competence of their commissioners was expanding by the inclusion of certain verbs and ritual terms.

64. The Zuoce Da ding 作冊大鼎 (JC2758, No. 11 in Table 9), excavated in Luoyang, mentions that a certain gong "Patriarch" cast a ding tripod in honor of Kings Wu and Cheng. The identity of this gong is unclear. Possibly, it could be a direct descendant of King Cheng, or a collateral patrilineal relative.

65. See Nos. 2, 7, and 10 in Table 9. 


\section{Commemoration of the Conquest and the First Kings During the Early Post-Conquest Generations}

The earliest evidence about handling the memory of the conquest within the cultural, rather than communicative, memory framework can be found in such inscriptions as the Yi hou Ze/Yu gui 宜侯吴 (柇/虞)筬 (JC4320, 126 characters), the He zun (JC6014, 122 characters), and the Da Yu ding (JC2837, 286 characters).

Characterized by their extraordinary length, complex structure, and eloquent language, these three inscriptions clearly stand out against the mass of short and simple early inscriptions like these discussed in the previous section. I suppose that the inclusion of narrative elements, quotations of direct speech, lengthy lists, and precise date notations into bronze inscriptions, resulting in the considerable increase in their length, reflects substantial changes to the functions of ritual bronzes in comparison to the late Shang and early Zhou reigns. The bronzes were being used not only as "containers of social memories" of families and lineages, but also as durable "documents" testifying about their owners' status, rights, and obligations in front of the kings and their peers. Complex narrative inscriptions became widespread during the reign of the fourth king, Zhao ("Radiant"). ${ }^{66}$ The trend in this direction emerged already during the reign of the third king, Kang ("Prosperous"), and the following inscription may reflect this development.

\section{The Yi hou Ze/Yu gui67}

This inscription represents a uniquely detailed record of investiture (not to be confused with an appointment of an official) of a local ruler, hou 侯. ${ }^{68}$ It lists the awards, properties, and subordinates transferred under Yi hou's control by the Zhou king. It includes a reference to kings $\mathrm{Wu}$ and Cheng, which most scholars consider to be only relevant for dating, not for insight into its meaning. Several full western translations

66. Cf., e.g., Ze/Yu Ling zun, yi 矢(虞)令尊, 彝 (JC6016, 9901); Ling ding 令鼎 (JC2803); Zhong yan 串獻 (JC949); Jing gui 靜笰 (JC4273).

67. The characters $y u$ 虞 and $w u$ 吳 both use 吴 (same as 吳 without kou 口 “mouth" element) as phonetic component. Hence, 吴, appearing in the designation of the Yi hou $\mathrm{Ze} / \mathrm{Yu}$ gui's commissioner and usually transliterated as ze 夬, should be transliterated as yu; see Li Xueqin 李學勤, “Shu Yu fangding shi zheng," 叔虞方鼎試證 in Jin hou mudi chutu qingtongqi guoji xueshu yantaohui lunwenji, ed. Shanghai bowuguan (Shanghai: Shanghai shuhua, 2002), 249-51. I use here both transliterations, since this inscription is already known to western readers as Yi hou Ze gui.

68. For a distinction between investitures and appointments, see Virginia C. Kane, "Aspects of Western Chou Appointment Inscriptions: The Charge, the Gifts, and the Response," Early China 8 (1982-1983), 14-28; Li Feng, "'Feudalism' and Western Zhou China: A Criticism," Harvard Journal of Asiatic Studies 63 (2003), 115-44; Khayutina, "Royal Hospitality and Geopolitical Constitution," 12 n. 26. 
are available. ${ }^{69}$ For the purpose of the present study, I will focus on the lineage affiliation of its commissioner, which is relevant for understanding the social and political context of the "present situation" that involved reference to the past. Then I will discuss the ritual setting in which the memory of the conquest and the first kings was recalled, and the medium by which it was transmitted.

The inscription ends with a dedication to the commissioner's deceased

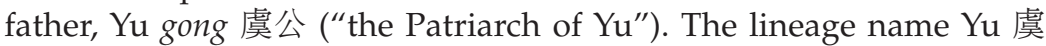
(OCM * Đwa) plausibly derives from the toponym wu 吳 (OCM * Đwâ), identifiable with the $\mathrm{Wu}$ mountain in the valley of the Qian 汧 River, flowing through the Gansu corridor and pouring into the Wei River near present-day Baoji 寶鷄..$^{\circ}$ The three characters 决, 吳 and 虞 were used in inscriptions interchangeably as common nouns and probably represent graphic variants of one character. ${ }^{71}$ As proper nouns, they were used to distinguish between the stem and branch lineages descending from the common $\mathrm{Wu} / \mathrm{Yu}$ stock..$^{72}$ During the Western Zhou period, the main area of activities of the $\mathrm{Wu} / \mathrm{Yu}$ lineages was along the Qian River and in the present-day Fengxiang 鳳翔 county of Shaanxi province about $50-60 \mathrm{~km}$ to the west from the Zhou Plain. At a yet undetermined time, Yu founded a dependency of the same name in present-day Pinglu 平陸 county in south-western Shanxi, which became its main seat during the Eastern Zhou period.73 The inscription under discussion is related to the foundation of Yu's dependency in a place referred to as $Y_{i}$ 宜/宜.74

69. For full translations, see Noel Barnard, "A Recently Excavated Inscribed Bronze of Western Chou Date," Monumenta Serica 17 (1958), 12-46, at 29; Edward L. Shaughnessy, "Historical Geography and the Extent of the Earliest Chinese Kingdoms," Asia Major (3rd Ser.) 2 (1989), 1-22, 14; Ulrich Lau, Quellenstudien zur Landvergabe und Bodenübertragung in der Westlichen Zhou-Dynastie (1045?-771 v. Chr.), Monumenta Serica Monograph Series 41 (Sankt Augustin: Monumenta Serica, 1999), 97-104; Li Feng, Bureaucracy and the State in Early China, 239; David Sena, "Yi Hou Ze gui," in A Source Book of Ancient Chinese Bronze Inscriptions, ed. Constance A. Cook and Paul R. Goldin (Berkeley: Society for the Study of Early China, 2016), 23-27.

70. For phonetic reconstructions, see Axel Schuessler, Minimal Old Chinese and Later Han Chinese: A Companion to Grammata Serica Recensa (Honolulu: University of Hawai'i Press, 2009), 1-35a, h.

71. Ch'en Chao-jung, "On the Possibility that the Two Western Zhou States Yu and Rui were Originally Located in the Qian River Valley," in Imprints of Kinship, ed. Edward L. Shaughnessy, 189-207, 193.

72. The proper noun $\mathrm{Yu}$ 央 in the designation of $\mathrm{Yi}$ hou Ze/Yu may not be merely his personal name, but also another identifier of his kinship affiliation.

73. Huang Shengzhang 黄盛璋, “Tongqi mingwen Yi, Yu, Ze de diwang ji qi yu Wu guo de guanxi” 銅器銘文宜、虞、知的地望及其與吳國的關系, Kaogu xuebao 1983.3, 295-305.

74. The Ba bo pan 霸伯盤, recently excavated from the tomb Mio17 in the Dahekou 大河口 cemetery of the Ba lineage in Shanxi, is dedicated to Ba bo's wife Yi Ji 宜姬; see Shanxi sheng kaogu yanjiusuo, Linfen shi wenwuju, Yicheng xian wenwu liuyou 
According to the transmitted tradition, the Yu lineage descended from Yu zhong 虞仲, the second-born son of gu gong ("Ancient Patriarch") Danfu 古公亶父, founder of the Zhou settlement on the Zhou Plain (see Figure 2). Since the Zhou royal lineage descended from the youngest son of Danfu, posthumously venerated as wang ji 王季 (Royal Junior), Yu should have had a senior status in the Zhou lineage network.75 If even King Wu's full brothers did not unanimously support the royal house, as already mentioned above, one can imagine that other patrilineal relatives who could claim a higher genealogical status required special care. The ceremony in which the king established his high-ranked kin relative, $\mathrm{Yu}$ hou, in a new location should be understood in this political context.

The unique feature of the $\mathrm{Yi}$ hou $\mathrm{Ze} / \mathrm{Yu}$ gui is that it explicitly represents both Kings Wu and Cheng as conquerors. As it will be made clear below, King Cheng would be removed from the official narrative of the conquest later. The memory of the first kings was re-enacted during Yu hou's investiture in the following way:

It was the fourth month. The chen was in day ding-wei (44)..$^{6}$ The king inspected the chart of the Shang conquered by King Wu and King Cheng, and then proceeded to inspect the chart of the Eastern Region. The king divined in $\mathrm{Yi}_{177}$ entered the earthen structure, ${ }^{8}$ [and] faced

julianhedui and Shanxi daxue beifang kaogu yanjiu zhongxin, "Shanxi Yicheng Dahekou Xi Zhou mudi 1017 hao mu fajue" 山西翼城大河口西周墓地1017號墓发掘, Kaogu xuebao 2018.1, 89-139, at 131. This confirms that during the late tenth century B.C.E. Yi was a Ji-surnamed lineage and corroborates that Yi hou Ze/Yu was of the Ji surname.

75. Allegedly, wang ji's elder brothers willingly yielded their priority rights to him so the junior branch legitimately dominated the lineages' hierarchy. It is likely that the junior branch of Danfu's descendants became prominent only because of King Wu's military talent, whereas the story of yielding was constructed much later to justify this fact. See Maria Khayutina, "King Wen, a Settler of Disputes or Judge?: The 'Yu-Rui' case in the Historical Records and its Historical Background," in Auf Augenhöhe: Festschrift zum 65. Geburtstag von Heiner Roetz, Bochumer Jahrbuch zur Ostasienforschung, ed. Wolfgang Behr, Licia Di Giacinto and Christine Moll-Murata (Munich: Iudicium, 2015), 261-76.

76. Presumably, chen 辰 was an asterism used to mark time. See Cook and Goldin, eds., A Source Book of Ancient Chinese Bronze Inscriptions, 303.

77. The character 1 in this inscription is often transcribed as $l i$ 立 "to take position," probably because the latter word is frequently used in descriptions of appointment ceremonies. All English translations follow this transcription. However, the character is clearly written differently from/立, which, moreover, became common only from the mid-tenth century в.C.E. onwards. It should be transcribed as bu卜 "to divine" (cf. Academia Sinica online database, http://bronze.asdc.sinica.edu.tw/rubbing. php?04320), accessed October 102021.

78. Guo Moruo interpreted the character following the place name $\mathrm{Yi}$ as zong "ancestral shrine" and supposed that, in combination with $t u$ 土 "land," it refers to she 
south. The king commanded to $\mathrm{Ze} / \mathrm{Yu}$, the hou of $\mathrm{Yu}$, saying: "Relocate to perform border service (or "be hou") in Yi!" (Yi hou Ze/Yu gui, JC4320)

唯四月, 辰才在丁未, 王省珷王、成王伐商圖, 沚省東或（域）圖, 王

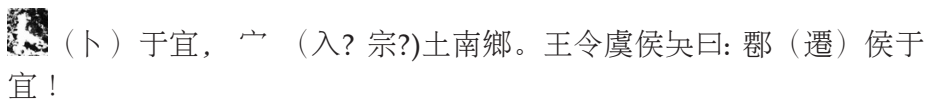

The meaning of $t u$ 圖 "drawing, picture, map" in this context has been a matter of debate. Many authors understand it simply as "map."79 A reader can imagine that the king rolled out a map on silk, for example, to pinpoint a location - somewhere in the east-where the new appointee had to relocate. However, considering the history of the evolution of graphical devices for representing terrestrial space in early China, it is unlikely that topographic maps of large geographic areas already existed during ca. eleventh and tenth centuries B.C.E. ${ }^{80}$ More plausibly,

社 “Altar of Soil” Guo Moruo 郭沫若, “Shi gui ming kaoshi” 矢(自殳)銘考釋, Kaogu xuebao 1956.1, 7-9; David Sena, "Yi hou Ze gui," 26. This interpretation may be anachronistic. She was a designation of the main sanctuary in polities of the Spring and Autumn period; see Claudius Müller, Untersuchungen zum "Erdaltar" she im China der Chou- [d. i. Zhou] und Han-Zeit (Munich: Minerva, 1980). However, it is not mentioned in any other bronze inscription. In the Shang shu, she appears in the "Shao gao" as a verb, designating a sacrificial act of slaughtering animals. Notably, the latter was related to the foundation of the new settlement; see Shang shu ji shi 尚書集釋, ed. Qu Wanli 屈萬里 (Taipei: Liangjing, 1983), 172. It cannot be confirmed that she altars existed as specific structures already during the early Western Zhou. Other translators follow Guo Moruo's transcription zong tu 宗土, but interpret it as "ancestral temple"; see Edward L. Shaughnessy, "Historical Geography and the Extent of the Earliest Chinese Kingdoms," 14; Li Feng, Bureaucracy and the State in Early China, 239. This is, however, also problematic, because the lower part of the first character includes an element that seems to be " "roof," but the rest is illegible.

79. Huang Shengzhang, "Tongqi mingwen Yi, Yu, Ze de diwang," 296; Shaughnessy, "Historical Geography and the Extent of the Earliest Chinese Kingdoms," 14-16; Li Feng, Bureaucracy and the State in Early China, 239-40; Sena, "Yi hou Ze gui," 26.

8o. See Vera Dorofeeva-Lichtmann, "Mapless Mapping: Did The Maps of the Shan hai jing Ever Exist?," in Graphics and Text in the Production of Technical Knowledge in China: The Warp and the Weft, ed. Francesca Bray, Vera Dorofeeva-Lichtmann and Georges Métailié (Leiden: Brill, 2007), 217-94; Vera Dorofeeva-Lichtmann, "Ritual Practices for Constructing Terrestrial Space (Warring States-Early Han)," in Early Chinese Religion, Part One, 595-644. In transmitted sources, the use of the word tu in the sense of "map" is witnessed for the first time in connection with historical events of the mid-third century B.C.E., whereas the earliest excavated maps, schematically representing local geographical relationships, date from the third and second centuries B.C.E. It is highly implausible that area maps were in use seven centuries earlier, but not in-between. The earliest area maps representing the whole Chinese empire date from the Song period. 
$t u$ represented a cardinally oriented, ideologically charged cosmograph, spatially arranging symbols or place names, typologically similar to later divination charts. ${ }^{81} \mathrm{~T} u$ charts representing the results of divination are mentioned in the Shang shu. In the "Luo gao" 洛誥, commemorating the foundation of the Luo Settlement (Chengzhou), the Zhou gong sends a messenger to the king who "comes to submit the results of this divination by means of a chart" (ping lai yi tu ji xian bu 伻來以圖及獻卜)..$^{82}$ In the Yi hou Ze/Yu gui, the king performed a divination after having inspected the $t u$ of the conquest of Shang and the $t u$ of the Eastern Region.

It is unclear whether $t u$ were only graphical devices, or if they combined graphic and text. It is also unclear what material they were made of..$^{83}$ In any case, in one or another way, the $t u$ represented the achievements of Kings $\mathrm{Wu}$ and Cheng in the east. How was this related with the fact that Yi hou was commanded to become the ruler of Yi?

The location of Yi is thus relevant for understanding the context of the reference to the conquest and the first kings. The Yi hou Ze/Yu gui was found in 1954 in Yandunshan 煙墩山 in Dantu 丹徒 county of Jiangsu 江 蘇 province, on the southern bank of Yangzi, about $100 \mathrm{~km}$ to the east of present-day Nanjing. ${ }^{8}{ }_{4}$ Some scholars thought that Yi corresponds to the place of the vessel's discovery. ${ }^{85}$ However, the vessel was found together with eleven other bronzes dating from the early Western Zhou period to early Spring and Autumn period. Considering the heterogenous

81. Vera Dorofeeva-Lichtmann, personal communication on June 22, 2016. Cf. Michael Lackner, "Diagrams as an Architecture by Means of Words: the Yanji tu," in Graphics and Text in the Production of Technical Knowledge in China, 341-76. Wolfgang Behr has proposed that $t u$ designated in the $\mathrm{Yi}$ hou $\mathrm{Ze} / \mathrm{Yu}$ gui "some sort of representational token which was used in feudal or military exchanges of the Western Zhou royal house, and aimed at the visual anchorage of territorial affiliation or rank in a court ritual." See Wolfgang Behr, "Placed into the Right Position: Etymological Notes on Tú 圖 and Congeners," in Graphics and Text in the Production of Technical Knowledge in China, 109-34, at 120. In other words, $t u$ could be individual regalia that the representatives of the defeated Shang and the Eastern Region presented to the king. This interesting hypothesis can not be correlated with early transmitted texts, nor is it supported by archaeological evidence.

82. Shang shu ji shi, 179-81.

83. The Chamber of Charts tu shi 圖室 in the Zhou temple, mentioned in two midto late ninth century's inscriptions, could the place where such charts were stored, although $t u$ equally could refer to pictorial representations on walls, for example. The information about this institution is currently insufficient.

84. Jiangsu sheng wenwu guanli weiyuanhui, "Jiangsu Dantu xian Yandunshan chutu de gudai qingtongqi” 江蘇丹徒縣煙墩山出土的古代青銅器, Wenwu cankao ziliao 1955.5, 58-62.

85. Tang Lan 唐蘭, “Yi hou Shi gui kaoshi” 宜侯矢段考釋, Kaogu xuebao 1956.2, 79-83. 
composition of this group, and the thin evidence of early Zhou presence in this area, it is more likely that the $\mathrm{Yi}$ hou Ze/Yu gui was brought there much later as an heirloom. ${ }^{86}$ Huang Shengzhang has proposed a localization of Yi near Yiyang 宜陽 in present-day Henan Province, about $25 \mathrm{~km}$ to the west from the eastern Zhou capital Luoyang in the Luo river valley. ${ }^{87}$ Although this localization can be accepted as an option, I suspect that Yi could be located even further in the west. An unprovenanced inscription witnesses that a polity of such a name existed during the late Shang period, while its ruler Yi zi / 宜子 acted as an intermediary between the Shang king and western polities ( $x i$ fang 西方). ${ }^{88}$ At the same time, Yi was never mentioned in Shang oracle bone inscriptions (OBI). This means that Yi was not a stable partner of Shang. Probably, it was located far in the western periphery of the Shang interaction sphere, while the latter inscription on a relatively crudely cast tripod witnesses a one-time transaction. Transmitted texts further indicate that the pre-conquest Yi belonged to the circle of polities allied with the Zhou on the eve of the conquest of Shang. ${ }^{89}$ This also supports

86. Huang Shengzhang, "Tongqi mingwen Yi, Yu, Ze de diwang," 297-8; Shaughnessy, "Historical Geography and the Extent of the Earliest Chinese Kingdoms," 15; Sena, "Yi hou Ze gui," 26.

87. Huang Shengzhang, "Tongqi mingwen Yi, Yu, Ze de diwang," 297; adopted in Shaughnessy, "Historical Geography and the Extent of the Earliest Chinese Kingdoms," 18. Yiyang is attested since the Warring States period both by transmitted texts and inscriptions. This place name is composed of the proper noun Yi and the term yang, meaning in this context "north of," indicating that Yi was the name of a river. River names are believed to be relatively stable, at least comparing to the names of polities and cities that frequently relocated, while original names could shift to new locations. The river name Yi could exist long before the Warring States period. Nevertheless, this name was not necessarily unique, and this localization still can be regarded as tentative.

88. See Yi zi ding 宜子鼎 (JC2694).

89. According to the "Jun Shi" 君真 chapter of the Shang shu, one trusted affiliate of King Wen was a certain San Yi sheng 散宜生 (see Shang shu ji shi, 209). In inscriptions, the word sheng 生 usually stands for sheng 特, referring to various categories of affinal relatives. Designations including this term sometimes include the names of two intermarrying lineages (see Maria Khayutina, "Marital Alliances and Affinal Relatives," 59-60). Hence, San Yi sheng was plausibly a member of the San lineage whose mother was a woman from the Yi lineage. Thus, Yi was simultaneously a placename. Considering that San Yi sheng was active before the conquest, it is likely that his mother was from the Wei River valley, rather than from somewhere far away. As the discovery of the San shi pan basin has revealed, San was a non-Ji lineage residing in present-day Fengxiang county, that is, near Yu. This long inscription from about the ninth century в.C.E. describes in detail a lawsuit about landed property between the San and the Ze/Yu lineages, in which also the Yu branch of Ze/Yu was involved. It is therefore likely that $\mathrm{Yi}$ was also located somewhere in this vicinity. The very detailed 
that Yi was located west of Shang and not very far from the Zhou core territories.

Both localizations suggest that the new place of Yi hou's residence was neither in the vicinity of Shang, nor in the Eastern Region. Thus, there was no direct pragmatic relation between the activities of the kingconquerors Wu and Cheng in the east and Yi hou's relocation. In this case, the current king reactivated the memory of the conquest on the symbolic level, reminding contemporaries about past achievements that would serve as the foundation of future stability. In this respect, the Yi hou Ze/ Yu gui is similar to inscriptions from later reigns that refer to the memory of the first kings in a general way as part of the foundational past. The act of investiture, by which a certain territory was entrusted to a royal patrilineal relative, served to reproduce the political order established as a result of the conquest. This was one type of "present situation" that involved instrumentalization of a foundational memory, and it was clearly of a political nature. The inscription further relays that during the early post-conquest generations, apart from oral communication, the memory of the conquest and of the first kings was transmitted with the help of material objects, including visual representations and ritual utensils. Once this ritual commemoration was recorded in an inscription, this new instrument was added to the toolkit of memory-keeping, and the archaeological context of the vessel's discovery suggests that it was used other the course of many generations.

\section{The He zun}

The He zun provides a more detailed account of a different ceremony that also involved the commemoration of the conquest of Shang and the first kings. It quotes several royal speeches encased in one another. My analysis below will focus on three aspects: the identity of the commissioner, the purpose of the reflected interaction, and the speech as a medium of memory transmission. Although several translations exist, there are discrepancies in readings of some key terms..$^{\circ}$ Hence, I will include a full translation below:

description of the territory bestowed on Yi hou Ze/Yu suggests that this was a very familiar place. This also supports the close geographic location of Yi.

90. See, e.g., Edward L. Shaughnessy, "Western Zhou Bronze Inscriptions," in New Sources of Early Chinese History: An Introduction to the Reading of Inscriptions and Manuscripts, ed. Edward L. Shaughnessy (Berkeley: Institute of East Asian Studies, 1997), 57-84, at 77-79; Khayutina, "Royal Hospitality and Geopolitical Constitution," 19-20; Eno, 3.10 Inscriptional Records of the Western Zhou, https: / /scholarworks.iu.edu/ dspace/handle/2022/23466/3.10-WZhou_Bronzes-2010.pdf; David W. Pankenier, "He zun," in A Source Book of Ancient Chinese Bronze Inscriptions, 16-18. 
The King moved [his] residence to Chengzhou for the first time. [He] returned [to the west in order] to carry out the feng ritual for King Wu..$^{1}$ [He performed] libation sacrifices starting from Heaven's [shrine]. In the fourth month, day bing- $x u$ (43), the king made an announcement to the minor sons of the ancestral shrine in the Lofty Chamber. [He] said: "Formerly, your pious patriarchs were able to approach King Wen. Thereupon, King Wen received this [Great Mandate?]..${ }^{2}$ Later on, King Wu conquered the Great Settlement Shang, and, staying in the courtyard [of a palace or temple], made an announcement to Heaven, saying: 'I shall reside in this central region and regulate the people from there!' $W u$ hu! You are but minor sons who have no knowledge. Look at [the example of your ancestors,] the patriarchs! Have merits before Heaven! Carry out commands! Respectfully offer sacrifices! May the wise king's reverent virtue satisfy Heaven! Follow me, [and you will have] no regret!" The king completed his announcement. He* was bestowed with thirty bundles of cowries. [I, $\mathrm{He}^{*}$ ] use [this occasion] to make this treasured sacrificial vessel for Patriarch $X$. This was the fifth sacrificial year of the king (He zun, JC6014). 93

\section{隹王初郘宅于成周, 復爯珷王豐, 裸自天, 在四月丙戌。王稁（誥） 宗小子于京室, 曰:『昔在爾考（孝）公氏，克菘（弨）玟（文）王， 觧玟王受茲 $\square \square$ (大命?), 唯珷王既克大邑商, 則廷告于天, 曰:「余 其宅茲中或 (域/國), 自之薜 (X) 民!」』鳥虖 (乎), 爾有唯小子 亡皒 (識)! 視于公氏, 有爵于天, 徹令敬享载（哉）! 叀王龏（恭）

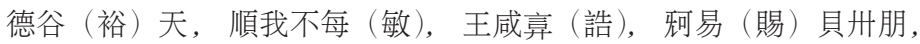 用作 $\square$ 公寶尊彝。隹 (唯) 王五祀。}

The He zun identifies the lineage name of the commissioner's father. The palaeographic character consists of the graphic element wei $\square$ that embraces two illegible elements. Thus, He's lineage name cannot be deciphered. This time, the place of the vessel's discovery provides a hint to He's identity. It was found in the Qian River valley north of Baoji, in the area of activity of the Ze/Yu lineages. Thus, He likely belonged to

91. The "Great feng" ritual performed by King Wu is commemorated in the Tian Wang gui 天亡筬, JC4261. A structurally similar ritual is described in greater detail in the Mai zun 麥尊 (JC6016), probably, roughly contemporary with the He zun. For the comparison and interpretation, see Hwang Ming-chorng, Ming-Tang (Ph.D. dissertation, Harvard University, 1996), 236-326.

92. There is a cavity on the surface of the inscription on the place where the collocation "Great Mandate" is supposed to be. These characters are unreadable, but most paleographers believe that there are no other options but the "Great" or even "Heavenly" Mandate that King Wen could "receive" (shou 受).

93. Khayutina, "Reflections and Uses of the Past," 162. 
the same group of the old Zhou elite as the commissioner of the Yi hou Ze gui. The inscription further records that he was one of these whom the king addressed as zong xiao zi 宗小子, “minor sons of the ancestral shrine," i.e. members of lineages that shared an ancestry and surname with the royal house. 94 Thus, the He zun equally reflects interactions in the Zhou network of patrilineally related lineages. If my reading of er xiao gong shi 爾考（孝）公氏 as “your pious patriarchs" is correct, the members of this network were expected to behave "piously" regarding the royal lineage. 95

The main topic of the interaction between the current king and the representatives of subordinated lineages reflected in the He zun was the king's decision to reside in Chengzhou. As other bronze inscriptions reveal, the Zhou kings were moving between their eastern and western residences, personally keeping an eye on their domain..${ }^{6}$ The He zun records that the current king already spent some time-perhaps several months, a year, or even several years-in Chengzhou and was now returning to the Zhou metropolitan region. There, he gathered his patrilineal relatives for a ritual primarily dedicated to King $\mathrm{Wu}$, though the ritual also served as an occasion to commemorate King Wen and the founders of other lineages who supported the dynasty's founders. Because the king was preparing to leave for Chengzhou for a longer period again, it is understandable that he needed to make sure that his relatives stayed "pious" and loyal during his absence.

The king legitimated his decision to reside in Chengzhou by referring to the will of king $\mathrm{Wu}$ and the Mandate received by King Wen. The "present situation" concerned the reproduction of the political order established after the conquest of Shang. Notably, unlike the Yi hou Ze/

94. The term xiao $z i$ "young son" was used as self-reference by the heir of the last lineage's head. The term zong xiao $z i$ "young sons of the ancestral shrine" referred to the descendants of the lesser-ranking descendants of the old trunk lineage who could themselves be heads of the branch lineages (see Falkenhausen, "The Inscribed Bronzes from Yangjiacun," 249). These persons were not necessarily young in terms of biological age (for a contrary opinion see Constance A. Cook, "Education and the Way of the Former Kings," in Writing \& Literacy in Early China: Studies from the Columbia Early China Seminar, ed. Li Feng and David Prager Branner (Seattle: University of Washington Press, 2011), 302-36, at 308).

95. The He zun uses the appellation er xiao/kao gong shi 爾孝/考公氏 “your pious/ deceased fathers-patriarchs," where shi is an honorific title applied to individuals meaning "Mr." or "Mrs." depending on gender, but is usually left untranslated. Bronze inscriptions script makes no distinction between xiao 孝 "filial piety, pious" and kao 考 "deceased father." The meaning thus can be deduced only based on context. In my translation, I opt for the first variant.

96. Khayutina, "The Royal Year-Count," 135-42; Khayutina, "Royal Hospitality and Geopolitical Constitution," 5-11. 
Yu gui, the He zun does not acknowledge King Cheng's contribution to the conquest. The lack of his mention is one of the reasons why most scholars assume that this inscription dates from King Cheng's reign. ${ }^{97}$ However, as I will demonstrate below, soon after Kings Wen and $\mathrm{Wu}$ began to be celebrated as a pair, King Cheng was removed from the conquest narrative. Hence, the absence of a reference to King Cheng does not necessarily suggest an early date for the vessel. The elaborate language and the complex structure of the He zun are among the reasons to suspect that it dates from the reign of King Kang98 or King Zhao (see more in the Appendix).

The king underlined that King $\mathrm{Wu}$ expressed his will in the wake of the conquest and communicated it to Heaven in a highly ritualized setting. The present ritual for King Wu similarly began in Heaven's shrine. The emulation of actions facilitated the transmission of memory about the king-conqueror and the conquest. In this ritual framework, the royal speech comes to the foreground as the medium of memory transmission. The inscription identifies it as a 稁 that Ma Chengyuan has interpreted as gao 誥 ("proclamation"). 99 If his interpretation, which has not yet been challenged, is correct, this inscription may indicate that proclamations represented a specific genre of ritualized speech pronounced in the setting of sacrificial ceremonies in front of an assembled public, thus helping to contextualize the "Proclamations" in the Shang shu. In any case, the character includes the yan 言 ("speech") element and obviously refers to a speech.

As many authors have already mentioned, the He zun includes such expressions as "conquered the Great Settlement Shang" (ke da yi Shang 克大邑商), “central region" (zhong yu 中或 (域)), to "regulate the min (people/external lineages?)" (yi min X民). This wording strongly recalls the earliest "Proclamations," especially, the "Shao gao" 召誥 and the "Luo gao" 洛誥. The He zun thus represents important counterevidence to Barnard's assumption that parallels with transmitted texts can be regarded as indicators of forgery. Their similarities do not imply that "Proclamations" already existed in their present form and that

97. Tang Lan 唐蘭, “He zun mingwen jieshi” 何尊銘文解釋, Wenwu 1976.1, 60-63; Ma Chengyuan 馬承源, “He zun mingwen chu shi” 何尊銘文初釋, Wenwu 1976.1, 6465; Zhang Zhenglang 張政烺, “He zun mingwen jieshi buyi” 何尊銘文解釋補遺， Wenwu 1976.1, 66; Shaughnessy, Sources of Western Zhou History, 110; Shaughnessy, "Western Zhou Bronze Inscriptions," 77.

98. Li Xueqin 李學勤, “He zun xin shi” 何尊新釋, Zhongyuan wenwu 1981.1, 35-45; Wang Entian 王恩田, “He you, He hu zhen wei bian-jian lun He gui, He zun de niandai yu zushu" 荷卢、荷锓真偽辨——兼論荷篮、荷尊的年代與族屬，Kaogu yu wenwu 2017.5, 54-59.

99. Ma Chengyuan, "He zun mingwen chu shi," 65. 
Western Zhou speakers quoted from them in the same way as Spring and Autumn statesmen or Warring States persuaders. Nevertheless, the He zun witnesses that some rhetorical formulas used to speak about the conquest and the First Kings, became fixed very early. The transmitted "Proclamations" incorporate these as building blocks, reflecting a certain continuity of tradition between the early Zhou time and the time of their composition. . $^{100}$

A noteworthy detail of the He zun is that, after having finished his account about King $\mathrm{Wu}$, the king emphasized that his addressees "lack knowledge" or "memory" (wang shi/zhi 亡䇅 (識) ). ${ }^{101}$ He probably referred to the genuine knowledge about the events that he just recalled in his speech, namely the conquest and the actions of King Wu. The zong xiao zi might lack knowledge not simply because they were born later and did not experience the conquest as eyewitnesses, but also because they stood farther from the direct channel of memory transmission within the royal lineage, through which the king acquired his own knowledge. The king now assumed the role of a "bearer of memory," who personally transmitted the memory of the conquest to the others within a ritual framework instead of entrusting this function to a trained priest, archivist, or historian, as such specialists possibly did not yet exist.

\section{The Da and Xiao Yu ding}

Two tripods commissioned by Yu, the head of the Ji-surnamed Nangong lineage, complete the group of inscribed bronzes reflecting the early stages of the production of the cultural memory of the conquest and the first kings. Both vessels were discovered during the 1870 in Licun 禮村, Meixian 腒縣 county, of Shaanxi province. ${ }^{102}$ They are usually

100. For the notion of a "building block" as a textual unit that can be moved between various texts, see William G. Boltz, "The Composite Nature of Early Chinese Texts," in Text and Ritual in Early China, ed. Martin Kern (Seattle: University of Washington Press, 2005), 50-78.

101. Several translations of this word, substantial for the understanding of this inscription, have been proposed: "experience" (Shaughnessy, "Western Zhou Bronze Inscriptions," 78; Eno, 3.10 Inscriptional Records of the Western Zhou, 11), and "understanding" (Pankenier, "He zun," 18). The standard Chinese interpretations of $z h i$ are $z h i$ 知 ("to know"), zhi 誌 ("to mark, to sign, to remember"), jizhu 記住 ("to remember"), and jish $u$ 記述 ("to transmit"). See Hanyu dazidian bianji weiyuanhui, Hanyu da zidian 漢語大字典 (Chengdu: Sichuan cishu, 1989), vol. 6, 4019-20.

102. Although many authors identify the place of discovery as Qishan County, the earliest records trace it to Licun, Meixian County, from which it was purchased by an antiquarian from the neighboring Qishan. For the history of the discovery and transmission of the vessel, see Li Chaoyuan 李朝遠, “Da Yu ding zhengbu er san li” 大 
regarded as dating from the reign of King Kang, ${ }^{103}$ but they more likely date from the end of the reign of King Mu. ${ }^{104}$ The Da Yu ding (Yu's large cauldron) is one of the largest Western Zhou vessels bearing one of the longest inscriptions. ${ }^{105}$ Several full translations are available. ${ }^{106}$ It is indeed one of the most frequently quoted and well-known inscriptions, which some scholars believe to be a typical example of how the past was used in Zhou political culture. ${ }^{107}$ To the contrary, I regard this inscription as outstanding for the time when it was produced, having only a few comparisons even among later pieces. ${ }^{108}$ The same is true for the Xiao Yu ding 小孟鼎 (Small Yu's cauldron), with more than 390 characters, which has been transmitted only in a rubbing on paper with nearly two fifths of the text illegible. ${ }^{109}$ The latter is usually translated in parts or

孟鼎證補二三例, Shanghai wenbo luncong 2004.1, 24-30; Xie Yaoting 謝耀亭, “Wan Qing 'si da guo bao' zhi yi Da Yu ding” 晚清 “四大國寶”之大孟鼎, Shanxi dang'an 2012.1, 17-21.

103. Chen Mengjia 陳夢家, “Xi Zhou tongqi duandai (san)” 西周銅器斷代(三), Kaogu xuebao 1956.1, 65-114, at 95.

104. Li Shan 李山 and Li Hui 李輝, “Da Xiao Yu ding zhizuo niandai Kang wang shuo zhiyi" 大小孟鼎制作年代康王說質疑, Beijing shifandaxue xuebao (Shehui kexue bian) 2012.2, 31-36; Lothar von Falkenhausen, "Review of Li Feng, 'Bureaucracy and the State in Early China: Governing the Western Zhou,'" Zhejiang University Journal of Art and Archaeology 1 (2014), 252-77, at 260; Khayutina, "The Tombs of the Rulers of Peng"; Khayutina, "Reflections and Uses of the Past," 166-67. The issue of the date of Yu's inscriptions shall be discussed in detail in the Appendix.

105. Kai Vogelsang raises doubts about the authenticity of the $\mathrm{Da} \mathrm{Yu}$ ding, citing Zhang Zhidong (Kai Vogelsang, "Inscriptions and Proclamations," 146).

106. For full translations, see W. A. C. H. Dobson, Early Archaic Chinese: A Descriptive Grammar (Toronto: University of Toronto Press, 1962), 221-26; Edward L. Shaughnessy, "Western Zhou History," in The Cambridge History of Ancient China, ed. Michael Loewe and Edard L. Shaughnessy (Cambridge: Cambridge Univ. Press, 1999), 292-352, at 320-322; Constance A. Cook, "Da Yu ding," in A Source Book of Ancient Chinese Bronze Inscriptions, 30-35.

107. Leung, The Politics of the Past in Early China, 33; cf. Michael Puett, The Ambivalence of Creation: Debates Concerning Innovation and Artifice in Early China (Stanford: Stanford University Press, 2001), 33.

108. This is true for the reign of King $\mathrm{Mu}$, but if the conventional date (the reign of King Kang) should be accepted, then its uniqueness must be perceived even more ostensibly.

109. For a long time, the Xiao Yu ding represented a unique example of a detailed record of a celebration that involved acts reminiscent of "guest rituals" described in Eastern Zhou ritual classics. Only recently, a comparable inscription, the Ba bo yu 霸伯 孟 (Shang $y u$ 尚孟), was excavated from the cemetery of the Ba polity in Dahekou 大河 口, Yicheng 翼城, Shanxi province. The tomb and the vessel have been dated about the reign of King $\mathrm{Mu}$. This inscription corroborates that both the rituals and related language reflected in the Xiao Yu ding were in use during the mid-tenth century B.C.E. For an analysis of the guest rituals in the Xiao Yu ding, see Maria Khayutina, "HostGuest Opposition as a Model of Geo-Political Relations in Pre-Imperial China," Oriens 
recounted. ${ }^{110}$ In this subsection, I will begin with Yu's identity, consider the settings in which the foundational memory of Zhou was recalled in his inscriptions, and then point out some differences regarding how this memory was used in different circumstances.

Nangong 南宮 was a metropolitan lineage, descending from Nangong Kuo 南公/宮括. Nan 南 probably corresponds to Nan/Ran/Dan 井/聘, mentioned in transmitted texts (see Figure 2). Thus, Nangong Kuo was plausibly the same person as Nan/Ran/Dan ji \#/䎶季 (The Junior of Nan/Ran/Dan), i.e. King Wen's youngest son by his primary wife. ${ }^{111}$ This hypothesis, first expressed by Tang Lan, has been confirmed by recently excavated inscriptions from the cemeteries of the Zeng lineage that equally descended from Nangong Kuo, in Yejiashan 葉家山,

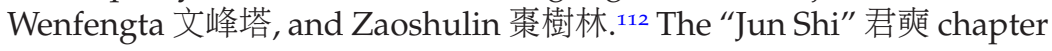
of the Shang shu mentions Nangong among King Wen's important

Extremus 43 (2002), 77-100, at 94-95; for the Ba bo yu, see Li Xueqin 李学勤, “Yicheng Dahekou Shang yu mingwen shishi" 翼城大河口尚孟铭文试释, Wenwu 2011.9, 67-68. For the parallels between the Ba bo yu and the Xiao Yu ding, see Huang Yifei 黃益飛, “Ba bo yu mingwen yu Xi Zhou pinlijian lun Mu wang zhi li" 霸伯孟銘文與西周朝聘禮— 兼論穆王制禮, Kaogu xuebao 2018.1, 25-48.

110. The only full translation in a Western language has been attempted by W. A. C. H. Dobson, Early Archaic Chinese, 226-33.

111. Tang Lan 唐蘭, Xi Zhou qing tong qi ming wen fen dai shi zheng 西周青銅器銘文 分代史徵 (Beijing: Zhonghua shuju, 1986), 170; cf. Shaughnessy, “Western Zhou History," 320.

112. First, inscriptions on the bells from the early Western Zhou period excavated in Yejiashan, as well as those from the Spring and Autumn period excavated in Wenfengta, were dedicated to the founding ancestor of Zeng Nangong Kuo, who was said to be appointed as ruler by kings Wen and Wu. Second, an inscription from a late Spring and Autumn tomb of a ruler of Zeng in Zaoshulin explicitly claimed descent from King Wen, which only makes sense if Nangong Kuo was King Wen's son. See Hubei sheng wenwu kaogu yanjiusuo, Suizhou shi bowuguan, "Hubei Suizhou Yejiashan Xi Zhou mu fajue jianbao" 湖北隨州葉家山西周墓地發掘簡報, Wenwu 2011.11, 4-60; Hubei sheng wenwu kaogu yanjiusuo, Suizhou shi bowuguan, “Suizhou Wenfengta M1 (Zeng hou Yu mu), M2 fajue jianbao" 隨州文峰塔 M1(曾侯 與墓)、M2 發掘簡報, Jiang Han kaogu 2014-4, 3-51, at 14-16; Huang Fengchun 黄凤春 and Hu Gang 胡刚, “Shuo Xi Zhou jinwen zhong de 'Nan gong': Jian lun Suizhou Yejiashan Zeng guo mudi de zushu” 说西周金文中的 “南公”: 兼论随州叶家山西周曾 国墓地的族属, Jiang Han kaogu 2014.2, 50-56; Khayutina, “Reflections and Uses of the Past," 171; Hubei sheng wenwu kaogu yanjiusuo, Beijing daxue kaogu wenbo xueyuan, Suizhou shi bowuguan, and Zeng duqu kaogudui, "Hubei Suizhou Zaoshulin mudi 2019 nian fajue shouhuo" 湖北隨州霜樹林墓地 2019 年發掘收獲, Jian Han kaogu 2019.3, 3-9, at 8; Shi Anrui 石安瑞 (Ondřej Škrabal), "You Zeng gong bianzhong mingwen cuoluan kan zhiming shi suo yong de xieben" 由曾公編鐘銘文 錯亂看製銘時所用的寫本, http://bsm.org.cn/show_article.php?id=3574, accessed on July 25, 2020. 
aides. ${ }^{113}$ Inscriptions from various reigns witness that the leaders of the Nangong lineage continued playing important roles at the Zhou court during the Western Zhou period. The Nangong lineage further followed King Ping to the east and retained its prominent role until 516 B.C.E., when its leaders, together with the heads of the other old lineages that included the Shao, Mao, and Shan, fled to Chu after the unsuccessful rebellion of wangzi 王子 (Royal Son) Zhao 昭, whom they all supported. ${ }^{114}$ It is likely that his status as the head of this important lineage was the reason why $\mathrm{Yu}$ was able to commission particularly large tripods with unprecedentedly long inscriptions, emphasizing his close connection to the reigning king. Yu's patrilineal kinship with the royal house, as well as his direct genealogical relation to King Wen, were probably the reasons why the king, whose speech is quoted in the Da Yu ding, several times referred to the first kings in his address.

Unlike in the case of the $\mathrm{He} z u n$, the royal speech quoted in the $\mathrm{Da} \mathrm{Yu}$ ding was pronounced not at an assembly, but at an individual audience. The king addressed $\mathrm{Yu}$ with the highest distinction, enumerating his various achievements. Although the speech also includes a royal command, delegating to $\mathrm{Yu}$ the control over considerable military forces, the inscription clearly differs from appointment inscriptions that usually only describe the appointment procedure and content, as well as related gifts. These became widespread only from the reign of King Gong. ${ }^{115}$ The reference to the memory of the first kings appears at the speech's opening:

... The King approvingly said: Yu! Illustrious King Wen received Heaven's blessings [and] the great Mandate. When King Wu gave way to King Wen, he created the bang, ${ }^{116}$ eliminated his foes, broadly pos-

113. Shang shu ji shi, 208.

114. S. W. Durrant, Li Wai-yee, and D. Schaberg, Zuo tradition = Zuozhuan: Commentary on the "Spring and Autumn Annals," 3 vols. (Seattle: University of Washington Press, 2016), vol. 2, 1663; Maria Khayutina, Kinship, Marriage and Politics in Early China (ca. 13-8th c. BCE) in the Light of Ritual Bronze Inscriptions (Habilitation thesis, University of Munich, 2017), 344-46.

115. Based on a systematic analysis of over 400 Western Zhou inscriptions related to gift-giving, Vassili Kryukov argued that the earliest "classical" description of the appointment (ce ming 冊命) ritual can be found in the Qiu Wei gui 䒾衛篮 (JC4256), dated to the twenty-seventh year of King Mu. See Kryukov, Ritualnaya kommunikatsiya, 122-36; cf. Kane, "Aspects of Western Chou Appointment Inscriptions," 16.

116. The Zhou term bang 邦 designates a polity ruled by hereditary rulers. Inscriptions reflect that the Zhou perceived the political organization of their epoch as wan bang "ten thousand bang." The Zhou kings ruled their bang and controlled several other bang within and outside the metropolitan region. Yet other bang were not subordinated to the Zhou kings. The term bang is often translated as "state," or even 
sessed the Four Quarters, [and] greatly governed his/their min (external lineages?) (Da Yu ding, JC2837).

…王若曰: 「孟, 丕顯文王受天有（佑）大令, 在武王嗣文作邦, 開 (闢)厥莀，匍有四方，㽙(畯)正厥民。」

As in the case of the He zun, Kings Wen and Wu are commemorated here as a pair, while King Cheng is not mentioned. The current king states that King Wen received the Great Mandate from Heaven, whereas King Wu succeeded him as the heir and created the bang 邦. At the end of the speech, the king encourages Yu to "take as a model his ancestor Nangong" just as he takes Kings Wen and Wu as models.

The situation reflected in the $D a \mathrm{Yu}$ ding was certainly politically relevant. By recalling the memory of the conquest, the king underlined the closeness of the royal house and the Nangong lineage. As has already been mentioned, Nangong was not only an important metropolitan lineage, but also had a dependency in a strategically important placethe Zeng 曾 polity in the Suizhou 隨州 corridor in northern Hubei. ${ }^{117}$ Paying respect to this patrilineal relative, the king aimed to secure the loyalty of a high-ranking political ally, and possibly that of the whole network of the Nangong connections extending far beyond the Zhou metropolitan region.

Notably, in contrast to the Yi hou Ze/Yu gui and the He zun, the Da Yu ding avoids the expressions "to conquer" and "to strike," and does not mention the place-name Shang. Nevertheless, it refers to the conquest, addressing the conquered by the name of the dynasty, Yin 殷:

I have heard that the Yin dropped the Mandate. This was because the hou and dian [lords] on the Yin periphery, as well as Yin administrators and one hundred rulers [all] submitted their will to alcohol and hence ruined their troops. (Da Yu ding, JC2837)

我聞殷述（墜）令, 唯殷邊侯、田（甸）雮（與）殷正百辟, 率肄于酉 (酒), 古 (故) 喪追 (師) 巳。

Many scholars have pointed out that this text is strongly reminiscent of the "Jiu gao" 酒誥 chapter of the Shang shu, allegedly rendering the

\footnotetext{
"nation," which leads to anachronistic interpretations of the Zhou political organization (Khayutina, Kinship, Marriage and Politics, 435-37).

117. See also Olivier Venture, "Zeng: The Rediscovery of a Forgotten Regional State," in China Across the Centuries: Papers from a Lecture Series in Budapest, ed. Gábor Kósa (Budapest: Department of East Asian Studies, Eötvös Loránd University, 2017).
} 
speech of Zhou gong Dan. ${ }^{118}$ Nevertheless, the propagation of abstinence in a speech —as the conventional dating of Yu's vessels suggests—of King Kang is puzzling considering the great number of zun 尊, $y i$ 彝, you 占, $z h i$ 觡, and other bronze vessels for alcoholic beverages commissioned during early Zhou reigns. This material evidence suggests that drinking was a widespread and fully legitimate element of the Zhou elite culture. This culture reached its culmination during the reign of King Zhao, as corroborated by inscriptions commemorating libation rituals on exquisite libation vessels. ${ }^{119}$ Archaeologists reveal that this culture started to change about the reign of King Mu or King Gong, as the focus of the assemblages for ancestral rituals and burials shifted from vessels for alcohol to vessels for meats and grain. This major change was probably initiated by the royal court in the context of the so-called "ritual revolution" (Rawson) or "ritual reform" (Falkenhausen). ${ }^{120}$ In light of the revised date of the $D a \mathrm{Yu}$ ding, the passage about Yin drunkenness in the inscription on the huge meat cauldron may be understood as an indirect criticism of earlier Zhou practices and as a manifesto of the ritual reform-a major political project for which king Mu likely sought support from the heads of the leading Ji-lineages.

The Xiao Yu ding, commissioned later than the Da Yu ding, commemorates a celebration of Yu's military achievements in the Zhou Temple on the Zhou Plain. In this case, the inscription describes a ritual performance without quoting a royal speech. The king gathered guests from various bang (bang bin 邦賓) to watch the presentation of captives and booty, as well as to attend to the offerings of animal victims and alcoholic beverages to several royal ancestors. These included the King of Zhou, King Wu, and King Cheng (cf. Xiao Yu ding, JC2839). For some reason, King Wen was not mentioned. It is not clear to whom the posthumous title "King of Zhou" referred. This could be Danfu, the founder of the Zhou settlement on the Zhou Plain, or, less probably, his son wang ji. The ceremonial emphasis on kings $\mathrm{Wu}$ and Cheng in

118. Dobson, Early Archaic Chinese, 225; Cook, "Da Yu ding," 31; Li Chaoyuan, "Da Yu ding zhengbu er san li," 27.

119. One bold example, describing a royal libation ceremony in detail, is the Mai zun (JC6015). For a full translation, see David W. Pankenier, "Zuoce Mai zun," in A Source Book of Ancient Chinese Bronze Inscriptions, 42-44.

120. Cf. Li Feng 李豐, “Huanghe liuyu Xi Zhou muzang chutu qingtong liqi de fenqi yu niandai" 黃河流域西周墓葬出土青銅禮器的分期與年代, Kaogu yu wenwu 1988.4, 383-418; Jessica Rawson, "Statesmen or Barbarians: The Western Zhou as Seen through their Bronzes," Proceedings of the British Academy 75 (1989), 71-95; Jessica Rawson, "Western Zhou Archaeology," in The Cambridge History of Ancient China, 352449, at 432-40; Falkenhausen, The Chinese Society in the Age of Confucius (1000-250 BC), $29-52$. 
the frame of a military celebration could be related to their roles as conquerors. This may suggest that there were possibly two different foundational narratives. ${ }^{121}$ The metaphysical narrative linked Heaven to the focal ancestors of the royal house and all lineages descending from it, namely, Kings Wen and $\mathrm{Wu}$, through the notion of the Mandate. ${ }^{122}$ The real-political narrative acknowledged the contributions of King Cheng, during whose reign the conquest of Shang was accomplished and many Zhou polities were effectively founded. ${ }^{123}$ As the following section will demonstrate, the first narrative became dominant in the subsequent royal memory policy.

Even if the conquest of Shang was not mentioned explicitly in the Xiao Yu ding, it is likely that the ritual for Kings Wu and Cheng involved its commemoration. Thus, warfare and the extension of the Zhou military presence into new areas represented another "present setting" in which the memory of the conquest of Shang was recalled.

The inscriptions of Yi hou, He, and Yu corroborate that the conquest of Shang was firmly established as the main point of reference for Ji-surnamed lineages. If the "guests from [various] bang," participating in celebrations such as those reflected in the Xiao Yu ding, included members of metropolitan lineages of other surnames, those were also encouraged to share this memory. If so, Wang Ming-ke may be right that the shared memory of the conquest helped to generate in-group feelings in the confederation of the lineage-based polities of the Wei river valley. However, it is clear that it primarily served to support the group identity of the Ji.

The situations reflected in the inscriptions considered in this section took place when the generation of the conquest's participants was either very old or had already passed away. The Yi hou Ze gui possibly reflects the stage when the memory about the beginning of the Zhou dynasty was still transmitted orally by the people who personally knew the conquest's participants. The He zun probably derives from the time when the "communicative modus" of transmission was already running into its limits, hence the royal remark that the "minor sons of the ancestral shrine" lack the "knowledge." It demonstrates that subsequent

121. The rubbing includes a lacuna after the title of King Cheng. Theoretically, it may contain the title of another king.

122. Michael Puett suggests that Heaven and the king-founders of the Zhou lineage were interlinked through the notion of zuo 作 ("creation"), for which he draws the Da Yu ding as an example. See Michael Puett, The Ambivalence of Creation, 30-36.

123. Puett does not distinguish between the two narratives and draws the He zun and the Shi Qiang pan as illustrations of the inclusion of King Cheng and all later kings into the creation narrative. 
kings gathered their patrilineal relatives for rituals and instructed them to internalize the memory about the conquest and the first kings. The $D a$ and Xiao $\mathrm{Yu}$ ding, if they date from the reign of King $\mathrm{Mu}$, fall beyond the horizon of the Assmanns' communicative transmission mode. They suggest that the memory of the conquest was recalled in a variety of contexts in connection to various political projects. Altogether, these inscriptions witness that as the foundational past was getting increasingly distant, special efforts were made to preserve it. These can be regarded as elements of a purposeful "memory policy" of the royal court. At the same time, the inscriptions reflect the importance of oral transmission, as they emphasize the acts of speaking (yue Đ, gao 誥) and hearing (wen 聞). The Yi hou Ze gui remains so far the only inscription that suggests the use of images or charts in the memory transmission process.

Commemorating the past was not the main purpose, but an integral element, of the ceremonies described in inscriptions. Although ceremonies that had no objectives other than worshipping the first kings and strengthening the shared identity of the worshippers probably also took place, these are not reflected in inscriptions available so far. Our current evidence thus only relates to the "practical applications" of the cultural memory in distinctively political contexts.

A noteworthy aspect of the Zhou memory policy is that in all available examples, the Zhou kings single-handedly transmitted the memory of the conquest and the first kings without relying on any trained specialists, either priests or archivists. Thus, the involvement of such specialists, as expected by the Assmanns in the context of cultural memory transmission, was not indispensable as long as this process involved a relatively compact metropolitan elite community. The Zhou kings performed divinations using the chart of the conquest, oversaw sacrificial rituals for the first kings, or recited the story of the conquest directly addressing other people collectively or individually. Thus, during the formative period of the Zhou cultural memory, reigning Zhou kings acted as major memory-keeping agents.

\section{The Royal Memory Policy from the Reign of King Gong to the Reign of King Xuan}

From the late tenth to the early eighth century в.C.E., only two inscriptions mention the conquest of Shang (or, rather, Yin) explicitly. They will be discussed in the next section. There are slightly more inscriptions that refer to the first kings. Such references constitute part of royal speeches addressed at important political partners. Notably, King Gong (922-900 в.С.Е.) conspicuously directed such speeches at lineage outsiders. 
One speech from his first year (922 в.C.E.) was addressed at Shi Xun 師㝘(詢), whose mother was a Ji-surnamed woman and who, therefore, was a royal affinal relative. ${ }^{124}$ Although the kinship degree between Xun and the King is unclear, the mention of the first kings and the overall trusting tone of the speech, in which the King not only commemorates the support of Xun's ancestors to Kings Wen and Wu, but also shares his worries and concerns about present lack of stability, imply that Xun had a special relationship with the royal house. ${ }^{125}$ Xun probably belonged to the $\mathrm{Mi}$ 弭 lineage that may correspond to the Si 姒-surnamed $\mathrm{Mi}$ 密 lineage mentioned in transmitted texts. ${ }^{126}$ According to the latter, the Mi lineage had its base in the Jing 涇 valley. ${ }^{127}$ This may explain Xun's appointment as a kind of general-governor (chi guan si 旁官司) in the upper flow of the Jing River, recorded in an inscription from King Gong's seventeenth year (906 в.C.E.). ${ }^{128}$ This inscription equally opens with a royal speech that commemorates the common past:

The King approvingly said: “Xun! Illustrious [Kings] Wen [and] Wu received the Mandate, whereas your ancestors stabilized the Zhou bang. (Xun gui 言(詢)筬, JC4321)

124. Shi Xun gui 師言(詢)笽 (JC4342); for a full translation, see Constance A. Cook, "Shi Xun gui," in A Source Book of Ancient Chinese Bronze Inscriptions, 112-14, at 114; for Xun as a Zhou affinal relative, see Khayutina, "Reflections and Uses of the Past," 168. This vessel is often regarded as dating from the reign of the ninth king, Yih (see Cook, "Shi Xun gui," 112; Khayutina, Kinship, Marriage and Politics, 433). However, its full date does not fit King Yih's first year. It can be fitted into King Gong's calendar if admitted that his first year included an intercalary month at the beginning and the months' numeration shifted (see Table 7 in the Appendix). There are no other alternatives, since Xun's second inscription securely dates to King Gong's reign.

125. Vincent Leung, The Politics of the Past in Early China, 35, regards the Shi Xun gui (again, a highly untypical piece) as representative of inscriptions that "bemoan the loss of historical continuity and proper inheritance from the founding rulers of the Zhou." Instead of treating it as reflecting a certain general trend and a common discourse, I believe that it should be contextualized in real political circumstances of a transition between two reigns. I agree with Constance Cook that such expressions like "Heaven sent down destruction/death" (tian ... jian sang 天 ... 降喪) in the inscription plausibly refer but to the passing away of the previous king (Cook, "Shi Xun gui," at 112).

126. Khayutina, "The Tombs of the Rulers of Peng," 108; Khayutina, Kinship, Marriage and Politics, 433.

127. Note the story in the Guo yu 國語 that Kang gong 康公 of Mi 密, the leader of Mi's lineage stem, had a close relationship with King Gong. However, the King killed him because of a woman; see Guo yu ji jie 國語集解, ed. Xu Yuangao 徐元誥, Wang Shumin 王樹民 and Shen Changyun 沈長雲 (Beijing: Zhonghua shuju, 2002), 9-10. This story possibly romanticizes an ambivalent relationship between the Zhou and the Mi lineage, dwelling in the middle flow of the Jing River.

128. For the localization of place-names in this inscription, see Khayutina, Kinship, Marriage and Politics, 296. 
王若曰 : 「訇, 丕顯文武受令, 則乃祖奠周邦.

The king proceeded to delegate to Xun the control of many groups, including trained warriors, both from the west and from Chengzhou. ${ }^{129}$

Between these two events from Xun's biography, the visit of the ruler of Guai 衛(乘) to King Gong took place in 914 B.C.E. A vessel with a commemorative inscription was probably cast as a gift for Guai bo 倬伯. It equally commemorates the Zhou foundational past and the recipient's ancestors, although in somewhat special terms:

The King approvingly said: “Guai bo! My illustrious ancestors King Wen and King Wu received the Great Mandate. Your ancestors were able to visit (?) the former Kings; strangers from another bang, [they] had a share (?) in the Great Mandate. I also do not [meaning unclear, perhaps cease] to enjoy [the possession of the] bang. Give you a [meaning unclear] fur coat!" (Guai bo gui 乘伯篮, JC4331)

\section{王若曰:「阼 (乘) 伯, 朕不 (丕) 顯祖玟王武王, 膺受大命, 乃祖 克苯 (拜?) 先王, 異自它邦, 又芇 (席?) 于大命。我亦弗䆓 (享?) 邦。易汝乿歨。」}

Guai was probably located upstream the Jing River in southern Gansu. ${ }^{130}$ It was likely an old polity that was explicitly referred to as "another bang." The inscription further celebrates "one hundred relatives by marriage" (bai zhu hun gou 百諸婚媾). This may suggest that Guai belonged to the affinal network of Zhou. Notably, the deceased father of Guai bo was referred to as King Wu Ji of Guai 武乘幾王, thus alluding to King Wu of Zhou as a model.

Both Xun's appointment and the audience of Guai bo were likely related to urgent concerns over stability in the north. This region was about to become the stage of permanent warfare with northern groups who eventually invaded Zhou in 771 B.C.E. and forced the royal house to leave to the east. ${ }^{131}$

During the ninth and early eight centuries, royal speeches alluding to the first kings appear again mostly in inscriptions commissioned by royal patrilineal relatives with great political weight. One of these was

129. For a full translation of the Xun gui 言(詢)笽, see Khayutina, “Xun gui and Shi You gui," in A Source Book of Ancient Chinese Bronze Inscriptions, 108-11.

130. For a full translation and analysis of the inscription and the localization of Guai, see Li Feng, "Literacy Crossing Cultural Borders: Evidence from the Bronze Inscriptions of the Western Zhou Period (1045-771 BC)," Bulletin of the Museum of Far Eastern Antiquities 74 (2002), 210-42. For another full translation, see Robert Eno, "Guai bo gui," in A Source Book of Ancient Chinese Bronze Inscriptions, 160-62.

131. See Li Feng, Landscape and Power in Early China, 141-92. 
Mao gong 毛公, the head of the metropolitan Mao lineage descending from King Wen, the commissioner of the already mentioned Mao gong ding. ${ }^{132}$ It is comparable in content and partly in wording with the $D a$ Yu ding. ${ }^{133}$ Most scholars date it to the reign of King Xuan. ${ }^{134}$ Another eminent recipient of a royal speech was shi Ke 師克, also known as shanfu Ke 善夫克, who was probably a high-ranking member of the metropolitan Ji-surnamed Jing 井 lineage. Ke commissioned a large set of inscribed bronzes, which were discovered in 1890 in Renjiacun 任家 村, Fufeng 扶風 county—in the middle of the Zhou Plain. One of his

132. To the many arguments provided in defense of Mao gong ding by Chinese specialists, I may add my rebuttal of Barnard's "criterium of forgery" Nr. 6: the presence of "rilievo graphs ',- , ' $\Lambda$ ' and ' + '" on the rear surface of the tripod's legs. The first was placed at the bottom, the second at the middle, and the third one towards the top. Barnard was able to recognize two of these graphs as “一" (1) and "七" (7), but stated that "there is no function, significance, nor any good reason for their presence at all"; see Barnard, "Chou China: A Review," 401. The " $\Lambda$ " graph can indeed be easily recognized as “六" (6), typically reduced to its upper part in numeric sequences in divinatory records. Such sequences, mostly of six numerals, but sometimes of three, have been attested in many manuscripts excavated since 1970s. They were first identified in bronze inscriptions in Zhang Zhenglang 張政烺, “Shi shi Zhou chu qingtongqi mingwen zhong de yi gua” 試釋周初青銅器銘文中的易卦, Kaogu xuebao 1980.4, 403-15; English translation in Chang Cheng-Lang, Jeffrey R. Ching, Scott Davis, Susan R. Weld, Robin D. S. Yates, and Horst Wolfram Huber, "An Interpretation of the Divinatory Inscriptions on Early Chou Bronzes," Early China 6 (1980-1981), 80-96). Zhang supposed that they correspond to the hexagrams of the Yi jing 易經 and represent complete (e.g., 1, 7), or yang 陽, and broken $(6,8)$, or yin 陰 lines. More recent studies have substantiated that numeric sequences rather refer to different mantic systems reflected in excavated manuals Guicang 歸藏 and Shifa 筮法 from the fourth century B.C.E. (see Andrea Bréard and Constance A. Cook, "Cracking Bones and Numbers: Solving the Enigma of Numerical Sequences on Ancient Chinese Artifacts," Archive for History of Exact Sciences 74 (2020), 313-43). The peculiarity of the Mao gong ding is that the numerals were placed on the legs, not making up part of the main inscription. A recent excavation of a bronze foundry in Anyang has demonstrated that artisans incised six-digit sequences on pottery molds for casting vessels' legs for whatever-perhaps apotropaic-reasons. In any case, this practice existed since ca. 1100 B.C.E., and such signs on the bottom or the rear side of vessels' legs could be easily overlooked on other bronzes and hence never be reported. The placement of the three numerals on the three legs of a tripod at various heights suggests that it could be "read" from bottom to top as 1-6-7. For Anyang molds with numerals, see Zhongguo shehui kexueyuan kaogu yanjiusuo Anyang gongzuodui, "2000-2001 nian Anyang Xiaomintun dongnan di Yin dai zhutong yizhi fajue baogao" 2000-2001 年安阳孝民屯 东南地殷代铸铜遗址发掘报告, Kaogu xuebao 2006.3, 351-81.

133. For full translations of the Mao gong ding 毛公鼎, JC 2841, see W. A. C. H. Dobson, Early Archaic Chinese 209-20; Constance A. Cook, "Mao gong ding," in A Source Book of Ancient Chinese Bronze Inscriptions, 204-9.

134. Zhang Maorong 張唀鎔, "Shilun Xi Zhou qingtongqi yanbian de feijunhengxing wenti” 試論西周青銅器演變的非均衡性問題, Kaogu xuebao 2008.3,33752 , at 350 . 
inscriptions, reproduced on several $x u$ 䁅 containers, quotes a royal speech containing a reference to Kings Wen and $\mathrm{Wu}$ and a command to take over military responsibilities. Another one of Ke's vessels, the $\mathrm{Da}$ Ke ding 大克鼎 (the large Ke's cauldron, JC2836), which inscribed with 281 characters and is one of the largest and heaviest Western Zhou tripods, boldly testifies to Ke's own political weight at the Zhou court. Ke's other inscriptions contain precise dates, revealing that he was equally active during the reign of King Xuan, especially during the $812-803$ B.C.E. ${ }^{135}$

The inclusion of references to Kings Wen and $\mathrm{Wu}$ in royal speeches addressed at key political allies can be understood as a part of an intentional royal memory policy, which was, however, not comprehensively addressed to a broad group of the elites, but exclusively to its top level. It is further obvious that all royal speeches quoted in inscriptions from the late tenth to the early eighth century B.C.E. bridge the gap between the time of Kings Wen and $\mathrm{Wu}$ and the present, avoiding mentioning intermediary kings. Inscriptions, commissioned personally by King Li 厲 “Terrible," r. 877 or $857-841$ в.С.Е., d. 828 в.С.Е.) corroborate that this was indeed the standard royal "master narrative."

The first of King Li's inscriptions, the Hu zhong 踟鐘, also known as Zongzhou zhong 宗周鐘 (JC260), begins with the phrase “The king set forth on an inspection tour through the borderlands acquired by the efforts of Kings Wen and Wu" (wang zhao sui sheng Wen Wu qin jiang tu 王肇通省文武勤疆土). The Hu zhong then proceeds to report King Li's own military and political achievements, including fighting back a ruler of a southern polity, and summoning the leaders of twenty-six bang of

135. For Shanfu Ke's inscriptions, including the Shi Ke $x u$ 師克盨, JC4467-68, see Ulrich Unger, "Zur Person des shan-fu K'êh (1. Teil)," Hao-ku. Sinologische Rundbriefe (Münster, privately published) 1982.9, 53-58; Ulrich Unger, "Verheiratet mit ... Zur Person des shan-fu K'êh (4. Teil)," Hao-ku. Sinologische Rundbriefe (Münster, privately published) 1982.15, 97-107; Lau, Quellenstudien zur Landvergabe und Bodenübertragung, 233-55; Maria Khayutina, "A Personal History of a Western Zhou Official: The Case of Shanfu Ke," in Dokumentation der Tagung der China AG, 2002, 15.-17.2.2002, ed. China AG (Tübingen: Arbeitsgemeinschaft junger Chinawissenschaftler und Chinawissenschaftlerinnen, 2002), 55-62; Maria Khayutina, "Povar ili ministr: Dragotsennye trenozhniki Dobrogo Muzha Ke," in Kazus, ed. M. Boitsov and I. Danilevskiy (Moscow: RGGU, 2004), 15-98; Constance A. Cook, "Da Ke ding and other related inscriptions," in A Source Book of Ancient Chinese Bronze Inscriptions, ${ }_{172-80}$. Ke's lineage affiliation is not obvious from his inscriptions, but it can be deduced from the fact that his vessels were found together with vessels of $Y u$ 禹, a member of the Jing lineage, whereas the $\mathrm{Da}$ Ke ding mentions that the king commanded Ke to recollect Jing people who fled to other places. 
the Huai River to a meeting. ${ }^{136}$ This inscription shows that the memory of the first kings was again recalled in connection to warfare and specific territorial claims. The fact that the events referred to in the Hu zhong pertain to the south reveals that in a similar fashion to the Yi hou Ze/ $\mathrm{Yu}$ gui, the narrative of the conquest was connected to the present-day needs on the symbolic level. Neither King Wen nor King Wu led wars in the south. Nevertheless, the acquisition of all territories became ascribed to the king-founders, and their alleged territorial claims could then be used to justify war. Although the first southern Zhou colonies, such as Zeng, probably emerged during the reign of King Cheng or later, King Li does not mention King Cheng or any other king in his inscription. This means that in the official memory culture of the mid-ninth century B.C.E., the metaphysical narrative completely replaced the real-political one.

The rest of this rhymed inscription consists of prayers and dedications to illustrious ancestors and the deceased father, the Former Kings (pi xian zu kao xian wang 丕顯祖考先王). The king thus links his own person directly to Kings Wen and $\mathrm{Wu}$, subsuming all intermediate kings under the category of "the Former Kings."

Another inscription commissioned by King Li during the fifth year of his reign represents a prayer addressed to royal ancestors, which was not related to any specific present situation, and should be understood in the context of regular ceremonies in a royal ancestral temple. It goes even further insofar as it lumps together the receiving of the Mandate of Heaven and the acquisition of the Four Quarters, otherwise distinguished as achievements of King Wen and King Wu, ascribing them instead to the "Former Kings" (xian wang 先王) as a group. ${ }^{137}$

\section{Transmission of Memory in Lineages and Inscribed Bronzes as its Media}

Whereas royal speeches and inscriptions link the present directly to the foundational past, the records of individuals' pedigree represent the past as a chain of generations where no link should be missed. ${ }^{138}$ The Shi Qiang pan, excavated from the hoard of Wei 微 lineage vessels in Zhuangbai 莊白 village on the ancient Zhou Plain traces Shi 史 ("Secretary") Qiang's 牆 pedigree from the era of the conquest up to the reign of king Gong. The inscription on the basin's internal surface is subdivided in two parts, separated from one another by an empty

136. For translations, see Khayutina, "Royal Hospitality and Geopolitical Constitution," 31-32; Constance A. Cook, "Hu gui and Hu zhong," in A Source Book of Ancient Chinese Bronze Inscriptions, 147-53, at 152.

137. Hu zhong 割鐘 (JCo358). For a full translation, see Cook, “Hu gui and $\mathrm{Hu}$ zhong," 149.

138. See Sena, "Arraying the Ancestors in Ancient China," 71, 74. 
space. The first part on the right panel commemorates the achievements of every king from King Wen to King Gong, while the second part on the left panel praises the services of Qiang's ancestors to respective kings, including solemn dedications at the end. ${ }^{139}$

The Shi Qiang pan is famous as an outstanding example of early Chinese memory culture and historical consciousness. On the one hand, it shows that by about 900 B.C.E., aristocratic lineages kept records of their pedigree and produced their own narratives. On the other hand, it demonstrates that not simply the persons of kings, but also historical events associated with these kings served as points of reference for aligning private memories. Lothar von Falkenhausen has suggested that the Shi Qiang pan may be based on a manuscript, a "primary version" of a "proclamation," "phrased in the subjective mode" and possibly based in-part on official records "drafted at the lineage level" and kept in the private archive of the Wei lineage. Pointing out intertextual relationships between the Shi Qiang pan and other inscriptions from the Zhuangbai hoard, Falkenhausen supposes that the inscriptions on the third set of bells commissioned by Xing 㾶, a son or a grandson of Shi Qiang, may be based on the same original documents from the lineage archive. ${ }^{140}$ Falkenhausen, however, did not analyze these inscriptions in detail. In the introduction to the recently published translations of Xing's inscriptions, Constance Cook has observed that the Xing zhong "retells the tale of the founding of Zhou by Kings Wen and Wu and of the Wei founder ancestor being resettled in Zhou, earlier recorded in the Shi Qiang pan."141 These two scholars suppose two quite different modes of memory transmission: either retelling and writing down an oral history (Cook), or "splicing apart and recombining" old manuscript documents stored in the lineage archives "in the process of their transcription onto bronzes" (Falkenhausen). I suspect a third possibility, namely that the Xing zhong neither retells a story, nor quotes a bamboo or wooden original, but partly directly copies the earlier inscription..$^{142}$

139. For translations and analyses, see, for instance, Vassili Kryukov, "Nadpisi na zapadnochzhouskich bronzovykh sosudakh iz Fufena [Inscriptions on Western Zhou Bronze Vessels from Fufeng]," Vestnik Dreoney Istorii 1988.1, 96-112, 98-101; Shaughnessy, Sources of Western Zhou History, 183-92; Lau, Quellenstudien zur Landvergabe und Bodenübertragung, 184-204; Constance A. Cook, "Shi Qiang pan," in A Source Book of Ancient Chinese Bronze Inscriptions, 93-100.

140. Falkenhausen, "Issues in Western Zhou Studies," 163. For an overview of Xing's sets and the translation of the First Xing's bell, see Lothar von Falkenhausen, Suspended Music: Chime-Bells in the Culture of Bronze Age China (Berkeley: University of California Press, 1993) 40-45.

141. Constance A. Cook, "Xing zhong and related inscriptions," in A Source Book of Ancient Chinese Bronze Inscriptions, 115-25.

142. Cook, "Xing zhong and related inscriptions," 121; Falkenhausen, "Issues in Western Zhou Studies," 163. 
The third set of Xing zhong consists of six bells of decreasing sizes with a continuous inscription. As the following comparison demonstrates, the inscription on bells 1 and 2 is indeed nearly identical to the first two stanzas of the Shi Qian pan (differences are emphasized):

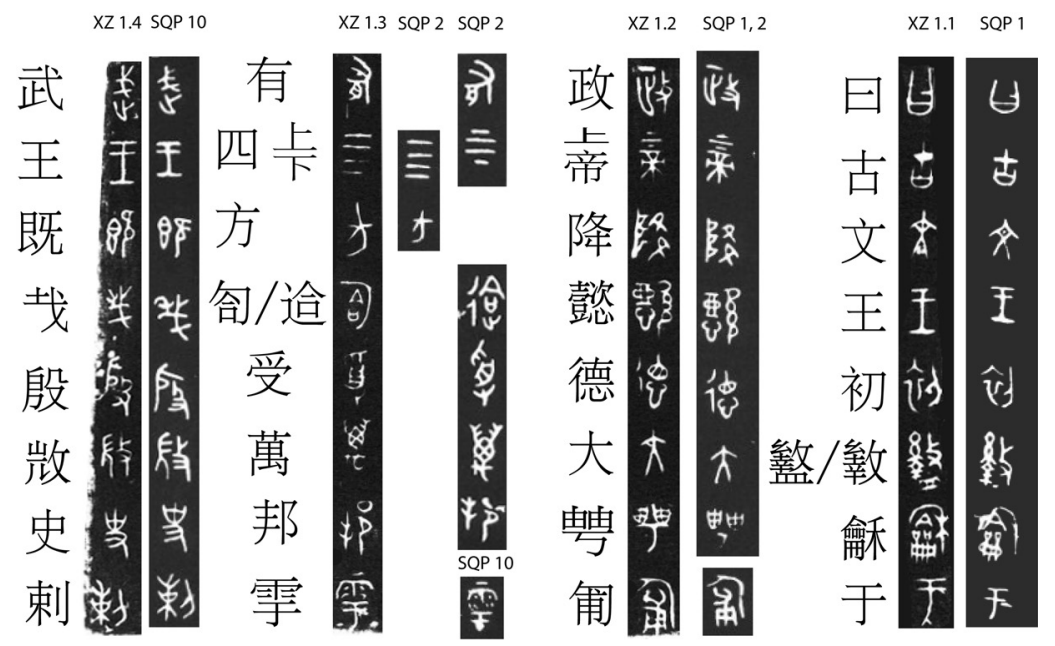

Figure 1 Comparison of the Shi Qiang pan (SQP) and Xing Zhong (XZ) inscriptions. The numbers correspond to the line number in the SQP and the bell and line number in the XZ.

\section{Shi Qiang pan (JC10175)}

Lines 1-2

It was said that in ancient times, King Wen

First brought harmony to the government.

The Deity on High sent down perfect de-power and great protection.

[So, he] broadly possessed [those] above and below,

Joined and accommodated ten thousand bang!

Interrogating and capturing, King $\mathrm{Wu}$

Proceeded to march on the Four Quarters,

Reaching the min remaining from the Yin

\section{Xing zhong}

Bell I (JC251), $70 \mathrm{~cm}$

It was said that in ancient times, King Wen

First brought harmony to the government.

The Deity on High sent down perfect de-power and great protection.

[So, he] broadly possessed the Four Quarters,

Joined and accommodated ten thousand bang! 
曰古文王，

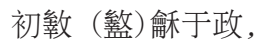

上帝降懿德大甹 (屏),

匍有上下,

䢔（會）受萬邦。

素（訊）囯武王，

週征四方,

達殷畯民

\section{Lines 10-12}

Calm and secluded was the High Ancestor, In Wei had he his dwelling.

When King Wu already tailored the Yin,

The Illustrious Ancestor Wei shi ("Secretary")

Thereupon came to see King Wu.

King $\mathrm{Wu}$ then commanded to Zhou gong

To allocate him space in Zhou

To dwell and to subsist [there]
曰古文王，

初敌倫于政,

上帝降懿德大甹 (屏),

匍有四方, 氛 (會) 受萬邦

Bell 2 (JC252), $64 \mathrm{~cm}$

When King Wu already tailored the Yin,

The Illustrious Ancestor Wei shi

("Secretary") [ ... ] came to see

King Wu.

King $\mathrm{Wu}$ then commanded to Zhou gong

To allocate him space of 50 qing to dwell.

Today, Xing mornings and evenings respectfully performs his hereditary services,

For the first time makes his harmonious bells to use them ...

青 (靜) 幽高且 (祖),

零武王既找殷,

才（在）改霝（靈）處,

凯史刺（烈）且（祖）

雲武王既找殷,

$\square$ 來見武王，

凯史刺 (烈) 且（祖）

武王則令周公

迺來見武王,

武王則令周公

舍（捨）㬂（宇）于周，

卑 (俾) 處甬 (容)。

舍（捨）㬂 (宇) 以五十頌（頃） 處,

今㾶咸夕虔敬欰厥死事, 肇作掄林鐘，用

The first bell in the set reproduces the first lines of the Shi Qiang pan, praising King Wen, but replaces the expression "broadly possessed [those] above and below" with "broadly possessed [the] the Four Quarters." It skips the immediately following commemoration of King Wu's military achievements, but this is where it borrows the expression "broadly possessed [the] the Four Quarters." Then, continuing on the 
second bell, the inscription reproduces a passage from the first line of the left panel of the Shi Qiang pan that briefly mentions King Wu's "tailoring of the Yin" and commemorates the arrival of the Illustrious Ancestor Wei shi ("Secretary") to King Wu. Here, Xing's inscription introduces a new detail, specifying that Zhou gong allocated to his family the space "of 50 qing to dwell in Zhou." In the next sentence, Xing praises himself as one who continues the service of his ancestors and begins the solemn dedication that extends to the following four bells.

A comparison of the original inscriptions corroborates that the scribe who prepared the clay slab for the casting of the Xing's bells accurately copied the Shi Qiang pan's lines layout, characters orthography and calligraphy. However, for some reason, he replaced the character he 悠. / 䢔 with he 圈/氛, presumably, used in the sense of hui 會 "to join." The first character appears in few very early inscriptions, while the second character does not appear anywhere else. The mid-ninth century's scribe, possibly, did not know the archaic character and simplified it as he thought convenient. In the inscription on the second bell, the scribe omitted the word nai 迺 ("thereupon/only then"), leaving a lacuna in the middle of the line. Quoting the expression "broadly possessed [the] the Four Quarters," he copied the calligraphy of the character fang $\mathrm{H}$ with the short lower left stroke beginning exactly under the horizontal stroke, like in the Shi Qiang pan (†), whereas in the standard mid-ninth century's calligraphy of fang this stroke began at the middle of the lower hooked vertical stroke, as, for example, in the Hu gui 割篮 (JC4317), commissioned by King Li ( The list of correspondences, which are certainly not accidental, can be extended, but this cannot be done in the context of the present article due to the space limitations. The finding of ink inscriptions from the Western Zhou period, although very rare, clearly demonstrates that the calligraphy of brush writing differed from the calligraphy of inscriptions incised on clay and cast on bronze and was more like the calligraphy of later manuscripts. ${ }^{143}$ Thus, the similarity of bronze characters would not be so high if the transmission had been mediated by an ink inscription. Hence, I argue that the inscription on Xing's bells does not simply quote the text transmitted orally or on a different written medium, but partly reproduces the earlier bronze inscription. ${ }^{144}$ This case demonstrates that-along with

143. Cai Yunzhang 蔡運章, “Luoyang Beiyao Xi Zhou mu moshu mingwen lüelun” 洛陽北窯西周墓墨書文字略論, Wenwu 1994.7, 73-79.

144. The process of inscriptions' casting probably included the pre-production of a master copy of the text on a perishable medium; see Ondřej Škrabal, "Writing before Inscribing: On the Use of Manuscripts in the Production of Western Zhou Bronze Inscriptions," Early China 42 (2019), 273-332. It is not clear whether this manuscript had a value on its own and would be kept in an archive or discarded. A comparison of inscribed vessels fitting identical inscriptions forming one set often demonstrate 
other media, such as oral tales or manuscripts on perishable materialsinscribed bronzes kept in ancestral temples served themselves as media for memory transmission.

At the same time, Xing's inscription modifies the original text by omitting or adding some details. First, it omits the High Ancestor, commemorated in the Shi Qiang pan as the founder the Wei lineage. It exclusively commemorates his ancestor who joined King $\mathrm{Wu}$ after the conquest of Shang, but none of the ancestors who lived later. This choice was not caused by restraints of space. The frontal panels of the four smaller bells were large enough to hold texts up to one hundred characters. ${ }^{145}$ It is therefore clear that Xing purposely focused on the Illustrious Ancestor who resettled to Zhou and who received the grant of land. Second, Xing's inscription specifies that this ancestor received 50 qing of land. This detail is certainly meaningful. Inscriptions from the late tenth and ninth centuries B.C.E. reflect that the Zhou metropolitan region was a stage of many conflicts over landed property. ${ }^{146}$ The fact that records of lawsuits were reproduced on ritual bronze vessels suggests their use as durable certificates of rights and obligations. Xing's ostensive demonstration of his rights on a piece of land by virtue of it being granted by Zhou gong after the conquest of Shang and, moreover, legitimized by the authority of King Wen who "joined and accommodated ten thousand bang," can be understood in this context.

These inscriptions illustrate what happened in the immediate surroundings of the court-based official "memory policy": within elite families, including those who did not belong to the royal patrilineal

significant differences in their layouts, calligraphy, and sometimes even characters' structure. This might be due to the division of labor in a workshop, where different scribes transcribed the same text, obviously not intending to strictly follow the model of the master-copy; see Li Feng, "Ancient Reproductions and Calligraphic Variations," 40-41. It is therefore unlikely that the artisans who worked on the Xing Zhong would attempt to imitate the calligraphy of the old manuscript so that the resulting inscription would be so similar to an inscription cast half a century earlier. If a later inscription would feature a text identical with an earlier one but would be written in a distinctively different way, the transmission by means of a manuscript would be more plausible, although copying text without imitating the calligraphy from an earlier inscription could not be ruled out in this case too. These assumptions require further research.

145. This is clear from a comparison with the bells of the same size from the second set of Xing's bells, found in the same hoard.

146. For examples and translations of inscriptions related to conflicts over landed property, see Lau, Quellenstudien zur Landvergabe und Bodenübertragung; Laura Skosey, The Legal System and Legal Tradition of the Western Zhou (ca. 1045-771. B.C.E.), PhD thesis, University of Chicago (1996); Maria Khayutina, “The ‘Bi shi' 枈誓, Western Zhou Oath Texts, and the Legal Culture of Early China," in Origins of Chinese Political Philosophy: Studies in the Composition and Thought of the Shangshu (Classic of Documents), ed. Martin Kern and Dirk Meyer (Boston: Brill, 2017), 416-45, at 424-27. 
network, cultural construction of the distant past also occurred during the late tenth century and subsequent periods. In new reconstructions, the past could be adjusted to better meet present needs, for instance, to protect status and property.

\section{Fluctuations in the Zhou Foundational Narrative}

A comparison of inscriptions from different periods reveals some changes in the perspectives on both the circumstances of the foundation of the Zhou dynasty and on the extent of the first kings' sovereignty. Inscriptions commissioned by eyewitnesses and participants of the events refer to Shang as a specific place, namely the Shang city. The Yi hou $\mathrm{Ze} / \mathrm{Yu}$ gui explicitly distinguishes Shang from the Eastern Region conquered, as we know from transmitted texts and inscriptions alike, in the second step. In the Zhong ding 事鼎 from the reign of King Zhao, the king bestows upon Zhong 害 the Land of $\mathrm{Li}$ 言土 because formerly, "the men of Li committed themselves to serve, [and] offered [themselves] to King Wu to become his servants" (Li ren ru shi, xi yu Wu wang zuo chen 衰人入史 (事), 易 (賜) 于珷王乍 (作) 臣). ${ }^{147}$ Here again, the reference concerns a specific place and group. The somewhat later Xiao Yu ding states that "the Yin dropped the Mandate" (Yin zhui ling /ming 殷述（墜）令 (命)), while the Da Yu ding states that King Wu "broadly possessed the Four Quarters" (pu you si fang 匍有四方). Here, Yin is understood as the dynasty that formerly controlled the whole space, which was then acquired by King Wu in a series of campaigns that need not be specified. The Four Quarters represented an ideal cosmological structure organizing the spaces endlessly extending in the four directions from the center occupied by the king. The imaginary Four Quarters embraced the whole world and had no outer borders. ${ }^{148}$ The Shi Qiang pan from the reign of King Gong states that King Wen "broadly possessed [those] above and below" ( $p u$ you shang xia 匍有 上下), referring to the worlds of spirits and humans, while "King Wu proceeded to march on the Four Quarters, reaching the min remaining from the Yin" (Wu wang sui zheng si fang, da Yin jun min 武王矞征四方, 達殷畯民). ${ }^{149}$ This inscription assumes the same perception of the Yin dynasty as a former central power and, moreover, shows that the Four Quarters were conceptualized not as spiritual entities, as could have been the case in Shang cosmology, but as inhabited space, where min-

147. The Zhong ding 串鼎 (JC2785).

148. Cf. Sarah Allan, The Shape of the Turtle: Myth, Art, and Cosmos in Early China (Albany: State University of New York Press, 1991); Wang Aihe, Cosmology and Political Culture in Early China (Cambridge: Cambridge University Press, 2000).

149. Shi Qiang pan 史牆盤 (JC10175). 
other peoples, or external lineages-dwelt. ${ }^{150}$ Intensifying conflicts with neighboring peoples promoted awareness of the territorial limitations of Zhou sovereignty. Thus, inscriptions produced in connection to warfare, such as the $\mathrm{Da} \mathrm{Yu}$ ding and the $\mathrm{Hu}$ zhong, emphasize territoriality referring to "borderlands" (jiang t $u$ 疆土) acquired by the efforts of Kings Wen and $\mathrm{Wu}$.

Additionally, it is noteworthy that earlier inscriptions appreciate the military achievements of King Wu, who fa 伐 "stroke, attacked" or ke 克 "overcame, subdued, conquered" Shang, pi ni 闢臨 "eliminated foes/ evil men," or zheng si fang 征四方 “marched against the Four Quarters." The Shi Qiang pan, however, suggests that King Wu treated different residents of the "Four Quarters" in different ways. He "reached the min remaining from the Yin" but kept specific groups of Di and Yi aliens in the north and in the east in fear. It is noteworthy that $d a$ 達 "to reach" also means "to promote," which can mean that King Wu was able to approximate and use the old elites. Indeed, Shi Qiang's inscription states that his ancestor, who was a member of an old lineage, submitted to King Wu voluntarily.

The expression cai Yin 国/戎殷, translated here tentatively as "to tailor the Yin" also deserves attention. Most translators interpret cai 载 as cai 裁 in the sense "to sanction, to punish," attested in Warring States' texts. I hesitate to project this meaning onto a much earlier text. The character 载 stands in Zhou bronze inscriptions either for the exclamatory particle $z a i$ 哉 or for as an integral part of the composite character 闻, embracing the wei 韋 "leather" element. ${ }^{151}$ In the latter case, it invariably refers to leather kneepads $f u$ 市 and can be understood as cai 裁 "tailored." In a few cases, cai 戎 appears in combination with kneepads without the

150. Wang Aihe suggests that the Zhou re-conceptualized the Shang idea of the Four Quarters as spiritual entities transforming it into a concept of political geography. She supposes that this transformation directly reflected Zhou military and political actions by which the Zhou transformed the people of the Quarters into their subjects (Wang Aihe, Cosmology and Political Culture in Early China, 67). I do not see that the "Four Quarters" referred only to effectively conquered and subordinated territories. However, I agree that during the Western Zhou period, this was a concept of political, rather than spiritual cosmology. For the meaning of $\min$ as external lineages, see Thomas Crone, "Der Begriff min 民 in Texten der Westlichen Zhou-Dynastie (1050-771 v. Chr.)," Orientierungen 2014.1, 33-53, with further references.

151. Professor Shaughnessy pointed my attention to the use of cai 载 in Shang oracle bone inscriptions (personal communication on July 18, 2020). Presumably, cai corresponds there to $\$$, although the structure of the latter is different from in the Zhou bronze inscriptions. In the OBI, this character usually stands for zai 災 "disaster." In a few cases, it is used in a verbal function referring to apparently hostile transactions with alien peoples. Its meaning requires further research, but the number of cases is very small. 
wei element. ${ }^{152}$ Kneepads of various types represented one of the most frequent categories of gifts distributed in appointment ceremonies, ${ }^{153}$ and it is understandable that they had to be tailored according to the individual body size. I wonder whether there could be an idea of transforming the Yin by cutting them like leather or tissue and making them usable. ${ }^{154}$

Inscriptions from the ninth and early eighth century в.C.E. completely avoid militant rhetoric while commemorating the first kings. They reaffirm their legitimate possession of the Mandate of Heaven and their pacifying ability to "broadly possess the Four Quarters," which became a standard expression.

The choice of nonviolent vocabulary in commemorations of the foundational past correlates with the tendency to represent current kings as these who bao 保 "protect" rather than "strike" fa 伐 the si yu四或 (域) "Four Regions" that can be observed in other inscriptions from the ninth to the early eighth century. ${ }^{155}$ This does not mean that late Zhou kings became pacifists. However, some wars referred to in inscriptions from this time were clearly defensive and related to big losses. ${ }^{156}$ Thus, late Western Zhou kings could be realistic about their limited opportunities to stage themselves as conquerors. Besides, later kings usually delegated military tasks to others, minding the case of King Zhao, who fell in a war.

The attitude towards military virtues might theoretically have changed during the reign of King Xuan, whose commanders were quite successful and who personally led a number of "inspections" (cf. Jin hou $\mathrm{Su}$ zhong 晉侯鮴鐘, YHB870, from the thirty-third year of King Xuan). However, this was not the case. The Qiu pan, commissioned about the fortieth year of King Xuan (ca. 787 B.C.E.), ${ }^{157}$ combines several rhetorical "building blocks" that appeared earlier in different inscriptions from the tenth to the ninth centuries B.C.E., while praising Kings Wen and Wu. It records that the kings

152. See Si gui 猫篮 in Wu Zhenfeng 吳鎮烽, “Si qi mingwen kaoshi” 膒器铭文考释, Kaоgu уи wепwи 2006.6, 58-65, Figure 3.

153. Kryukov, Ritualnaya kommunikatsiya, 263.

154. Possibly, this can be linked to the idea of "making new min" (zuo xin min 作新 民) as referred to in the "Kang gao" 康誥 chapter of the Shang shu, but more evidence and investigations would be required to support this.

155. Khayutina, Kinship, Marriage and Politics, 459-63.

156. Li Feng, Landscape and Power in Early China, 141-92.

157. For translations and analysis, see Falkenhausen, "The Inscribed Bronzes from Yangjiacun," 279-83; Sena, "Arraying the Ancestors in Ancient China," 72-76; Constance A. Cook, "Lai pan," in A Source Book of Ancient Chinese Bronze Inscriptions, $230-38$. 
reached to the Yin, received the generous Heavenly Mandate to broadly possess the Four Quarters, to dwell within their borderlands acquired by their efforts [so] as to become the mates for the Deity on High.

達殷, 膺受天魯令 (命), 匍有四方, 並宅氐 (厥) 堇（勤）疆土, 用 配上帝。

Royal speeches quoted in inscriptions from the late tenth to the early eighth century в.C.E., as well as the inscriptions of King Li, demonstrate that the royal lineage cultivated the memory about the beginning of the dynasty not as being anchored to a particular historical event (the conquest of Shang), but to the figures of kings Wen and $\mathrm{Wu}$. These two "ritual figureheads," 158 constituted a stable pair in the context of the royal commemorative policy. They obviously eclipsed King Cheng, who was held in a higher regard earlier, as this is suggested by the Yi hou Ze gui and the Xiao Yu ding. I suppose that this fixation on the two first kings was probably related to their roles as progenitors of the politically most influential metropolitan and external Ji-surnamed lineages (Figure 2). King Cheng, who was either not blessed by a numerous progeny, or who did not encourage his sons to found new lineages, keeping them instead at the court, was thus less relevant as an ancestor. Therefore, despite his contributions to the conquest of Shang and to the acquisition of territories further in the east, he became overshadowed by his more prolific father and grandfather.

King Cheng appears only in the two available records of pedigree that mention each king as a reference for commemorating the lineage's ancestors. The earlier of them, the Shi Qiang pan from King Gong's reign, characterizes King Cheng as "exemplarily and sagely" (xian sheng 憲聖); he was supported by his aides and cleared the land for the Zhou bang (JC 10175). It is not so clear whether this indicates a high appreciation of his efforts. The Qiu pan from King Xuan's reign recognizes that King Cheng fulfilled the Great Mandate:

朕皇高且祖公叔， My Radiant High ancestor gong shu 克逨匹成王, 成受大令 (命), was able to come to become a mate to King Cheng, [who] accomplished the receipt of the Great Mandate. 用奠四或（域/國） great offerings.

萬邦 Used [them] to stabilize the ten thousand bang in the Four Regions. < .. > (Qiu pan 逨盤, YHB0757)

158. Yuri Pines, Envisioning Eternal Empire: Chinese Political Thought of the Warring States Era (Honolulu: University of Hawai'i Press, 2009), 13-20. 


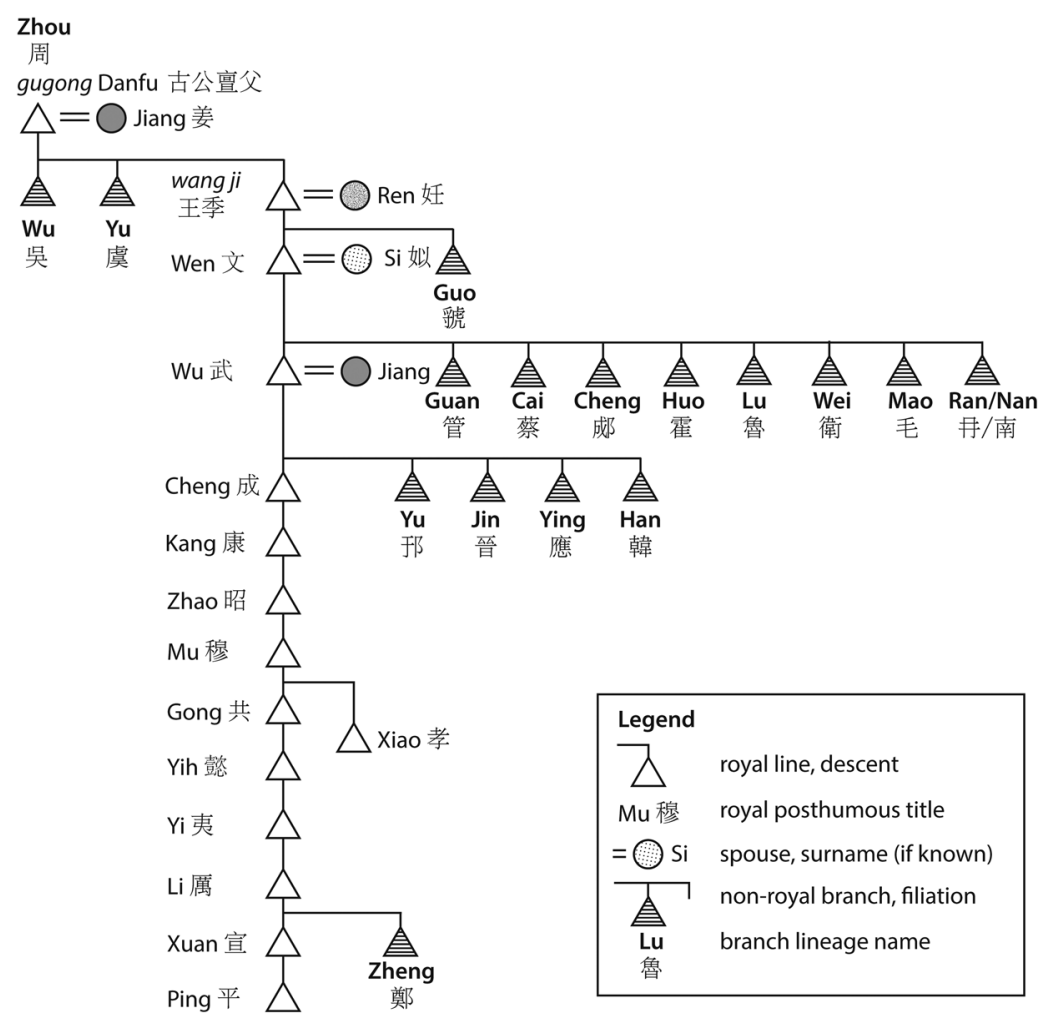

Figure 2 Zhou royal lineage and lineages descending from Zhou kings.

It seems that Qiu's inscription gives more credit to King Cheng than Shi Qiang's does. It is unclear whether this reflects Qiu's own perspective as a descendant of gong shu 公叔, who personally served to King Cheng, ${ }^{159}$ or a more profound change of the royal memory policy. Considering that this and several other inscriptions commissioned by Qiu quote royal speeches, it is possible that Qiu transmitted the current official narrative. ${ }^{160}$ The reconnection of King Cheng to the Mandate could be related to his role as founder of Chengzhou, where King Xuan regularly performed some affairs of government, probably already preparing the relocation of the court to the east that eventually took place only during the reign of King Ping. ${ }^{161}$

159. The Xiao chen Shan inscription discussed in the first section may be related to the engagement of the Shan lineage into King Cheng's campaign against the Shang.

160. This is also plausible considering the further development of the official memory culture manifested in the written tradition of the Shang shu.

161. For the visits of late Western Zhou kings to Chengzhou, see Khayutina, "Royal Hospitality and Geopolitical Constitution," 8, 23-29, 46. 
Again, the Qiu pan represents King Cheng's role not as militant, but as pacifying and stabilizing. In contrast, it underlines the military achievements of Kings Zhao and $\mathrm{Mu}$, who "invaded and conquered the Four Quarters, decimated and struck Chu-Jing" (dao zheng si fang, jian $f a \mathrm{Chu}$ Jing 盜政四方, 翌伐楚荊). ${ }^{162}$ All other kings are praised for their civil virtues. King Xuan himself is portrayed as one who "protects and stabilizes the Zhou bang, admonishes and regulates the Four Quarters" (bao zheng Zhou bang, jian yi si fang 保奠周邦, 諫觪 (X) 四方. Although "admonishing and regulating" certainly involved application of force, describing the current policy as militant was obviously not regarded as politically correct. ${ }^{163}$

In sum, late Zhou kings who positioned themselves as world pacifiers rather than as conquerors preferred not to emphasize the former kings' active military roles, adjusting the image of the past to their current political needs.

\section{Conclusions}

Bronze inscriptions show that the conquest of Shang became established as an important reference point in the collective memory of Ji-surnamed lineages. However, the earliest available inscriptions refer to the conquest within a factual, "communicative" framework, while the earliest evidence of the transmission of this memory within a "cultural" framework derives from generations that did not experience the conquest as adults. This does not necessarily suggest that there must have been a large gap between a historical event and the beginning of cultural memory production. Commemorative rituals could have been established much earlier than the first references to them appeared in inscriptions, which indeed reflect only a limited view of Western Zhou ritual communication. However, it is not self-evident that such rituals took place already shortly after the conquest or that they occurred

162. Matsui suggests that the Qiu pan may reflect a late Western Zhou tendency to combine the kings in pairs, e.g., Zhao-Mu, Gong-Yi, following the precedent set up for Kings Wen and Wu already during the middle Western Zhou period (Matsui Yoshinori, "Western Zhou History in the Collective Memory," 668). However, as there are no further examples of such pairings in other inscriptions, this hypothesis cannot be verified yet.

163. This correlates with the appeasing tone of some Shang shu chapters rendering how the Zhou king-conquerors dealt with subdued enemies. See Joachim Gentz, "One Heaven, One History, One People: Repositioning the Zhou in Royal Addresses to Subdued Enemies in the 'Duo shi' 多士 and 'Duo fang' 多方 Chapters of the Shangshu and in the 'Shang shi' 商誓 Chapter of the Yi Zhoushu," in Origins of Chinese Political Philosophy, ed. Martin Kern and Dirk Meyer, 146-92, at 174. 
regularly in the same way that yearly celebrations of foundational events take place in modern states. In the absence of contemporaneous written materials, this cannot be verified.

Inscriptions reveal present needs that involved references to the past. Zhou kings from different generations recalled the memory of the conquest and the first kings to legitimate their decisions relevant to the current political order, such as resettling Ji-surnamed relatives to control new places, changing their own places of residence, or, possibly, even launching "ritual reform." They did so while requesting support from the heads of prominent Ji-surnamed lineages and delegating major government affairs to them. Occasionally, they did so while engaging in service important old lineages who settled on the periphery of the metropolitan region, or while requesting loyalty from rulers of neighboring alien polities. They also did so while claiming territorial rights beyond the metropolitan region, sometimes on occasions of military celebrations. It is also evident that the Zhou kings addressed their speeches with references to the foundational past at the top elites, especially lineage heads. They did not routinely pronounce such speeches during appointment ceremonies for officials, who were recruited from lower-ranked members of Ji- and non-Ji-surnamed lineages. ${ }^{164}$ Thus, the cultural memory of the conquest and of the First Kings was tightly related to the present major political needs of the Zhou royal house, but it was not yet instrumentalized in the field of routine fostering of morality among the emerging bureaucracy.

Inscriptions shed light on some means by which the memory of the conquest and the first kings was transmitted in the metropolitan Zhou. These included, in the Assmann's terms both "cultural formation" (rites, formulaic language, visual media) and "institutional communication" (royal speeches during assemblies and individual receptions of important political partners). Commemorative rites and royal speeches represented the instruments of a targeted memory policy maintained by the royal house and directed primarily at the Ji-surnamed elite as well as politically relevant lineage outsiders. Commemorative inscriptions quoting royal speeches with references to the Zhou foundational past

164. For the lower layers of the Western Zhou metropolitan elite, the main point of reference was King Kang, whose temple complex, including auxiliary shrines for the following kings, became the main reception place for newly recruited officials; cf. Khayutina, "Reflections and Uses of the Past," 167. As Matsui Yoshinori has suggested, King Kang played a special role in the Western Zhou memory culture, but, since in the memory culture of the Eastern Zhou period, Kang and Cheng became blended together as a pair during whose reigns everything was fine and nothing bad happened. See Matsui Yoshinori, "Kioku sa reru Seishû shi"; Matsui Yoshinori, "Western Zhou History in the Collective Memory," 679. 
also represented important media of transmission. The kings probably encouraged the casting of such inscriptions in royal foundries, which could also be a part of the royal memory policy. Some bronzes with inscriptions rendering royal speeches with commemorations of the conquest, like in the case of the Guai bo gui, were probably given to Zhou allies as gifts. ${ }^{165}$ Whether the royal court also disseminated wood or bamboo copies of commemorative texts comparable to the hymns and odes of the Shi jing or the early chapters of the Shang shu lies beyond the scope covered by inscriptions.

Concerning the "specialization of the bearers of memory,"166 inscriptions contain no mention of any trained specialists responsible for the transmission of the memory of the beginning of the dynasty. The particularly detailed account of the Zhou royal house in the inscription of Shi Qiang has been initially understood as related to his position of shi ("secretary" or, as many translators suggest, "scribe"). However, his son or grandson Xing, who quoted a record about his ancestors' relationships with the dynasty's founders, was a member of the royal retinue but was not a shi. The more recent find of the Qiu pan, whose commissioner was a military man and yulin 虞林 ("administrator of forests"), even more clearly shows that the production of private records about the past was unrelated to the commissioners' administrative functions. Such inscriptions were produced to demonstrate a noble pedigree and rights and were used in the elite lineages-not at court. Apart from the commissioners' ancestors, living family, and descendants, this display was probably also intended for the public, including distinguished guests from other lineages in attendance at weddings, cappings, funerals, and other feasts. ${ }^{167}$

In most cases reflected in inscriptions other than pedigree records, the kings transmitted the memory about the conquest and the first kings themselves. Thus, it may be suggested that keeping and invoking the foundational memory of the dynasty was one of the royal functions.

Metropolitan lineages who participated in the transmission of memory through the casting and copying of bronze inscriptions also acted as memory-keeping agents. ${ }^{168}$ Members of the lineages who

165. Cf. Li Feng, "Literacy Crossing Cultural Borders," 221.

166. Cf. Jan Assmann, "Collective Memory and Cultural Identity," 131.

167. Cf. Maria Khayutina, "Welcoming Guests-Constructing Corporate Privacy: An Attempt at a Socio-Anthropological Interpretation of Ancestral Rituals Evolution in Ancient China (ca. XI-V c. BC)," Berliner China-Hefte 24 (2003), 35-50; Falkenhausen, "The Inscribed Bronzes from Yangjiacun," 74-76.

168. The casting of inscribed bronzes certainly involved many specialized craftsmen. 
followed King Ping to the east, such as Nangong, Shan, or Mao, certainly continued cultivating the memory of the conquest and the first kings as the basis of their common identity. ${ }^{169}$ Together with the royal house, they plausibly stood behind the production of texts, venerating the conquest of Shang, the first Zhou kings, and legitimating the relocation to Luoyang as a place best suitable to rule the world, rather than an asylum for refugees who left their homeland unwillingly. Possibly, migrant Ji elites became specialists who kept, commented on, and disseminated such texts during the early Spring and Autumn period. Hence, it may be not accidental that some speeches in the Shang shu were ascribed to founders of metropolitan Ji-lineages, while founders of other related lineages were mentioned in the texts. Other texts in the same compendium directly address Ji-surnamed ruling lineages of external colonies founded at the beginning of the dynasty, including Wei, Jin, Cai, and $\mathrm{Lu} .{ }^{170}$ The prominence of Ji-lineages in the Shang shu may suggest that during the early Spring and Autumn period, commemorative texts were produced in order to foster political solidarity constructed along agnatic ties, as this was also typical for the Western Zhou period. As far as it is possible to judge based on the Zuo zhuan that often refers to "all the Ji" (zhu Ji 諸姬) as a political interest group, this was a successful strategy.

Bronze inscriptions convey precious little about the substance of the early history of the dynasty. ${ }^{171}$ The memory of the conquest and the first kings was reduced to short formulaic statements. The paucity of content and form cannot be simply explained by technical limitations, such as difficulties with producing casting molds for long texts, or by the nature of bronzes as media of religious communication. Examples of lengthy and detailed inscriptions about recent events experienced by commissioners are quite numerous and can prove the opposite. Thus, at least from the middle Western Zhou period, factual memory could be sufficiently rendered specifically and comprehensively. It is likely that the transmission of foundational memories followed a different logic of ritual communication in which "meaning is constituted 'not in terms of information but in terms of pattern recognition and configurational

169. One may speculate that the mysterious Mr. Mao 毛 who transmitted the Mao tradition of the Shijing was authorized to comment on this anthology because of his membership in the ancient Mao lineage.

170. "Kang gao" in the Shang shu, as well as the lost "Tang gao" 唐誥 and "Cai hou zhi ming" 蔡侯之命.

171. I paraphrase here Knoblock's observation regarding transmitted narratives of the early Zhou past. See John Knoblock, Xunzi: A Translation and Study of the Complete Works (Stanford: Stanford University Press, 1990), 4. 
awareness' achieved through restraint and the orchestrated use of 'redundancy and recursive loops."'172 It was not the relocation of the Zhou royal house to the east in 770 в.C.E. that caused the "loss of the Zhou collective memory," as suggested by Wang Ming-ke, because this memory was highly selective and had been fragmentary ever since.

Even if the references to the memory of the conquest and the First Kings were very short, the comparison of inscriptions from different reigns demonstrates that its interpretation was constantly negotiated. If earlier inscriptions (Yi hou Ze/Yu gui, and, possibly, Xiao Yu ding) suggest that the conquest was recognized as a military achievement of Kings $\mathrm{Wu}$ and Cheng, later inscriptions treat it as an appeasing act of Kings Wen and Wu. King Cheng was mentioned only very seldom, and, if so, was assigned the role as a general stabilizer. Yet an inscription from the early eighth century в.C.E. suggests that he was restored as one who "accomplished the mandate" received by Kings Wen and Wu. This may reflect a shift in King Cheng's perception.

If inscriptions commissioned by the conquest's eyewitnesses and some members of early post-conquest generations, such as the Yi hou $\mathrm{Ze} / \mathrm{Yu}$ gui and the He zun, refer to the conquest of Shang as a specific place, other inscriptions use the name of the Yin dynasty, while inscriptions from the late tenth to early eighth centuries B.C.E. claim that Kings Wen and Wu broadly possessed the Four Quarters. Yet in connection to military conflicts with neighboring peoples, more specific claims about the jiang $t u$-land within the borders or territory-were raised. These fluctuations in the cultural memory of the conquest are explainable against the background of the changing political situation.

The representations of the beginning of the dynasty in Western Zhou inscriptions differ from those in the Shang shu, where Zhou gong, nearly invisible beyond the "communicative horizon" in inscriptions, comes to the foreground as the main architect of the Zhou political project. ${ }^{173}$ More conspicuously, the concepts of tianxia 天下 (Under heaven) and xia 夏 ("the Great ones," or the Xia dynasty) that have key importance in the discourse of the Shang shu do not appear in inscriptions from this period. ${ }^{174}$ Equally, the Shang shu' emphasis on the foundation

172. Stanley Jeyaraja Tambiah, A Performative Approach to Ritual, Proceedings of the British Academy 65 (Oxford: Oxford University Press, 1979), 134.

173. Kryukov, Tekst $i$ Ritual, 296-376.

174. The concept tianxia occurs only on the unprovenanced Bin/Sui gong $x u$ 圈/

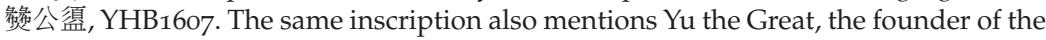
Xia dynasty. Many scholars recognize this inscription as unique evidence of the historicity of Xia, or of the early date of the "Yu gong" 禹貢 chapter of the Shang shu. However, this vessel, acquired by the Poli Museum from an antiquities dealer, has been dated around 900 B.C.E. solely because it is decorated with a bird pattern widespread 
of the eastern royal residence that was regularly used but did not become capital before the eighth century в.C.E. is not self-explainable in the context of the Western Zhou "present situation." Therefore, the mid-to late Western Zhou date for the earliest parts of the Shang shu, as suggested by Martin Kern, possibly, needs a further revision towards an even later period. I rather agree with Vassili Kryukov, who suggested that the earliest parts of the Shang shu derive from the eighth or seventh century B.C.E. ${ }^{175}$ The present situation that required a massive effort of "asserting identity" was plausibly the restoration of the dynasty during the reign of King Ping. ${ }^{176}$

during the reign of king Gong. There are, however, many examples when ancient patterns and shapes were reproduced as a part of an antiquarian program. I have argued elsewhere that this inscription dates from the Spring and Autumn period. See Maria Khayutina, "'Bin (Sui)-gong $x u^{\prime}$ i konstruirovanie proshlogo v kitaiskoy traditsii [Bin (Sui)-gong $x u$ and the construction of the past in Chinese tradition]," in Materialy kitaevedcheskoy konferentsii ISAA pri MGU (Mai 2004 g.) [Materials of the Sinological Conference of the Institute of Asian and African Countries of the M.V. Lomonosov Moscow State University (May 2004)], ed. K. M. Tertitskiy and M. Yu Ul'yanov (Moscow: ISAA, 2005), 59-70.

175. Kryukov, Tekst $i$ Ritual, 322; for a summary, see Vogelsang, "Inscriptions and Proclamations," 198-200.

176. As the newly excavated manuscript Xi nian 繫年 reveals, this was a lengthier process than originally thought. See Chen Minzhen and Yuri Pines, "Where is King Ping? The History and Historiography of the Zhou Dynasty's Eastward Relocation," Asia Major 31 (2018), 1-27. 


\section{APPENDIX}

During the early stages of bronze inscriptions studies, scholars expected that inscriptions would normally refer to the events known from transmitted texts, particularly the Shang shu. ${ }^{177}$ These texts focus on Kings Wen and $\mathrm{Wu}$, as well as the conquest of Shang during the reigns of King Wu and King Cheng, but they provide little information about later rulers. They compress the historical time, thereby associating the political and cultural achievements of numerous periods with the single, foundational decade. For instance, they ascribe the creation of the whole system of Zhou rituals to the single figure of the Zhou gong, as well as suggesting that the conquest of western Shandong and the foundation of the Zhou colonies happened very quickly. Scholars who relied on transmitted texts thus understandably first dated all inscriptions referring to the warfare in the "Eastern Region" or mentioning investitures of regional rulers to the reigns of King Cheng and King Kang. ${ }^{17^{8}}$ Since the 1970s, new discoveries and investigations have repeatedly revealed the need to adjust the chronologies established during the mid-twentieth century. Although new chronologies proposed by several scholars after the mid-1980s hold the received tradition in high regard, they also take into account contradictions between various transmitted texts and consider interrelations between different inscriptions as well as between inscriptions and archaeological complexes. ${ }^{179}$

177. For a summary of Guo Moruo's and Chen Mengiia's methodology of dating inscriptions, see Shaughnessy, Sources of Western Zhou History, 16-19. For the summary of the Japanese scholarship, especially the work of Shirakawa Shizuka, see ibid., 27-30.

178. Guo Moruo 郭沫若, Liang Zhou jinwen ci daxi kaoshi 兩周金文辭大系考釋 (Tōkyō: Bunkyūdō, 1935); Guo Moruo 郭沫若, Liang Zhou jinwen ci daxi tulu 周金文辞 大系图录 (Tōkyō: Bunkyūdō, 1935); Guo Moruo 郭沫若, Liang Zhou jinwen ci daxi tulu kaoshi 兩周金文辭大系圖錄考釋 (Beijing: Kexue, 1957); Rong Geng, Shang Zhou yiqi tongkao; Chen Mengjia, “Xi Zhou tongqi duandai (yi)," 137-75; Chen Mengjia 陳夢家, “Xi Zhou tongqi duandai (er)" 西周銅器斷代(二), Kaogu xuebao 1955.2, 69-142; Chen Mengjia, "Xi Zhou tongqi duandai (san)," 65-114; Shirakawa Shizuka 白川靜 Kinbun tsūshaku 金文通釈, Hakutsuru bijutsukanshi 白鶴美術館誌, 56 vols. (Kōbe: Hakutsuru bijutsukan, 1966-1983).

179. Ma Chengyuan 马承源, Shang Zhou qingtongqi mingwen xuan 商周青銅器銘文 選 (Beijing: Wenwu, 1983); Tang Lan, Xi Zhou qing tong qi ming wen fen dai shi zheng; Wang Shimin 王世民, Chen Gongrou 陳公柔, and Zhang Changshou 張長壽, Xi Zhou qingtongqi fenqi duandai yanjiu 西周青銅器分期斷代研究 (Beijing: Wenwu, 1999); Peng Yushang 彭裕商, Xi Zhou qingtongqi niandai zonghe yanjiu 西周青銅器年代綜合研究 (Chengdu: Ba Shu, 2003). For a brief critical assessment of the main dating methods, see Cao Bin 曹斌, “Xi Zhou tongqi duandai fangfa tanwei” 西周銅器斷代方法探微, Zhongyuan wenwu 2014.4, 59-65. 
In order to inform oneself on just how dramatically the chronology of bronze inscriptions has changed since 1935, when Guo Moruo 郭沫 若 published the first systematic reconstruction, the reader may consult the table of 169 inscribed bronzes compiled by Zhang Maorong 張禁 鎔. ${ }^{180}$ As one of the currently leading specialists in Zhou bronzes, Zhang has tabulated the dates of selected bronzes proposed by ten influential scholars, including himself. This table, an excerpt of which is represented in Table A1, below, shows that nearly all inscriptions excavated before 1976 and estimated by mid-twentieth century's scholars as dating from the reigns of Kings Cheng and Kang have been subsequently re-dated to later reigns. ${ }^{181}$ For instance, while Guo Moruo dated twenty-six of these inscriptions to the reign of King Cheng, not a single one is currently dated as being that early. Shirakawa Shizuka, who accepted Guo's dating and expanded the scope of his investigation to some more recently published inscriptions, dated to the reign of King Cheng thirty-six inscriptions from Zhang Maorong's selection. Of these, later scholarship corroborated only the date of the Bao you 保备 (JC5415). Seven other inscriptions have been shifted to the reign of either King Kang or King Zhao. The remaining twenty-eight bronzes have been re-dated to the reign of King Zhao and even of King Mu (cf. Table A1). ${ }^{182} \mathrm{As}$ a result, the number of inscriptions dated about the beginning of the dynasty dwindled, and the majority shifted towards later reigns.

This important, systematic shift went unnoticed by many scholars who look at bronze inscriptions only sporadically, to trace the earliest occurrence of a certain term, for example. These authors then check Shirakawa or Chen Mengjia-perhaps simply since many libraries do not collect newer, specialized studies of the Zhou bronzes-and stick to the far-too-early dates. I do not provide here any references since it my aim is not to point out that someone's dating is inaccurate, but to increase awareness of the relevance of more recent scholarship. Chronological sequences proposed by different scholars all have a systematic character. Therefore, re-dating a single inscription in the sequence often calls for the re-dating of a whole group of related texts. Scholars who only occasionally turn to inscriptions while searching for early roots of certain phenomena without following updates from this field of research should be aware that it is not possible to accept a

180. Guo Moruo, Liang Zhou jinwen ci daxi kaoshi; Zhang Maorong, "Shilun Xi-Zhou qingtongqi yanbian de feijunhengxing wenti," 344-351.

181. 1976 was the year of the discovery of the Zhuangbai hoard, which became one of the keys to adjusting the earlier chronologies.

182. Zhang Maorong, "Shilun Xi Zhou qingtongqi yanbian de feijunhengxing wenti," 344 . 
TABLE A1 A comparison between the nine chronologies of bronze inscriptions with evaluation by the author of this article. Adopted from Zhang Maorong, "Shilun Xi Zhou qingtongqi yanbian de feijunhengxing wenti," 344-46; complemented by the data from Ma Chengyuan, Shang Zhou qingtongqi mingwen xuan. Abbreviations: EWZ = early Western Zhou; LEWZ = late early Western Zhou.

\begin{tabular}{|c|c|c|c|c|c|c|c|c|c|c|c|c|}
\hline \multicolumn{2}{|l|}{ Title } & \multirow[b]{2}{*}{ Jicheng Nr. } & \multirow{2}{*}{$\begin{array}{l}\text { Guo } \\
\text { Moruo } \\
(1932 / \\
57)\end{array}$} & \multirow[b]{2}{*}{$\begin{array}{l}\text { Chen } \\
\text { Mengjia } \\
\left(1955^{-}\right. \\
56)\end{array}$} & \multirow{2}{*}{$\begin{array}{l}\text { Shirakawa } \\
\text { Shizuka } \\
(1966- \\
\text { 1983) }\end{array}$} & \multirow{2}{*}{$\begin{array}{l}\text { Tang } \\
\text { Lan } \\
(1986)\end{array}$} & \multirow[b]{2}{*}{$\begin{array}{l}\text { Ma } \\
\text { Chengyuan } \\
(1986)\end{array}$} & \multirow[b]{2}{*}{$\begin{array}{l}\text { Li Xueqin } \\
(1990)\end{array}$} & \multirow{2}{*}{$\begin{array}{l}\text { Wang } \\
\text { Shimin } \\
\text { et al. } \\
\text { (1999) }\end{array}$} & \multirow[b]{2}{*}{$\begin{array}{l}\text { Peng } \\
\text { Yushang } \\
(2003)\end{array}$} & \multirow[b]{2}{*}{$\begin{array}{l}\text { Zhang } \\
\text { Maorong } \\
(2008)\end{array}$} & \multirow{2}{*}{$\begin{array}{l}\text { The } \\
\text { author } \\
\text { of the } \\
\text { present } \\
\text { article }\end{array}$} \\
\hline Transcription & Chinese & & & & & & & & & & & \\
\hline Bao you, zun & 保卢, 尊 & 5415,6003 & & $\mathrm{Wu}$ & Cheng & Cheng & Cheng & & Cheng & Cheng & Cheng & EWZ \\
\hline $\begin{array}{l}\text { Zuoce Ling } \\
\text { fangzun, } \\
\text { fangyigui }\end{array}$ & $\begin{array}{c}\text { 作冊令方 } \\
\text { 尊, 方 } \\
\text { 暽, 篮 }\end{array}$ & $\begin{array}{c}6016,9901 \\
4301\end{array}$ & Cheng & Cheng & Cheng & Zhao & Zhao & Zhao & & Zhao & Zhao & Zhao \\
\hline $\begin{array}{l}\text { Shi Shang } \\
\text { you, he, zun }\end{array}$ & $\begin{array}{l}\text { 士上备, } \\
\text { 盉, 尊 }\end{array}$ & $\begin{array}{c}5421,9454 \\
5999\end{array}$ & Cheng & Cheng & Cheng & Zhao & Zhao & & ca. Zhao & Zhao & LEWZ & Zhao \\
\hline $\begin{array}{l}\text { Zhong fang- } \\
\quad \text { ding }\end{array}$ & $\begin{array}{c}\text { 串方鼎, } \\
\text { 甗, 觶 }\end{array}$ & $\begin{array}{c}1957,949 \\
6514\end{array}$ & Cheng & Kang & Cheng & Zhao & Zhao & Zhao & & Zhao & $\mathrm{Mu}$ & Zhao \\
\hline Qian zun, you & 遣尊，占 & 5992,5402 & Cheng & Cheng & Cheng & Zhao & Zhao & Zhao & ca. Zhao & Zhao & $\mathrm{Mu}$ & Zhao \\
\hline Ban $g u i$ & 班篮 & 4341 & Cheng & $\begin{array}{r}\text { Cheng- } \\
\text { Kang }\end{array}$ & Zhao-Mu & $\mathrm{Mu}$ & $\mathrm{Mu}$ & $\mathrm{Mu}$ & LEWZ & & $\mathrm{Mu}$ & $\mathrm{Mu}$ \\
\hline $\begin{array}{c}\text { Jing (Xing) } \\
\text { hou gui }\end{array}$ & $\begin{array}{c}\text { 井 (邢) } \\
\text { 侯筬 }\end{array}$ & 4241 & Kang & $\begin{array}{r}\text { Cheng- } \\
\text { Kang }\end{array}$ & $\begin{array}{r}\text { Cheng- } \\
\text { Kang }\end{array}$ & Kang & Kang & $\begin{array}{r}\text { Cheng- } \\
\text { Kang }\end{array}$ & EWZ & Zhao & $\begin{array}{l}\text { Kang- } \\
\text { Zhao }\end{array}$ & $\mathrm{Mu}$ \\
\hline $\begin{array}{c}\text { Geng Ying } \\
\text { you, ding }\end{array}$ & 庚贏备，鼎 & 5426,2748 & Kang & Kang & Zhao & $\mathrm{Mu}$ & Kang & & LEWZ & $\mathrm{Mu}$ & $\mathrm{Mu}$ & $\mathrm{Mu}$ \\
\hline $\begin{array}{l}\text { Zuoce Zhe } \\
\text { zun, fangyi }\end{array}$ & $\begin{array}{c}\text { 作冊折尊, } \\
\text { 方彝 }\end{array}$ & 6002,9901 & & & Cheng & & Zhao & Zhao & Zhao & Zhao & $\mathrm{Mu}$ & Zhao \\
\hline $\begin{array}{c}\text { Shang/Geng } \\
\text { Ji zun, you }\end{array}$ & $\begin{array}{c}\text { 商（庚姬） } \\
\text { 尊, 占 }\end{array}$ & 5997,5404 & & & Cheng & & EWZ & Zhao & EWZ & $\begin{array}{l}\text { Kang- } \\
\text { Zhao }\end{array}$ & $\mathrm{Mu}$ & $\mathrm{Mu}$ \\
\hline
\end{tabular}


date proposed by Tang Lan or Li Xueqin for one vessel and to maintain Shirakawa Shizuka's or Chen Mengiia's date for a related vessel.

The calibrated chronology of bronze inscriptions suggests that some processes, including the colonization of the east, lasted for much longer than previously assumed. It also indicates that the development of the Zhou written culture equally underwent a lengthier germination period. It shows that lengthy narrative inscriptions became widespread during the reign of King Zhao, who was remembered in the tradition mostly for being killed in a war, and King $\mathrm{Mu}$, who was transformed into a semifictional figure in the Mu Tianzi zhuan 穆天子傳 (Biography of the Son of Heaven $\mathrm{Mu}$ ). The rich epigraphic heritage, which has been re-attributed to these reigns, calls on scholars to reconsider the significance of the early and middle tenth century в.C.E. as an important formative stage in the history of the early Chinese written, material, and political culture. ${ }^{183}$

Notably, Zhang Maorong's list omits early bronzes enjoying the status of "National Treasures" in present-day China, including the He zun and the $\mathrm{Da} Y \mathrm{Yu}$ ding, discussed in this article. ${ }^{184}$ I agree that, apart from political considerations about the sensitivity of this debate in the context of present-day nationalist memory culture, it is reasonable to first adjust the dates of other bronzes before turning to such prominent exemplars that have to be accessed individually. Critically revising the dates of the He zun and the $D a$ Yu ding is important for tracing when and under which historical circumstances the first building blocks of early Chinese cultural memory were laid down. Before addressing these two inscriptions, I will briefly discuss the Yi hou Ze/Yu gui.

\section{The Date Of the Yi hou Ze gui}

The Yi Hou Ze Gui is a four-handled bowl on a round foot with a height of $15.7 \mathrm{~cm}$ and a diameter of $22.5 \mathrm{~cm}$. Its belly is decorated with highrelief bosses with a whirl pattern. Spaces between the bosses and the foot are filled with zoomorphic patterns. The handles are decorated with animal heads. Below each handle, hooked flanges are attached to the foot, which is decorated with a dragon pattern.

Four-handled gui on a round foot were widespread during the eleventh to the mid-tenth century B.C.E. ${ }^{185}$ One similar vessel, the Zi gui

183. Cf. Kryukov, Tekst i Ritual.

184. For the "career" of the He zun as a celebrity in Chinese mass media, see Maria Khayutina, "The Story of the He Zun: From Political Intermediary to National Treasure," Orientations 50 (2019), 2-8.

185. Liang Yanmin 梁彦民, “Xi Zhou shiqi de si er qingtong gui yanjiu” 西周時期的 四耳青銅筫研究, Jiang Han kaogu 2009.2, 75-80. 

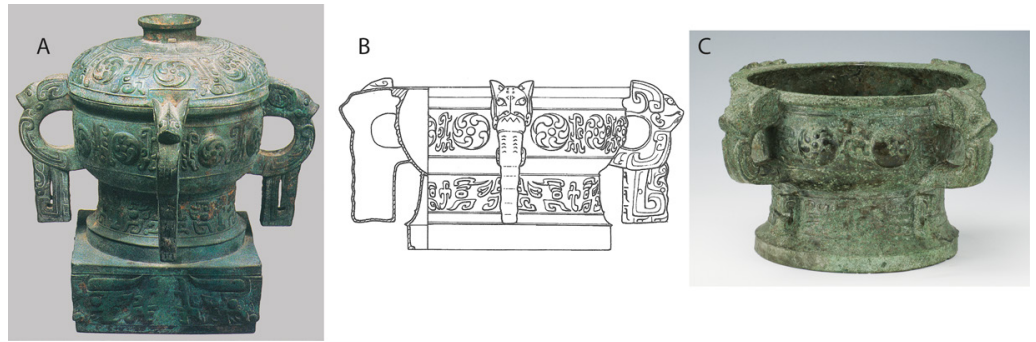

Figure 3 Bronze gui in comparison. A. Zhifangtou BZM1:6. B. Taiqinggong M1:84. C. Yi hou Ze gui. ${ }^{186}$

子籃, excavated from the tomb of Changzi Kou 長子口 in Taiqinggong 太清宮, Luyi 鹿邑, a county in south-eastern Henan province, has been tentatively dated to the edge of the Shang and Zhou periods (YHBo551, 1 character, Figure 3.B). The shape and decorations of the Yi hou Ze gui are similar to the Yu bo gui 魥伯籃 from the tomb of Yu bo in Zhifangtou 紙坊頭, near Baoji, which, however, further features a square base and a lid (JC3528, 6 characters, Figure 3.A). The latter tomb also yielded two li tripods commissioned by $\mathrm{Ze} / \mathrm{Yu}$ bo 吴伯, corroborating interactions between $\mathrm{Yu}$ 魥 and Ze/Yu 矢 polities, both located near Baoji. This supports that the similarity between the tureen from Zhifangtou and the Yi hou Ze gui is not accidental. They were probably made after the same model and may derive from the same workshop. Still, these vessels also manifest some differences. Unlike two other vessels, the Yi hou Ze gui lacks pendants on the handles (cf. Figure 3.C). Hooked flanges attached to its ring foot are untypical for tureens, but often seen on the feet of "flamboyant" vessels for liquors, such as the He zun that will be discussed in the next section.

Since the inscription mentions the posthumous title of King Cheng, the vessel definitively dates after this reign. At the same time, it does not include any other clues regarding its date. Although it is generally regarded as dating from the reign of King Kang, the posthumous name of King Cheng only provides a terminus post quem. Therefore, a later date, e.g. the reign of King Zhao, cannot be ruled out. A yet later date is less plausible since the four-handled gui from the reign of King $\mathrm{Mu}$ feature a much shorter ring foot.

186. A: Li Xixing 李西興, ed. Shaanxi qingtongqi 陝西青銅器, (Xi'an: Shaanxi renmin meishu, 1994), Figure 63; B: Henan wenwu kaogu yanjiusuo, Zhoukou diqu wenhuaju, “Henan Luyi xian Taiqinggong Xi Zhou mu de fajue” 河南鹿邑縣太清宮西 周墓的發掘, Kaogu 2000.9, 9-23, Figure 6; C: Collection of the National Museum of China, courtesy of Dr. Tian Shuai. 
As a record of a local ruler's investiture, the Yi hou Ze gui can be compared to the Ke he 克盉 and the Ke lei 克罍 (YHB1367,1368), excavated from the cemetery of Yan 燕 in Liulihe 琉璃河 and bearing an identical inscription of 43 characters. ${ }^{187}$ Ke was the son of taibao 太保 (“Grand Protector") Shao gong Shi 召公顛. According to the Shi ji, King Wu established Shao gong Shi as the first ruler of Yan, while the Shang shu mentions him as one of the aids of King Kang. The excavated Ke's inscriptions reveal that he was commanded to govern Yan as a reward to his father. Most scholars assume that this happened during the reign of King Cheng, although King Kang's reign cannot be ruled out. ${ }^{188}$ The inscription renders the royal command to Ke to be a hou 侯 in Yan, a list of proper names (possibly referring to subordinated lineages), and statements about the arrival to the destination and the vessel's making. The content and the structure resemble those of the Yi hou Ze gui, but the latter is not only longer ( 126 characters), but also more complex. Its meticulousness in listing gifts, people, and settlements transferred under the control of Yi hou reflects the trend towards using inscriptions as certificates of rights and properties, which became widespread during the reign of King $\mathrm{Mu}$ and even more so during the reign of King Gong. ${ }^{189}$ The Yi hou Ze gui includes a relatively long (23 characters) narrative "event notation," informing about the ritual setting of the "investiture ceremony." Comparable accounts of "appointment ceremonies" also became common during the reign of King Mu. ${ }^{190}$ Several inscriptions from the reign of King Zhao already display these features. ${ }^{191}$ In contrast, inscriptions unambiguously datable to the reign of King Kang

187. Cf. Lau, Quellenstudien zur Landvergabe und Bodenübertragung, 82-90; Li Feng, "Ancient Reproductions and Calligraphic Variations," 4-15; Li Feng, Landscape and Power in Early China, 335.

188. Cf. Li Zhongzao 李仲操, “Yan hou Ke lei, he mingwen jian shi” 燕侯克罍盉銘 文簡釋, Kaogu yu wenwu 1997.1, 70-72; Du Naisong 杜茜松, “Ke lei, Ke he mingwen xin shi" 克罡、克盉銘文新釋, Beijing Gugong bowuyuan yuankan 1998.1, 61-64; Ren Wei 任 偉, “Xi Zhou Yan guo tongqi yu Shao gong feng Yan wenti” 西周燕國銅器與召公封燕 問題, Kaogu yu wenwu 2008.2, 58-63.

189. Cf. various examples in Lau, Quellenstudien zur Landvergabe und Bodenübertragung, 169-383.

190. See, for instance, Hu gui gai 虎篮蓋 (YHBo633, 161 characters), from the reign of King Mu, translated in Constance A. Cook, "Hu gui gai," in A Source Book of Ancient Chinese Bronze Inscriptions, 74-76.

191. Cf. e.g., Mai zun 麥尊 (JC6015, 164 characters), translated in Shaughnessy, "Historical Geography and the Extent of the Earliest Chinese Kingdoms," 19-20; Lau, Quellenstudien zur Landvergabe und Bodenübertragung, 105-19. 
are similarly as short as these from the reign of King Cheng. ${ }^{192}$ Thus, if the Yi hou Ze gui dates from the reign of King Kang, it was made towards its end rather than at the beginning, while it is also conceivable that it may date from the reign of King Zhao.

\section{The Date of the He zun and the Issue of the He gui 歌筬.}

The He zun was found in 1963 by a farmer in Jiacun 賈村 in the vicinity of Baoji not far from the confluence of Qian 汧 and Wei 渭 Rivers, about $70 \mathrm{~km}$ to the east of the Zhou Plain. The inscription was noticed more than a decade later when the vessel was cleaned from patina. Several leading scholars of this time analyzed this inscription and dated it to the reign of King Cheng. They assumed that zhai 宅 ("residence/to reside") was used in the sense "to construct a residence," and that the inscription therefore refers to the foundation of the eastern royal residence in Chengzhou, which, according to the Shang shu, took place under King Cheng. ${ }^{193} \mathrm{~A}$ few years later, Li Xueqin expressed an objection, pointing out that zhai only means "to reside," and, therefore, the inscription could simply mention the decision of a Zhou king-not necessarily Cheng-to dwell in Chengzhou. Moreover, Li Xueqin pointed out that the calendrical reference in the He zun is incompatible with the calendar of King Cheng rendered in the Shang shu. As an alternative, he suggested that the He zun may date from the reign of King Kang. ${ }^{194}$ However, Li Xueqin did not insist on his opinion, and the first proposed date became largely accepted. ${ }^{195}$ Recently, however, Wang Entian 王恩田 has argued in favor of King Kang's date, revealing that the mainstream view on the He zun is not shared unanimously. ${ }^{196}$

192. Cf. Zuoce Da ding 作冊大鼎 (JC2758-61; 41 characters); Xian hou ding 獻侯鼎， JC2626 (20 characters)

193. Tang Lan, "He zun mingwen jieshi"; Ma Chengyuan, "He zun mingwen chu shi"; Zhang Zhenglang, "He zun mingwen jieshi buyi," 66.

194. Li Xueqin, "He zun xin shi," 45.

195. Shaughnessy, Sources of Western Zhou History, 110; Puett, The Ambivalence of Creation, 33-34; Zhu Fenghan 朱鳳瀚, “'Shao gao,' 'Luo gao,' He zun yu Chengzhou” 《召誥》、《洛誥》、何尊與成周, Lishi yanjiu 2006.1, 3-14; Edward L. Shaughnessy, "History and Inscriptions, China," in The Oxford History of Historical Writing: Volume 1. Beginnings to $A D$ 600, ed. Andrew Feldherr and Grant Hardy (Oxford: Oxford University Press, 2011), 371-93, 380; Songlin Zhang and Davia Sevillano-López, "El primer registro del nombre de China, la inscripción de He Zun (何尊)," Boletín del Archivo Epigráfico 2019.4, 128-35.

196. Wang Entian, "He you, He hu zhen wei bian," 59. 
There are several reasons to reconsider the date of the He zun. Its lengthy inscription is very unusual not only for early Zhou reigns in general, but also for the area where it was excavated. Elite families who settled near Baoji, similar to the family of $\mathrm{He}$, commissioned splendid bronzes, some of which may date to the earliest Zhou reigns. ${ }^{197}$ Most of them bear only short inscriptions, however, usually including lineage emblems and dedications to fathers and grandfathers. Additionally, these inscriptions do not mention the king. ${ }^{198}$ The He zun clearly deviates from this trend. Nevertheless, most inscription specialists and historians would defend the early date of the He zun, which is already firmly established in the present-day historical narrative of the Western Zhou. Their main argument would be the early appearance of this object.

The He zun is representative of the "flamboyant style" characteristic of the first century of the Zhou dynasty. ${ }^{199}$ While round in its cross section, it is vertically divided into four compartments by prominent hooked flanges. Horizontally, it is subdivided into three registers: the neck, the belly, and the foot. Cicada and snake patterns fill the upper register. Masks of hybrid beasts with the appearance of horned felines populate the middle and lower registers.

Most late Shang and early Western Zhou zun were ornamented only on the belly, while the neck and foot were left undecorated. Such zun have no flanges. Late Shang zun with their entire surfaces decorated and featuring flanges are rare. One such zun with cicada patterns, zoomorphic masks, and flanges, decorated with a low relief pattern imitating perforated hooks, and bearing the "ya Yang fu Ding" 亞養父丁 inscription, has been excavated from the hoard $\mathrm{H}_{2} 498$ in Liujiazhuang 劉家莊, Anyang, dating to the last phase of Yinxu. ${ }^{200}$ A flanged zun with cicada patterns, horned feline masks, and the "Shi" 史 lineage emblem was found in the early Western Zhou tomb Mi1 in the cemetery of the Shi lineage on Qianzhangda 前掌達 in Shandong (Figure 4B). In both cases, the flanges are less prominent than those on the He zun, and

197. Cf. Rawson, "Statesmen or Barbarians," 79-87.

198. Cf. Wang Guangyong, "Shaanxi Baoji Daijiawan chutu Shang Zhou qingtongqi diaocha baogao"; Shigushan kaogudui, "Shaanxi Baoji Shigushan Xi Zhou mu" 陝西 省寶雞市石鼓山西周墓, Kaogu yu wenwu 2013.1, 3-24; Shigushan kaogudui, “Shaanxi Baoji Shigushan Xi Zhou muzang fajue jianbao" 陝西寶雞石鼓山西周墓葬發掘簡報, Wenwu 2013.2, 4-54.

199. Cf. Jessica Rawson, Western Zhou Ritual Bronzes from the Arthur M. Sackler Collections (New York: Arthur M. Sackler Foundation, 1990), 35.

200. He Yuling 何毓靈, “Yinxu Liujiazhuang beidi qingtong jiaocangkeng xingzhu tanxi” 殷墟劉家莊北地青銅窝藏坑性質探析, Nanfang wenwu 2014.1, 96-100, at 97. 
A
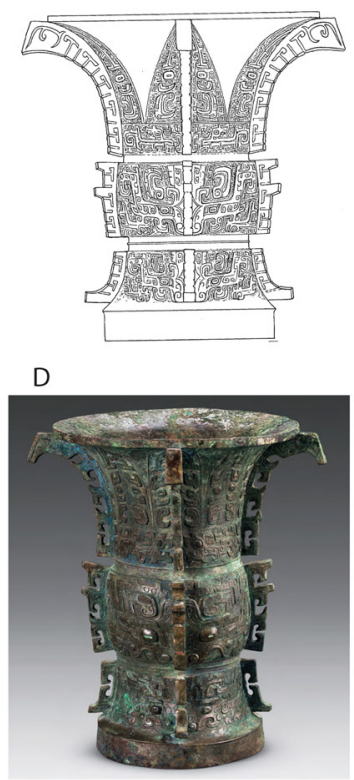

G

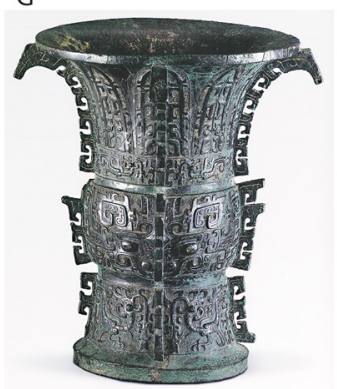

B

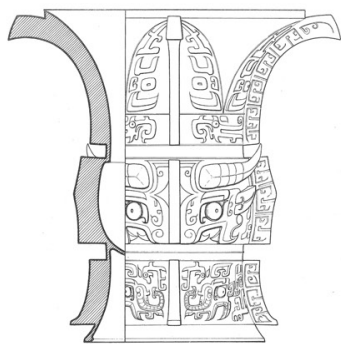

E

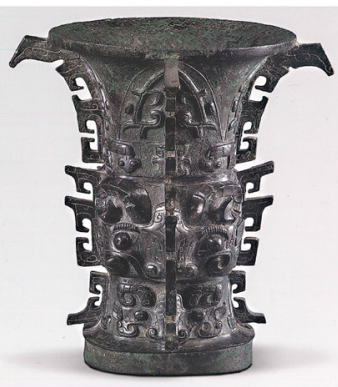

$\mathrm{H}$

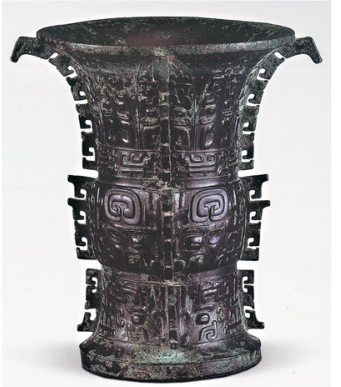

C

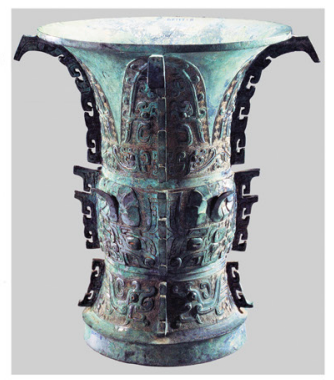

$\mathrm{F}$

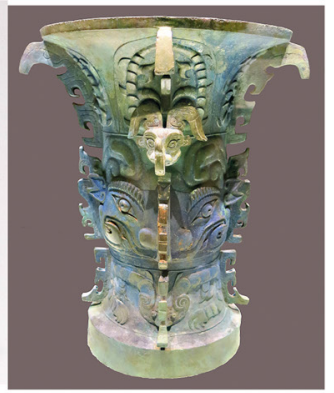

I

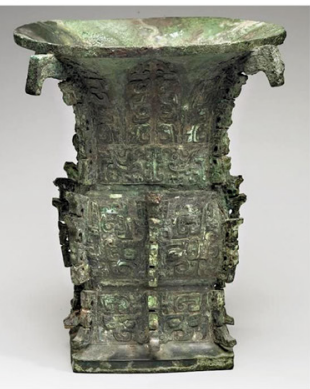

Figure 4 Bronze zun in comparison. A. Liujiazhuang H2498:1. B. Qianzhangda Mi1:76. C. Bo Ge zun. D. Yi zun. E. He zun. F. Yangzishan M4. G. Zuoce Zhe zun. H. Geng Ji zun. I. Ze Ling zun. ${ }^{201}$

the hooks on the flanges are only indicated in high relief, but do not represent a real openwork. ${ }^{201}$

201. A: Zhongguo shehui kexueyuan kaogu yanjiusuo Anyang gongzuo dui, “Henan Anyang shi Yinxu Liujiazhuang beidi 2010-2011 nian fajue jianbao" 河南安陽市殷 墟劉家莊北地 2010-2011 年發掘簡報, Kaogu 2012.12, 26-42, Figure 6.1; B: Zhongguo shehui kexueyuan kaogu yanjiusuo, Tehgzhou Qianzhangda mudi 滕州前掌大墓地 (Beijing: Wenwu, 2005), 268, Figure 191; C, E, G, H: Baoji Museum of Bronze, courtesy of the Museum; D: Han Binghua 韓炳華, “Xin jian Yi zun yu Yi fangyi”新見義尊與義 
Jessica Rawson has suggested that Zhou craftsmen borrowed hooked flanges from the south. ${ }^{202}$ The find of an uninscribed zun with animal masks, cicada patterns, and hooked flanges in the tomb of $\mathrm{E}$ hou 哥侯, Yangzishan 羊子山 in northern Hubei province (Figure $4 \mathrm{~F}$ ) may support this hypothesis. However, considering its overall appearance, this vessel is difficult to date. ${ }^{203}$

During the recent large-scale crackdown on tomb-looting, the police of the Shanxi province confiscated a set of a zun and a square yi. Both vessels feature feline masks with flattened horns on the belly and clearly pronounced hooks on flanges (Figure $4 \mathrm{D}$ ). They bear an example of a typical, early post-conquest inscription, counting twenty characters:

In the thirteenth month, day ding-hai (24), King Wu gave Yi thirty bundles of cowries. [Yi] used them to make this sacrificial vessel to fu yi. Bing. ${ }^{204}$

唯十三月丁亥珷易義貝卅朋, 用作父乙寶尊義。丙。

According to investigations, these vessels derive from a tomb in Nanqin 南秦 in Hongdong 洪洞 county. ${ }^{205}$ This find supports that zun with hooked flanges were widespread during the reign of King Cheng. This, however, does not mean that they quickly went out of fashion.

The Bo Ge zun 伯各尊 (JC5855), excavated in tomb BZM7 at the cemetery of the Yu 魥 polity in Zhuyuangou 竹園溝, Baoji, features similar proportions as the zun from Qiangzhangda, and more pronounced openwork hooks on the flanges (Figure $4 \mathrm{C}$ ). It should be

方彞, Jiang Han kaogu 2019.4, 78-83, figure 1; F: Suizhou Museum, photograph by the author; I: The Collection of National Palace Museum.

202. Rawson, Western Zhou Ritual Bronzes from the Arthur M. Sackler Collections, vol. $1,48$.

203. Zhang Changping 張昌平, "Lun Suizhou Yangzishan xinchu E guo qingtongqi" 論隨州羊子山新出哥國青銅器, Wenwu 2011.11, 87-94.

204. Han Binghua, "Xin jian Yi zun yu Yi fangyi."

205. This tomb was probably associated with a cemetery where archaeologists, who came after the looters, were so far only able to find bronzes from the early Eastern Zhou period. However, an important Western Zhou cemetery was excavated during the 1980 os in Yongningbu 永凝堡, only about $1 \mathrm{~km}$ away from here. Some scholars suppose that this was the cemetery of the Ji 姞-surnamed-Yang polity (see Li Lin 李林, “Yongningbu Xi Zhou mudi yu gu Yang guo" 永凝堡西周墓地與古楊國, Wenwu jianding yu jianshang 2018.14, 66-69). The Yi zun and yi bear the lineage emblem Bing that is associated with a lineage that was active during the Late Shang period and whose cemetery was excavated ca. 8o km further to the north in Jingjie 旌介, Lingshi 靈 石 county. The find of these vessels raises many questions that cannot be discussed in this article. For the sake of this study it is relevant that Yi was a member of the old "Shang" elite. 
noted that several tombs in the cemeteries of the Yu polity have yielded objects with the Shi lineage emblem, suggesting direct interactions between these lineages. ${ }^{206}$ These interactions could be related to the Zhou conquest of Shandong, which, as already mentioned, was a lengthy process. The excavators date the tomb $\mathrm{BZM} 7$ to between the late reign of King Kang and the early reign of King Zhao. ${ }^{207}$ The Bo Ge zun most closely resembles the He zun, supporting the possibility that the latter vessel could be a local cast. Considering the date of the tomb, the Bo Ge zun may equally date to the first half of the tenth century в.C.E.

Vessels of the same type and with similar decorations were continuously produced up to the mid-tenth century в.C.E. Two vessels, excavated from the Zhuangbai hoard-the Zuoce Zhe zun 作冊折 尊 (JC6002) and the Geng Ji zun 庚姬尊 (also known as Shang zun 商 尊, JC5997), represent such examples (Figure $4 \mathrm{G}, 4 \mathrm{H}$ ). ${ }^{208}$ Based on the analysis of the ancestors' list in the Shi Qiang pan, deriving from the same hoard, most scholars agree that Zhe was active during the reign of King Zhao, while some even argue that he lived during the reign of King Mu. ${ }^{209}$ The Geng Ji zun is regarded as contemporaneous with the Zhe $z u n .{ }^{210}$ Another example of this decorative scheme is manifested in the Ze/Yu Ling zun 矢令尊 (JC6016, Figure A1I), excavated in Luoyang Mapo during the 1920s. Although early scholars, such as Guo Moruo and Shirakawa Shizuka believed that it derives from the reign of King Cheng, most scholars currently agree that it dates from the reign of King Zhao (cf. Table A1). ${ }^{211}$ An attentive look at the vessels from the reign of King Zhao reveals that they recombine various elements that appear on the vessels from the late Shang and early Zhou periods without adding

206. Khayutina, Kinship, Marriage and Politics, 238-40.

207. Lu Liancheng 盧連成 and Hu Zhisheng 胡智生, Baoji yu guo mu di 寶雞魚國墓 地 (Beijing: Wenwu, 1988), 102.

208. Zhang Changping also points out of this close similarity in a paper that became available to me during the final editing of this manuscript. See Zhang Changping 張昌 平, “Tan xin jian Yi zun, Yi fangyi de niandai ji zhuangshi fengge” 談新見義尊、義方彞 的年代及裝飾風格, Jiang Han kaogu 2019.4, 84-89.

209. Compare Zhang Maorong, "Shilun Xi Zhou qingtongqi yanbian de feijunhengxing wenti," 345 with Falkenhausen, The Chinese Society in the Age of Confucius (1000-250 BC), 56-61.

210. The Geng Ji/Shang you 庚姬/尚卢 from the same hoard features the lineage emblem Ju眮/擧, revealing that Geng Ji or Shang was not a patrilineal member of the Wei lineage. Depending on whether these vessels were commissioned by a woman, Geng Ji Shang, or a man, Shang, it could be either Zhe's wife, or one of Zhe's in-laws.

211. Tang Lan 唐蘭, “Xi Zhou qingtongqi duandai zhong de 'Kang gong' wenti” 西 周銅器斷代中的 “康宮” 問題, Kaogu xuebao 1962.1, 15-48; Shaughnessy, Sources of Western Zhou History, 193-214; Zhang Maorong, "Shilun Xi Zhou qingtongqi yanbian de feijunhengxing wenti," 344 . 
anything new. Only their inscriptions and correlations with other inscriptions reveal their real age.

The transmitted tradition holds that although Luoyi/Chengzhou was founded for King Cheng he never resided there. There is also no information regarding whether King Kang ever left the metropolitan Zhou. Sima Qian argued that before the reign of King Ping, Chengzhou was not used as a capital. ${ }^{212}$ However, inscriptions from various reigns show that Zhou kings used Chengzhou as a secondary residence, and that King Zhao was definitely one such king. In particular, the Jing ding 靜鼎 (YHB1795) records that Jing first received the royal command in Zongzhou to accompany Zhong 事 on the inspection of the Southern Region. Zhong's own inscriptions, discovered in Anlu 安 陸, Hubei province, corroborate that on this inspection, Jing and Zhong visited Zeng and E (Zhong yan 㐁獻, JC949). Jing then proceeded to Chengzhou to report to the king, who was already there, about their ten-month expedition. Zhong and Jing's respective inscriptions are unanimously regarded as dating from the reign of King Zhao. Jing's inscription corroborates that King Zhao used Chengzhou to coordinate communication with colonies, and frequently moved between his western and eastern residences. This may explain why the He zun uses the word chu 初 "for the first time." It refers to the fact that the king went to reside there for the first time and that he was going to return there again after a visit to the metropolitan region, during which he met $\mathrm{He}$ and other patrilineal relatives.

Cheung Kwong-yue has published a pair of gui tureens from a private collection commissioned by a person whose name can be equally transcribed as $\mathrm{He}$ 旑. The inscription commemorates that a certain gong "smoothed/wiped out Yin" (yi Yin 䧅/夷殷), gave three $z u$ 族 (lineage military units) under He's command, and donated cowries to him. Cheung has supposed that the gong mentioned in the inscription was indeed Zhou gong, while He was indeed the same person who commissioned the He zun. ${ }^{213}$ Some other scholars regard the He gui as proof of the early date of the He zun and use the data of both inscriptions to surmise the identity of He. ${ }^{214}$ The ease with which objects excavated

212. Maria Khayutina, “Western 'Capitals' of the Western Zhou Dynasty (1046/5771 BC): Historical Reality and its Reflections Until the Time of Sima Qian," Oriens Extremus 47 (2008), 25-65.

213. Cheung Kwong-yue 張光裕, “He gui mingwen yu Xi Zhou shishi xinzheng" 何篮銘文與西周史事新證, Wenwu 2009.2, 53-56; Edward L. Shaughnessy, “Newest Sources of Western Zhou History: Inscribed Bronze Vessels, 2000-2010," in Imprints of Kinship, ed. Edward L. Shaughnessy, 133-88, at 151.

214. Li Kai 李凱, “He gui yu Shang Zhou junshi zhidu” 何篮與商周軍事制度, Kaogu уи шепwи 2015.4, 46-48. 
at different times in different places get linked together is worrisome, especially considering the far-reaching consequences of such collations for the study of early Zhou history. ${ }^{215}$

The relation between the He gui and the He zun has been raised as an argument against my revision of the date of the He zun in the first draft of this article presented in Beijing in November 2016. I have considered this possibility and I disagree with the identification of both $\mathrm{He}$ as one person because of the following reasons.

The name of the commissioner is written as in the He zun and in the He gui. Although these both characters can be transcribed as he 脗, the difference is quite evident. The first character has a vertical stroke in the lower-right corner, while the second has the additional element in the lower-left corner. Inscriptions commissioned by other people whose names have also been transcribed as He feature further calligraphic

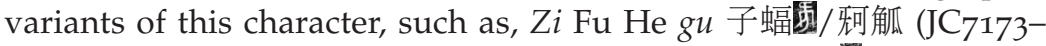
7174, unprovenanced, Late Shang), He you, zun and zhi /葋旬, 尊, 觶 (JC5339, 5933, Late Shang or early Western Zhou), He gui 笴/䄆筬 (JC4202, unprovenanced, mid- to late Western Zhou), and He gui gai 圈 / 㑸筬蓋 (JC3761, unprovenanced, late Western Zhou). These examples show not only that He was a relatively widespread name, but also that it was usually written in the same way on several vessels commissioned by one person. ${ }^{216}$ The difference between the graphic composition of the name He on the He gui and that of the He zun is one reason to doubt that these two vessels were commissioned by the same man.

Further, as Wei Xinying points out, the He gui was dedicated to two ancestors identified by posthumous day-names, whereas the name of the ancestor to whom the He zun was dedicated consists of a lineage name and the term gong. Relying on Zhang Maorong's theory that "the Zhou people did not use day-names for their ancestors," Wei argues that He of the He gui was a member of an old "Shang" lineage, whereas He of the He zun was a member of the royal clan. ${ }^{217}$ I do not fully agree with this line of reasoning, as there is also evidence that even some members of Ji-lineages occasionally used day-names in ancestral

215. For the dangers of connecting inscriptions with identic names, see Cao Bin, "Xi Zhou tongqi duandai fangfa tanwei," 62.

216. Cf. Wang Hong 王宏, “He gui, He zun fei tong ren zhi qi bian” 何篮, 何尊非同 人之器辯, Yindu xuekan 2010.2, 21-24. One person's name could be occasionally written differently, but such cases are rare.

217. Wei Xinying 韋心灐, “He zun mingwen tanxi,” 何尊銘文探析 in Xin chu jinwen yu Xi Zhou lishi, ed. Zhu Fenghan (Shanghai: Shanghai guji, 2011), 267-74; cf. Zhang Maorong 张禁镕, “Zhou ren bu yong riming shuo" 周人不用日名說, Lishi yanjiu 1993.5, $173-77$. 
dedications. ${ }^{218}$ Thus, He of the He gui was not necessarily a "Shang" man. Nevertheless, it was unusual for one person to mix the two types of ancestral designations in dedications on bronze vessels. ${ }^{219}$ This supports that the He gui and He zun were commissioned by different people.

From the point of view of appearance, there are also no indications that the He gui and the He zun belong together. ${ }^{220}$ The paired He gui rest on ring feet about half of the bowl's height. Small, crudely cast high relief animal masks are placed in the center of the front below the rim and are integrated into decorative ribbons filled with three rows of small spirals and abstract shapes. The paired handles are decorated with animal heads and hooked pendants, while the feet are also decorated with ribbons of spirals. This appearance derives from Anyang prototypes and is typical for the early Western Zhou period, while examples can be found in many places all the way from Baoji to western Shandong, and from Yejiashan in Hubei to Liulihe near Beijing. An unusual feature of both vessels is that they feature lids, which are seldom seen on Shang and early Western Zhou tureens. Normally, the tureen lids are concave and feature a tubular crown on top (see Figure A1A), which could serve as a foot on which the lid could rest if reversed. Very few tureens with four flanges on the lids, running towards the tubular crown, are known. ${ }^{221}$ The lids of the He gui are decorated by ribbons of spirals around the rim and are subdivided into four sectors by relief flanges, which join at the top into a cowling that looks amorphous in the photograph. The flanges further extend into large protuberant hooks shaped as dragons with relief eyes standing on their heads and raising their tails upwards. These hooks could also serve as feet so that the reversed lid could be used separately as a shallow ding cauldron. Ding cauldrons on flat, bent feet occur from as far back as the late Shang period and were widespread during the early Western Zhou period. However, the round ding invariably possess only three feet, while only square-shaped cauldrons rest on four feet. Besides, the feet this type of ding are usually longer. So far, the He gui can only be compared with the Changzi Kou ding 長子口鼎 (YHB550) excavated from the tomb of Changzi Kou and the uninscribed ding from the Tomb Mi of the Yu polity in Zhifangtou 紙坊頭 near Baoji. Both of them are round and have flat lids with three

218. See, e.g., Falkenhausen, "The Inscribed Bronzes from Yangjiacun," 262.

219. Wang Entian, "He you, He hu zhen wei bian," 58 . Again, some counterexamples may be found, but they are rare.

220. Cheung Kwong-yue, "He gui mingwen yu Xi Zhou shishi xinzheng," Figure 1.

221. Unprovenanced examples can be found in Hayashi Minao, In Shü seidōki sōran 1, vol. 2, Figures 261-62. 
hooks representing dragons making a headstand. ${ }^{222}$ A square ding from the tomb Mi11 of the Zeng polity at Yejiashan in Hubei features four dragons standing on their feet and noses. ${ }^{223}$ In sum, the He gui is a highly idiosyncratic, eclectic vessel, breaking some artistic conventions of its time and not being fully harmonized, with a few remote parallels in Baoji, eastern Henan and northern Hubei. If genuine, it may be a highly valuable piece of art from the beginning of the Zhou dynasty, but its decorative scheme neither suggests that it could be a part of one set with the He zun, nor suggests a special connection to Baoji. Thus, I argue that this new find is irrelevant to the question of the date of the He zun.

According to its inscription, the He zun was cast on day bing- $x u$ of the fourth month of the fifth year of a certain reign. This date is compatible with the calendar of the nineteenth year of King Zhao reflected in the Zhe zun-the only other inscription from that reign that records the year, month, and day dates (see Table A2 and Table A3). ${ }^{224}$ According to the dates of King Zhao's reign proposed by Edward Shaughnessy, He zun would date from 973 or 971 B.C.E. According to the dates proposed by the Xia Shang Zhou periodization project, it would date twenty years earlier to 991 B.C.E. Both proposed dates are very early, and this inscription is definitively one most important pieces of evidence of early Zhou commemorative tradition and written culture. But it does not testify that this tradition and this culture fully blossomed within the first decade after the conquest.

\section{THE DATE OF THE YU DING}

Challenging the date of the $D a \mathrm{Yu}$ ding is as painstaking a task as questioning the date of the He zun. This one-and-a-half-hundredweightheavy cauldron, displayed in the National Museum of China and assigned the status of a National Treasure, cannot easily be shifted within the current historical narrative. ${ }^{225}$ If the He $z u n$ and the $D a \mathrm{Yu}$

222. Cf. Henan wenwu kaogu yanjiusuo, Zhoukou shi wenhuaju, Luyi Taiqinggong Changzi Kou mu 鹿邑太清宮長子口墓 (Zhengzhou: Zhongzhou guji, 2000), 57; Lu Liancheng and Hu Zhisheng, Baoji Yu guo mudi, 18.

223. Hubei sheng wenwu kaogu yanjiusuo and Suizhou shi bowuguan, Suizhou Yejiashan: Xi Zhou zaoqi Zeng guo mudi 隨州葉家山: 西周早期曾國墓地 (Beijing: Wenwu, 2013), Nr. 54 .

224. Indeed, without the record of the month's division, this data is imperfect. However, it contains no indication of incompatibility, which, in turn, would suggest that the He zun certainly does not date from King Zhao's reign.

225. For the $D a$ Yu ding featured in the frame of the current campaign of popularizing and "revitalizing" national heritage, addressed at a broad public, see Tian Shuai 田率, "Rang wenwu 'huoqilai': Zhongguo Guojia bowuguan cangpin xieying"

footnote continued on next page 
TABLE A2 Tentative reconstruction of the calendar of King Zhao (r. 977-957 B.C.E.)

\begin{tabular}{|c|c|c|c|c|c|c|c|c|c|c|c|c|c|c|}
\hline Year & B.C.E & & & & & & & Mont & & & & & & \\
\hline & & 1 & 2 & 3 & 4 & 5 & 6 & 7 & 8 & 9 & 10 & 11 & 12 & 13 \\
\hline 1 & 977 & 29 & 59 & 28 & 57 & 27 & 56 & 26 & 55 & 25 & 54 & 24 & 54 & \\
\hline 2 & 976 & 24 & 53 & 23 & 52 & 21 & 51 & 20 & 49 & 19 & 49 & 18 & 48 & 18 \\
\hline 3 & 975 & 48 & 17 & 47 & 16 & 45 & 15 & 44 & 13 & 43 & 12 & 42 & 12 & \\
\hline 4 & 974 & 42 & 11 & 41 & 11 & 40 & 9 & 39 & 8 & 37 & 7 & 36 & 6 & \\
\hline 5 & 973 & 36 & 5 & 35 & $\begin{array}{l}\text { A } \\
5\end{array}$ & 34 & 4 & 33 & 3 & 32 & 1 & 31 & 60 & 30 \\
\hline 6 & 972 & 59 & 29 & 59 & 29 & 58 & 28 & 57 & 27 & 56 & 25 & 55 & 24 & \\
\hline 7 & 971 & 54 & 23 & 53 & 23 & 52 & 22 & 52 & 21 & 51 & 20 & 50 & 19 & 48 \\
\hline 8 & 970 & 18 & 47 & 17 & 46 & 16 & 46 & 15 & 45 & 14 & 44 & 14 & 43 & \\
\hline 9 & 969 & 12 & 42 & 11 & 41 & 10 & 40 & 9 & 39 & 9 & 38 & 8 & 38 & \\
\hline 10 & 968 & 7 & 37 & 6 & 35 & 5 & 34 & 3 & 33 & 3 & 32 & 2 & 32 & 2 \\
\hline 11 & 967 & 31 & 1 & 30 & 59 & 29 & 58 & 27 & 57 & 26 & $\begin{array}{l}\text { B } \\
56\end{array}$ & 26 & 56 & \\
\hline 12 & 966 & 25 & 55 & 25 & 54 & 23 & 53 & 22 & $\begin{array}{l}\text { B } \\
51\end{array}$ & 21 & 50 & 20 & 50 & \\
\hline 13 & 965 & 19 & 49 & 19 & 49 & 18 & 47 & 17 & 46 & 15 & 45 & 14 & 44 & 13 \\
\hline 14 & 964 & 43 & 13 & 43 & 12 & 42 & 11 & 41 & 10 & 39 & 9 & 38 & 8 & \\
\hline 15 & 963 & 37 & 7 & 37 & 6 & 36 & 6 & 35 & 5 & 34 & 3 & 33 & 2 & 32 \\
\hline 16 & 962 & 1 & 31 & 60 & 30 & 60 & 29 & 59 & 28 & 58 & 27 & 57 & 26 & \\
\hline 17 & 961 & 56 & 25 & 55 & 24 & 54 & 23 & 53 & 23 & 52 & 22 & 51 & 21 & \\
\hline 18 & 960 & 50 & 20 & 49 & 19 & 48 & 18 & 47 & 17 & 46 & 16 & 46 & 15 & 45 \\
\hline 19 & 959 & 15 & 44 & 13 & 43 & $\begin{array}{l}C \\
12\end{array}$ & 41 & 11 & 40 & 10 & 40 & 10 & 39 & \\
\hline 20 & 958 & 9 & 39 & 8 & 37 & 7 & 36 & 5 & 35 & 4 & 34 & 4 & 33 & \\
\hline 21 & 957 & 3 & 33 & 3 & 32 & 1 & 31 & 60 & 29 & 59 & 28 & 58 & 27 & 57 \\
\hline
\end{tabular}

ding date later than assumed, then the first post-conquest reigns of Kings Cheng and Kang will appear as a dull period without spectacular evidence about the extensive use of writing.

The $D a \mathrm{Yu}$ ding was discovered during the reign of the Daoguang 道 光 emperor (r. 1825-1850). Qing scholars Xu Tongbo 徐同柏 (1775-1854 or 1860), Wu Dacheng 吳大澂 (1835-1902), and even Wang Guowei 王

讓文物“活起來”——國國家博物館藏品擷英, Lingdao kexue luntan 2018.7, 61-73. For bronze tripods as symbols of state power and national unity in present-day China, see Maria Khayutina, "Neun heilige Dreifüße, vier Tausend Jahre: zur Repräsentation von Herrschaft und Tugend in China," in Hou Han(s') shu. Festschrift zum 50. Geburtstag von Hans van Ess, ed. Daniel Leese (Munich: Institut für Sinologie, 2012), 83-104. 
TABLE $\mathrm{A}_{3}$ Dated vessels from King Zhao's reign

\begin{tabular}{|c|c|c|c|c|c|c|c|}
\hline \multicolumn{3}{|c|}{ Vessels } & \multirow{2}{*}{$\frac{\text { Year }}{5}$} & \multirow{2}{*}{$\begin{array}{l}\text { Month } \\
4\end{array}$} & \multirow{2}{*}{$\frac{\text { Phase }}{n}$} & \multirow{2}{*}{$\begin{array}{l}\text { Ganzhi } \\
23\end{array}$} & \multirow{2}{*}{$\begin{array}{l}\text { Day of } \\
\text { Month }\end{array}$} \\
\hline A & He zun & 砢尊 & & & & & \\
\hline \multirow[t]{3}{*}{ B } & Jing ding ${ }^{\mathrm{a}}$ & 靜鼎 & $\mathrm{n}$ & 10 & $\mathrm{n}$ & 1 & 5 \\
\hline & & & $\mathrm{n}$ & 8 & 1 & 57 & 6 \\
\hline & & & $\mathrm{n}$ & [8] & 3 & 14 & 23 \\
\hline C & Zuoce Zhe zun & 作冊折尊 & 19 & 5 & $\mathrm{n}$ & 25 & 14 \\
\hline
\end{tabular}

a. The Jing ding (YHB1795) is generally regarded as dating from the reign of King Zhao. It does not indicate the year but provides the month, phase, and day-dates of the events during two consequent years. This combination of dates can only be found during the eleventh and twelfth years of King Zhao's reign.

國維 (1877-1927) suggested that the $D a$ Yu ding dates from the time of King Cheng, as it mentions Kings Wen and $\mathrm{Wu}$ and its anti-alcohol polemic recalls the "Jiu gao" associated with king Cheng. Guo Moruo has demonstrated that the $D a$ and the Xiao Yu ding belong together and, since the latter mentions King Cheng as an ancestor receiving sacrifices, he re-dated both cauldrons to the reign of King Kang; Chen Mengjia and Li Xueqin supported this dating. ${ }^{226}$ Again, few objected that the posthumous name of King Cheng only suggests a post quem date, that is, any time from King Kang onwards. ${ }^{227}$ Only recently, Li Shan 李山 and Li Hui 李輝 have attempted to revise the date of the Da Yu ding based on the analysis of their content and language. ${ }^{228}$

Yu's inscriptions not only are extraordinarily long and eloquent, but also include certain features that are witnessed in some inscriptions from the reign of King $\mathrm{Mu}$ and become truly widespread beginning with the reign of King Gong. As Li Shan and Li Hui point out, these include the phrase wang ruo yue ("the king said as follows" or "the king approvingly said"), introducing the royal speech, some other expressions, as well as the arrangement of the inscription on two parallel panels similar to the Shi Qiang pan.229 At the same time, as Li Xueqin pointed out, neither of

226. Chen Mengiia, "Xi Zhou tongqi duandai (san)," 95 with further references; Li Xueqin 李學勤, “Da Yu ding xin lun” 大孟鼎新論, Zhengzhou daxue xuebao 1985.3, 51-64; see also Shaughnessy, "Western Zhou History," 320-22; Shaughnessy, "History and Inscriptions, China," $380-81$.

227. Although Edward Shaughnessy has mentioned that "a reference to a deceased king could logically derive from any later reign," he nevertheless has accepted the Da Yu ding as a "standard vessel" of the reign of King Kang. See Shaughnessy, Sources of Western Zhou History, 108 and Table 4 on p. 110-11.

228. Li Shan and Li hui, "Da Xiao Yu ding zhizuo niandai."

229. Li Shan and Li hui, "Da Xiao Yu ding zhizuo niandai," 33-34. 
Yu's inscriptions contain any single cross-reference that would correlate them to other known inscriptions. The main argument in favor of the early date of the $\mathrm{Da} \mathrm{Yu}$ ding is its presumably archaic shape.

The $\mathrm{Da}$ Yu ding is an unusually massive tripod with a deep belly decorated with ornamental ribbons made of animal masks below the rim and similar masks on the legs (Figure $5 \mathrm{~A}$ ). This shape and ornamentation became standard already during the late Shang period. At the beginning of the Western Zhou period, such cauldrons appear in the tombs of higher elites in the metropolitan region and beyond, including, e.g., a cauldron from the tomb of Zhangzi Kou (Figure 5D). Indeed, the shape and the decorations of the $D a$ Yu ding are based on these prototypes. However, its "early" appearance is probably a case of Western Zhou "antiquarianism" manifested in the reproduction of ancient models, as is the case with the Zhe zun, Ze Ling zun, and the He $z u n . .^{230}$ Imitations of early models were continuously produced during the following centuries, but those from the ninth to the eighth century B.C.E. are clearly distinguishable because, although reproducing classical shapes, they use modern ornamental schemes, such as in the obvious case of the Shanfu Ke ding (Figure ${ }_{5} \mathrm{E}$ ). Objects from the tenth century B.C.E. made near the early prototypes would be dated to the early Zhou period in cases of doubt unless their inscription would reveal a midWestern Zhou date. Nevertheless, the Qi (?) ding 旗鼎 (JC2704) represents one clearly datable parallel to the $\mathrm{Da}$ Yu ding. It was excavated in 1972 from a hoard in Yangjiacun 楊家村 in Meixian county, not far from the place where the bronze hoard of the Shan 單 lineage was found in 2003 (see Figure ${ }_{5} \mathrm{~B}$ ). The geographical vicinity of both finds suggests that Qi was related to the Shan lineage. The Qiu Wei he 表衛盉 from the third year of King Gong (920 B.C.E.) mentions sima Shan Qi 司馬單旗. This corroborates that Qi was a member of the Shan lineage, and that he was active during the late reign of King $\mathrm{Mu}$ and the early reign of King Gong.

Moreover, in his inscription, Qi commemorated a donation received from wang Jiang, a royal spouse or concubine. A cauldron commissioned by a Zhou king to zhong ("Second-born" lady) Jiang 仲姜 was excavated from a hoard in Youfangbao 油房堡 in Meixian county (JC2191, Figure ${ }_{5} \mathrm{C}$ ). This find shows that the royal spouse Jiang was active in the

230. Lothar von Falkenhausen has expressed his suspicion that the $\mathrm{Da}$ Yu ding may be one of "archaising creations" of the Middle and Late Western Zhou periods. See Falkenhausen, "Review of Li Feng, 'Bureaucracy and the State in Early China: Governing the Western Zhou,'" 278, n. 21. For other "antiquarian" cases, see Jessica Rawson, "Reviving Ancient Ornament and the Presence of the Past: Examples from Shang and Zhou Bronze Vessels," in Reinventing the Past: Archaism and Antiquarianism in Chinese Art and Visual Culture, ed. Wu Hong (Chicago: Art Media Resources, 2010), 47-76. 

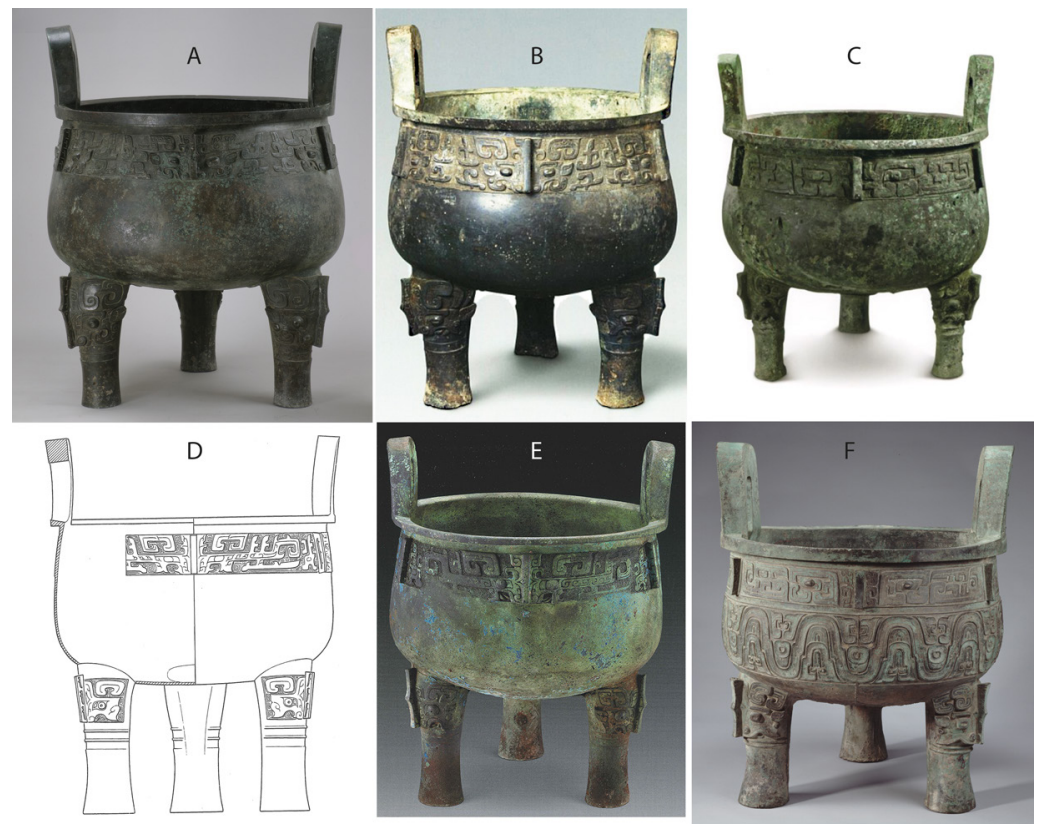

Figure 5 Bronze ding in comparison. ${ }^{231}$ A. Da Yu ding. B. Qi ding. C. Wang zuo zhong Jiang ding. D. Zhangzi Kou ding. E. Yejiashan Mi11:75. F. Da Ke ding. A: $\mathrm{H}=101.9 \mathrm{~cm}$, $\mathrm{D}=77.8 \mathrm{~cm}, \mathrm{~W}=153.5 \mathrm{~kg} ; \mathrm{B}: \mathrm{H}=77 \mathrm{~cm}, \mathrm{D}=56.5 \mathrm{~cm} ; \mathrm{W}=78.5 \mathrm{~kg} ; \mathrm{C}: \mathrm{H}=54.1 \mathrm{~cm}$, $\mathrm{D}=45.8 \mathrm{~cm} ; \mathrm{D}: \mathrm{H}=50.8 \mathrm{~cm}, \mathrm{D}=38 \mathrm{~cm} ; \mathrm{E}: \mathrm{H}=49 \mathrm{~cm}, \mathrm{D}=37,5 \mathrm{~cm} ; \mathrm{F}: \mathrm{H}=93.1 \mathrm{~cm}$, $\mathrm{D}=75.6 \mathrm{~cm}, \mathrm{~W}=201.5 \mathrm{~kg}$.

vicinity of the Shan lineage. The Zhong Jiang's cauldron is made based on the same model as the $D a$ Yu ding and the Qi ding, but it is more easily recognizable as a mid-Western Zhou vessel because of a higher degree of abstraction of the animal masks in the decorative ribbon below the rim (see Figure ${ }_{5} \mathrm{~B}$ ). The Da Yu ding is obviously very similar to but much bigger than the Qi ding (see Figure ${ }_{5} \mathrm{C}$ ). I see no reason why the $\mathrm{Da} \mathrm{Yu}$ ding should date much earlier, and instead I argue that these vessels are contemporaneous.

231 A: Collection of the National Museum of China, courtesy of Dr. Tian Shuai; B: Liang Yanmin 梁彥民, Shenyun yu huihuang: Shaanxi lishi bowuguan guobao jianshang (qingtongqi juan) 神韻與輝煌--陝西歷史博物館國寶鑑賞 (青銅器卷) (Xi'an: Sanqin, 2006), Figure 45; C: Zhang Tian'en 張天恩, Shaanxi sheng guji zhengli bangongshi and Shaanxi sheng kaogu yanjiuyuan, eds., Shaanxi jinwen jicheng 陝西金文集成 (Xi'an: Sanqin, 2016), vol. 6, Nr. 667; D: Henan wenwu kaogu yanjiusuo, Zhoukou diqu wenhuaju, "Henan Luyi xian Taiqinggong Xi Zhou mu de fajue," Figure 4; E: Hubei sheng wenwu kaogu yanjiusuo and Suizhou shi bowuguan, Hubei sheng wenwu kaogu yanjiusuo et al. 2013, Nr. 57; F: Collection of the Shanghai Museum, courtesy of the museum. 
The Xiao Yu ding is, moreover, fully dated. Its rubbing is available in two variants. On the rubbing used by Guo Moruo and included in the Yin Zhou jinwen jicheng, the year number appears as twenty-five, while another one, used by Ma Chengyuan, shows that the character nian 廿 (twenty) has an additional line in the middle, indicating that it should be read as $s a$ \# (thirty) and the year-number is thirtyfive. ${ }^{232}$

The first date perfectly fits King Mu's calendar (see Table A4 and Table A5). ${ }^{233}$ Among other things, it correlates with the date of the Qiu Wei gui 蓑衛篮, commissioned by the donor of the already mentioned Qiu Wei he during the twenty-seventh year of King Mu. Different dates for King Mu's reign have been proposed. In light of new evidence, I suggested amending the dates proposed by Edward Shaughnessy, 956918 в.C.E., to $956-923$ в.C.E., and dated the Xiao Yu ding to 932 в.C.E. ${ }^{234}$ In the case if, as the Xia Shang Zhou periodization project suggests, King Mu reigned during 976-923 B.C.E., this date can be shifted twenty years back to 952 в.C.E.

The second date definitively does not fit the reign of King Kang, as none of the current standard chronologies assumes that he reigned longer than twenty-five years. It would be even necessary to accommodate it within the reign of King Mu, since King Zhao's reign was even shorter. This can be done both within the longer chronology proposed by the Xia Shang Zhou periodization project and the shorter chronology proposed by Shaughnessy, even with the date of Mu-Gong transition shifted to 923/22 B.C.E. As I share Professor Shaughnessy's

232. Cf. Guo Moruo, Liang Zhou jinwen ci daxi kaoshi, No. 19; Ma Chengyuan, Shang Zhou qingtongqi mingwen xuan, 41-43. Some scholars who attempted to reconstruct the Western Zhou chronology based on astronomical data in transmitted texts and dated bronze inscriptions supposed that the Xiao Yu ding dates from the reign of King Zhao or King Mu. See Ding Su 丁驌, “Xi Zhou jin qi nianpu” 西周金器年譜, Zhongguo wenzi 10 (1985), at 32-33; Zhang Wenyu 張聞玉, “Xiao Yu ding fei Kang wang qi" 小孟鼎非康 王器, Renwen zazhi 1991.6, 76-78, 90. Both scholars assumed the date as the thirty-fifth year. However, their chronologies, extending the Western Zhou period to further several decades, are unrealistic, while they barely consider the vessels' appearance as a factor for dating. This made their further arguments assailable and, therefore, I did not pay due attention to the question of the thirty-fifth year. I am therefore even more indebted to Ondřej Škrabal for drawing my attention to the second rubbing clearly displaying a $s a$ character (personal communication on July 3, 2020).

233. Cf. Zhang Peiyu 張培瑜, Zhong guo xian Qin shi li biao 中國現秦史歷表 (Jinan: Li Lu shushe, 1987).

234. Cf. Maria Khayutina, "The Tombs of the Rulers of Peng," 115. 
TABLE A4 Partially reconstructed calendar of King Mu (r. 956-923 B.C.E.). 235

\begin{tabular}{|c|c|c|c|c|c|c|c|c|c|c|c|c|c|c|}
\hline \multirow[b]{2}{*}{ Year } & \multirow[b]{2}{*}{ B.C.E. } & \multicolumn{13}{|c|}{ Months } \\
\hline & & 1 & 2 & 3 & 4 & 5 & 6 & 7 & 8 & 9 & 10 & 11 & 12 & 13 \\
\hline 20 & 937 & 6 & 36 & 6 & 35 & 5 & 35 & 4 & 33 & 3 & 32 & 1 & 31 & \\
\hline 21 & 936 & 1 & 31 & 60 & 30 & 59 & 29 & 58 & 28 & 57 & 27 & 56 & 26 & \\
\hline 22 & 935 & 55 & 25 & 54 & $\begin{array}{l}\text { A } \\
24\end{array}$ & 53 & 23 & 52 & 22 & 52 & 21 & 51 & 20 & 50 \\
\hline 23 & 934 & 19 & 49 & 18 & 47 & 17 & 47 & 16 & 46 & 15 & 45 & 15 & 44 & \\
\hline 24 & 933 & 14 & 43 & 13 & 42 & 11 & 41 & 10 & 40 & B & 39 & 9 & 39 & 8 \\
\hline 25 & 932 & 38 & 7 & 37 & 6 & 35 & 5 & 34 & C & 33 & 3 & 33 & 2 & \\
\hline 26 & 931 & 32 & 2 & 31 & 1 & 30 & 59 & 29 & 58 & 27 & 57 & 27 & 56 & \\
\hline 27 & 930 & 26 & 56 & $\begin{array}{l}\text { D } \\
26\end{array}$ & 55 & 25 & 54 & 23 & 53 & 22 & 51 & 21 & 50 & 20 \\
\hline 28 & 929 & $\begin{array}{l}\mathbf{E} \\
50\end{array}$ & 20 & 50 & 19 & 49 & 18 & 47 & 17 & 46 & 15 & 45 & 14 & \\
\hline 29 & 928 & 44 & 14 & 44 & 13 & 43 & 12 & 42 & $\begin{array}{l}F \\
11\end{array}$ & 41 & 10 & 39 & 9 & \\
\hline 30 & 927 & 38 & 8 & 38 & $\begin{array}{l}\text { G } \\
7\end{array}$ & 37 & 7 & 36 & 6 & 35 & 5 & 34 & 4 & 33 \\
\hline 31 & 926 & 2 & 32 & 1 & 31 & 1 & 30 & 60 & 30 & 59 & 29 & 58 & 28 & \\
\hline 32 & 925 & 57 & 27 & 56 & 25 & 55 & 24 & 54 & 24 & 53 & 23 & 53 & 22 & \\
\hline 33 & 924 & 52 & 21 & 51 & 20 & 49 & 19 & 48 & 18 & 47 & 17 & 47 & 16 & 46 \\
\hline 34 & 923 & 16 & 45 & 15 & 44 & 13 & $\begin{array}{l}\mathbf{H} \\
43\end{array}$ & 12 & 41 & 11 & 41 & 10 & 40 & \\
\hline
\end{tabular}

opinion that it is unlikely that King Mu reigned fifty years, I will only substantiate the second option.

The amended chronology of King Gong's reign suggests that it begun in 922 B.C.E. This means that King Mu ruled only thirty-four full years. Nevertheless, the year-count of a king who just had passed away could be still in use some time afterwards. ${ }^{236}$ As I have demonstrated

235. Amended from Khayutina 2016, 115, based on Zhang Peiyu 1987, 48-53.

236. David Nivison and Edward Shaughnessy have revealed in inscriptions the traces of a "dual first year institution" in the Western Zhou. Apparently, events could be dated according to the royal year-count beginning either with the year of the king's de-facto succession, or two years later, probably, after the end of the ritual mourning period. See David S. Nivison, "The Dates of Western Chou," Harvard Journal of Asiatic Studies 1983.43.3, 481-580, esp. 524-535; Shaughnessy, Sources of Western Zhou History, 147-155. 
TABLE A5 Dated vessels from King Mu's reign

\begin{tabular}{|c|c|c|c|c|c|c|c|}
\hline \multicolumn{3}{|c|}{ Vessels } & \multirow{2}{*}{$\begin{array}{l}\text { Year } \\
22\end{array}$} & \multirow{2}{*}{$\frac{\text { Month }}{4}$} & \multirow{2}{*}{$\begin{array}{l}\text { Phase } \\
3\end{array}$} & \multirow{2}{*}{$\frac{\text { Ganzhi }}{46}$} & \multirow{2}{*}{$\begin{array}{l}\begin{array}{l}\text { Day of } \\
\text { Month }\end{array} \\
23\end{array}$} \\
\hline A & Geng Ying ding & 庚贏鼎 & & & & & \\
\hline B & Shi Lu gui & 師录篮 & 24 & 9 & 3 & 27 & 19 \\
\hline C & Xiao Yu ding (1) & 小孟鼎 & 25 & 8 & 3 & 21 & 18 \\
\hline $\mathrm{D}$ & Qiu Wei gui & 装衛篮 & 27 & 3 & 2 & 35 & 12 \\
\hline E & Jin gui & 䖐筬 & 28 & 1 & 2 & 4 & 14 \\
\hline $\mathrm{F}$ & Ban gui & 班笽 & {$[29]^{\mathrm{a}}$} & 8 & 1 & 11 & 1 \\
\hline \multirow[t]{2}{*}{ G } & Hu gui gai & 虎笽蓋 & 30 & 4 & 1 & 11 & 5 \\
\hline & Zuoce Wu he & 作冊吳盉 & 30 & 4 & 2 & 19 & 13 \\
\hline $\mathrm{H}$ & Xiangui & 鮮篮 & 34 & 5 & 3 & 55 & 13 \\
\hline
\end{tabular}

a. The Ban gui does not indicate the year. Edward Shaughnessy has attempted to locate it during the 922 в.C.E., as he supposes that King Mu reigned until 919 в.C.E. Shaughnessy, Sources of Western Zhou History, 253). My calculations show that it perfectly fits the twenty-ninth year, or 928 в.C.E. The thirtieth year (927 в.C.E.) is also conceivable. Although the month-phase-day combination referred to in this inscription can also be found during the fourth and nineteenth years, I assume that this is less plausible because other dated inscriptions cluster towards the end of the reign rather at its beginning.

elsewhere, the royal year-count was not yet a tool for the routine dating of events, but it was used optionally and usually to display a close relationship to the king. ${ }^{237} \mathrm{Yu}^{\prime}$ 's close association with King Mu, clearly manifested in the $\mathrm{Da}$ Yu ding, could be the reason why he would prefer using the old calendar, even while interacting with the new king who had not yet completed the mourning period for his deceased father. Other people, such as Xun 氛, called into service by King Gong, would, in contrast, commemorate the events from their own biography starting from the year of that king's de-facto ascension to the throne. ${ }^{238}$ The date in the Shi Xun gui indicate that at the beginning of King Gong's first year, there was an irregular intercalary month. ${ }^{239}$ Possibly, this was related to

Logically, one who would regard the year after the end of mourning as the "real" first year of the new king, would attach the time of the mourning to the previous reign.

237. Khayutina, "The Royal Year-Count," 151-53.

238. Cf. Shi Xun gui 師言篮 (JC4342); Xun gui 言篮 (JC4321).

239. During the celebration of the victory over Guifang in the Zhou temple, recorded in the Xiao Yu ding, Yu presented his booty together with another commander, named Rong 榮. Shi Xun was accompanied at the royal audience by Rong, who, judging upon his role as a right-hand convoy of a high-ranked military man, was an even higher-ranked commander. Although Rong was probably a lineage name, and persons referred by this name also appear in inscriptions from other periods, the mention of Rong in Shi Xun's and Yu's inscriptions may be not accidental. 
TABLE A6 Partially reconstructed calendar of King Gong (922-900 B.C.E.).

\begin{tabular}{|c|c|c|c|c|c|c|c|c|c|c|c|c|c|c|}
\hline \multirow[b]{2}{*}{ Year } & \multirow[b]{2}{*}{ B.C. } & \multicolumn{13}{|c|}{ Months } \\
\hline & & 1 & 2 & 3 & 4 & 5 & 6 & 7 & 8 & 9 & 10 & 11 & 12 & 13 \\
\hline 1 & 922 & 10 & 40 & $\begin{array}{l}\text { A, B } \\
9\end{array}$ & 39 & 8 & 37 & 7 & 36 & $C_{5}$ & 35 & 4 & 34 & 4 \\
\hline 2 & 921 & 34 & 4 & 33 & 3 & 32 & 1 & 31 & 60 & 29 & 59 & 28 & 58 & \\
\hline 3 & 920 & 28 & 58 & $\begin{array}{l}\text { D } \\
27\end{array}$ & 57 & 27 & 56 & 25 & 55 & 24 & 53 & 23 & 52 & \\
\hline
\end{tabular}

TABLE A7 Dated vessels from the first years of King Gong's reign

\begin{tabular}{|c|c|c|c|c|c|c|c|}
\hline \multicolumn{3}{|c|}{ Vessels } & \multirow{2}{*}{$\begin{array}{l}\text { Year } \\
1\end{array}$} & \multirow{2}{*}{$\begin{array}{l}\text { Month } \\
2\end{array}$} & \multirow{2}{*}{$\begin{array}{l}\text { Phase } \\
3\end{array}$} & \multirow{2}{*}{$\begin{array}{l}\text { Ganzhi } \\
27\end{array}$} & \multirow{2}{*}{$\begin{array}{l}\text { Day of } \\
\text { Month }\end{array}$} \\
\hline A & Shi Xun gui & 師訇篮 & & & & & \\
\hline B & Dou Bi gui & 豆閉篮 & [1?] & 2 & 2 & 15 & 7 \\
\hline $\mathrm{C}$ & Xiao Yu ding (2) & 小孟鼎 & 35 & 8 & 3 & 21 & 17 \\
\hline D & Qiu Wei he & 袈衛盉 & 3 & 2 & 2 & 39 & 13 \\
\hline
\end{tabular}

the death of King $\mathrm{Mu}$ during the first month of his thirty-fifth year. As the result, the year had two first months and the numbers of all other months shifted. Hence, the day-date recorded in the Shi Xun gui fits the third (instead of the second) month of the reconstructed calendar of 922 в.C.E. The fact that the date of the Xiao Yu ding fits the ninth (instead of the eighth) month of the reconstructed calendar supports that it dates from the same year. ${ }^{240}$

240. As the present paper has already been submitted to Early China, Prof. Shaughnessy shared with me his new article in which he supports my revision of the Yu vessels' date and equally dates the Xiao Yu ding to 922 в.C.E. See Xia Hanyi 夏含夷, “Cong 'Zeng gong Qiu bianzhong' mingwen chongxin kaolü 'Da Yu ding' he 'Xiao Yu ding' de niandai," 從《曾公求編鐘》銘文重新考慮《大孟鼎》和《小孟鼎》的年代 in Zhang Changshou, Chen Gongrou xiansheng jinian wenji, ed. Li Feng 李峰, Cui Lequan 崔 乐泉, Shi Jingsong 施劲松, Zheng Daning 郑大宁, and Jing Zhenglie 金正烈 (forthcoming). 
TABLE A8 Inscriptions mentioning the conquest of Shang or the first Kings

\begin{tabular}{|c|c|c|c|c|c|c|c|c|c|c|}
\hline \multicolumn{3}{|c|}{ Commissioner's identity } & \multicolumn{3}{|l|}{ Inscriptions } & \multicolumn{3}{|c|}{ First Kings } & \multicolumn{2}{|c|}{ Conquest } \\
\hline $\mathrm{Nr}$. & Name, function & Surname, lineage & Title & Exemplars & Signs & 文王 & 武王 文武 & 成王 & 商 & 殷 \\
\hline 1 & $\begin{array}{l}\text { Tian Wang 天亡, ritual spe- } \\
\text { cialist, member of royal } \\
\text { retinue }\end{array}$ & unclear & $\begin{array}{l}\text { Tian Wang gui } \\
\text { 天亡笽 }\end{array}$ & 1 & 77 & 1 & & & & \\
\hline 2 & $\begin{array}{l}\text { Zhou gong 周公, royal family } \\
\text { member }\end{array}$ & $\mathrm{Ji}$, Lu 魯 lineage & $\begin{array}{l}\text { Zhou gong } \\
\text { ding 周公鼎 }\end{array}$ & 1 & 7 & 1 & & & & \\
\hline 3 & $\begin{array}{l}\mathrm{Li} \text { 利, ritual specialist, mem- } \\
\text { ber of royal retinue }\end{array}$ & unclear & Li gui 利筬 & 1 & 32 & & 1 & & 1 & \\
\hline 4 & $\begin{array}{c}\text { Mei situ Yi 沫司徒疑, member } \\
\text { of retinue of a colony ruler }\end{array}$ & unclear & $\begin{array}{l}\text { Mei situ Yi gui } \\
\text { 沫司徒疑篮 }\end{array}$ & 1 & 24 & & & & 1 & \\
\hline 5 & Xiaochen Shan 小臣單, official & $\begin{array}{l}\mathrm{Ji} \text { (?, if Shan 單 is } \\
\text { a lineage name) }\end{array}$ & $\begin{array}{c}\text { Xiaochen Shan } \\
\text { zhi 小臣單觶 }\end{array}$ & 1 & 21 & & & & 1 & \\
\hline 6 & $\begin{array}{l}\text { Yi 義, head or high-ranked } \\
\text { member of an old "Shang" } \\
\text { lineage }\end{array}$ & $\begin{array}{l}\text { non-Ji, Bing 丙 } \\
\text { lineage }\end{array}$ & $\begin{array}{l}\text { Yi zun, yi } \\
\text { 義尊, 彝 }\end{array}$ & 2 & 18 & & 1 & & & \\
\hline 7 & $\begin{array}{l}\text { De 德, member of royal } \\
\text { retinue, possibly, the king's } \\
\text { younger brother, cf. Shu De } \\
\text { gui 叔德䈍, JC 3942) }\end{array}$ & $\begin{array}{l}\text { Ji (if the same } \\
\text { person as shu } \\
\text { De) }\end{array}$ & De ding 德鼎 & 1 & 23 & & 1 & & & \\
\hline 8 & $\begin{array}{l}\text { He 䄆, member of retinue } \\
\text { of a certain gong, possibly, } \\
\text { member of an old "Shang" } \\
\text { lineage }\end{array}$ & unclear & He gui 歌篮 & & 34 & & & & & 1 \\
\hline 9 & $\begin{array}{l}\text { Xian hou 獻侯, colony ruler, } \\
\text { member of an old "Shang" } \\
\text { lineage }\end{array}$ & $\begin{array}{l}\text { non-Ji, Big Turtle } \\
\text { lineage }\end{array}$ & $\begin{array}{l}\text { Xian hou ding } \\
\text { 獻侯鼎 }\end{array}$ & 2 & 20 & & & 1 & & \\
\hline 10 & $\begin{array}{l}\text { unknown (probably, a mem- } \\
\text { ber of the royal lineage } \\
\text { entitled to sacrifice to dead } \\
\text { kings) }\end{array}$ & $\begin{array}{l}\text { Ji }(?, \text { probably, } \\
\text { royal lineage })\end{array}$ & $\begin{array}{l}\text { Cheng wang } \\
\text { ding 成王鼎 }\end{array}$ & 1 & 3 & & & 1 & & \\
\hline 11 & $\begin{array}{l}\text { Zuoce Da 作冊大, member of } \\
\text { the retinue of a high-ranked } \\
\text { royal relative, member of an } \\
\text { old "Shang" lineage }\end{array}$ & $\begin{array}{l}\text { non-Ji, Hawk } \\
\text { lineage }\end{array}$ & $\begin{array}{l}\text { Zuoce Da ding } \\
\text { 作冊大鼎 }\end{array}$ & 4 & 41 & & 1 & 1 & & \\
\hline 12 & $\begin{array}{l}\text { Yi hou Ze/Yu 宜侯失, royal } \\
\text { relative, colony ruler }\end{array}$ & $\begin{array}{l}\mathrm{Ji}, \mathrm{Ze} / \mathrm{Yu} \text { 决虞 } \\
\text { lineage }\end{array}$ & $\begin{array}{l}\text { Yi hou } \\
\text { Ze/Yu gui 宜 } \\
\text { 侯矢篮 }\end{array}$ & 1 & 126 & & 1 & 1 & 1 & \\
\hline 13 & $\begin{array}{l}\text { He 跔, royal collateral lineage } \\
\text { leader }\end{array}$ & Ji (?) & He zun 佑尊 & 1 & 119 & 1 & 1 & & 1 & \\
\hline 14 & $\begin{array}{l}\text { Zhong 事, high military } \\
\text { commander, founder of a } \\
\text { colony }\end{array}$ & unclear & $\begin{array}{l}\text { Zhong ding } \\
\text { 事鼎 }\end{array}$ & 1 & 57 & & 1 & & & \\
\hline
\end{tabular}




\begin{tabular}{|c|c|c|c|c|c|c|c|c|}
\hline \multicolumn{4}{|c|}{ Reference context } & \multicolumn{5}{|l|}{ Date } \\
\hline $\begin{array}{l}\text { personal } \\
\text { interaction }\end{array}$ & $\begin{array}{l}\text { ancestral } \\
\text { sacrifice }\end{array}$ & $\begin{array}{l}\text { royal } \\
\text { speech }\end{array}$ & other & Period & Reign & Place of discovery & $\begin{array}{l}\text { Date of } \\
\text { discovery }\end{array}$ & References \\
\hline & 1 & & $\begin{array}{l}\text { The king performed cere- } \\
\text { monies for his deceased } \\
\text { father (考) King Wen, } \\
\text { acknowledged merits } \\
\text { of the commissioners }\end{array}$ & Early & $\mathrm{Wu}$ & $\begin{array}{l}\text { Shaanxi, Meixian } \\
\text { 眉縣 County }\end{array}$ & 12th c. & $\mathrm{JC}_{4261}$ \\
\hline & 1 & & - & & Cheng & & $\begin{array}{l}\text { Song } \\
\text { dynasty }\end{array}$ & $\mathrm{JC} 2268$ \\
\hline \multirow[t]{3}{*}{1} & & & $\begin{array}{l}\text { Participated in the } \\
\text { conquest of Shang, } \\
\text { received gifts from } \\
\text { the king }\end{array}$ & & & $\begin{array}{l}\text { Shaanxi, Lingtong } \\
\text { 臨潼 Lingkou } \\
\text { 零口 }\end{array}$ & 1976 & $\mathrm{JC}_{4131}$ \\
\hline & & & $\begin{array}{l}\text { Participated in the } \\
\text { foundation of Wei 衛 } \\
\text { together with Kang } \\
\text { hou 康侯 (King Wu's } \\
\text { brother) }\end{array}$ & & & $\begin{array}{l}\text { Henan, Junxian } \\
\text { 濬縣, or } \\
\text { Huixian } \\
\text { Guweicun 輝縣 } \\
\text { 固圍村 }\end{array}$ & $\begin{array}{l}\text { prior to } \\
1949\end{array}$ & $\mathrm{JC}_{4059}$ \\
\hline & & & $\begin{array}{l}\text { After the conquest } \\
\text { the king was in } \\
\text { Chengzhou, Zhou } \\
\text { gong gave gifts to the } \\
\text { commissioner }\end{array}$ & & & unclear & $\begin{array}{l}\text { prior to } \\
1911\end{array}$ & JC6512 \\
\hline \multirow[t]{3}{*}{1} & & & $\begin{array}{l}\text { King Wu gave gifts to the } \\
\text { commissioner }\end{array}$ & & & $\begin{array}{l}\text { Shanxi, Hong- } \\
\text { dong, Nanqin }\end{array}$ & & \\
\hline & & & $\begin{array}{l}\text { The king was in Cheng- } \\
\text { zhou, transferred the } \\
\text { offerings to King } \mathrm{Wu} \\
\text { from Hao, gave gifts to } \\
\text { the commissioner }\end{array}$ & & & $\begin{array}{l}\text { unclear (collection } \\
\text { of the Shanghai } \\
\text { Museum) }\end{array}$ & $\begin{array}{l}\text { prior to } \\
1949\end{array}$ & $\mathrm{JC}_{2661}$ \\
\hline & & & $\begin{array}{l}\text { Certain gong pacified } \\
\text { the Yin, donated to } \mathrm{He} \\
\text { subordinates }\end{array}$ & & $\begin{array}{l}\text { Cheng } \\
\text { or } \\
\text { later }\end{array}$ & $\begin{array}{l}\text { unclear (private } \\
\text { collection) }\end{array}$ & after 2000 & $\begin{array}{l}\text { see refer- } \\
\text { ence s } \\
\text { in this } \\
\text { paper }\end{array}$ \\
\hline \multirow[t]{6}{*}{1} & & & $\begin{array}{l}\text { King Cheng was in } \\
\text { Zongzhou, gave gifts to } \\
\text { the commissioners }\end{array}$ & & Kang & $\begin{array}{l}\text { unclear (Tai- } \\
\text { pei Gugong } \\
\text { Museum) }\end{array}$ & $\begin{array}{l}\text { prior to } \\
1911\end{array}$ & $\begin{array}{l}\mathrm{JC} 2626- \\
2627\end{array}$ \\
\hline & 1 & & - & Early & $\begin{array}{c}\text { Kang } \\
\text { or } \\
\text { later }\end{array}$ & $\begin{array}{l}\text { unclear (Nelson- } \\
\text { Atkins Museum } \\
\text { of Art, Kansas } \\
\text { City) }\end{array}$ & $\begin{array}{l}\text { prior to } \\
1949\end{array}$ & $\mathrm{JC}_{1734}$ \\
\hline & 1 & & $\begin{array}{l}\text { Certain gong or taibao } \\
\text { was in Chengzhou, } \\
\text { performed ancestral } \\
\text { sacrifices to Kings Wu } \\
\text { and Cheng, gave gifts } \\
\text { to the commissioner }\end{array}$ & & & $\begin{array}{l}\text { Henan, Luoyang } \\
\text { 洛陽 Mangshan } \\
\text { Mapo 亡阝山馬坡 }\end{array}$ & 1929 & $\begin{array}{c}\mathrm{JC}_{2758}{ }^{-} \\
2761\end{array}$ \\
\hline & & 1 & $\begin{array}{l}\text { Records a transfer of } \\
\text { land and subordinates }\end{array}$ & & & $\begin{array}{l}\text { Jiangsu, Dantu } \\
\text { 丹徒, Yandun- } \\
\text { shan 煙墩山 }\end{array}$ & 1954 & $\mathrm{JC}_{4320}$ \\
\hline & & 1 & $\begin{array}{l}\text { Describes a meeting } \\
\text { of royal collateral } \\
\text { relatives, sacrifices to } \\
\text { deceased kings, gifts }\end{array}$ & & $\begin{array}{c}\text { Zhao } \\
(?)\end{array}$ & $\begin{array}{l}\text { Shaanxi, Baoji 寶 } \\
\text { 雞, Jiacun 賈村 }\end{array}$ & & $\mathrm{JC6014}$ \\
\hline & & 1 & $\begin{array}{l}\text { Records a transfer of } \\
\text { land and subordinates }\end{array}$ & & Zhao & $\begin{array}{l}\text { Hubei, Anlu 安陸, } \\
\text { Xiaogan 孝感 }\end{array}$ & 1118 & $\mathrm{JC}_{2785}$ \\
\hline
\end{tabular}


TABLE A8 Inscriptions mentioning the conquest of Shang or the first Kings

\begin{tabular}{|c|c|c|c|c|c|c|c|c|c|c|c|}
\hline \multicolumn{3}{|c|}{ Commissioner's identity } & \multicolumn{3}{|l|}{ Inscriptions } & \multicolumn{4}{|c|}{ First Kings } & \multicolumn{2}{|c|}{ Conquest } \\
\hline $\mathrm{Nr}$. & Name, function & Surname, lineage & Title & Exemplars & Signs & 文王 & 武王 & 文武 & 成王 & 商 & 殷 \\
\hline \multirow[t]{2}{*}{15} & $\begin{array}{l}\text { Nangong Yu 南宫孟, royal } \\
\text { collateral lineage head, high }\end{array}$ & $\begin{array}{l}\text { Ji, Nangong 南宮 } \\
\text { lineage }\end{array}$ & Yu ding 孟鼎 & 1 & 286 & 1 & 1 & & & & 1 \\
\hline & & & $\begin{array}{l}\text { Xiao Yu ding } \\
\text { 小孟鼎 }\end{array}$ & 1 & $\begin{array}{l}\text { ca. } \\
390\end{array}$ & & 1 & & 1 & & \\
\hline 16 & $\begin{array}{l}\text { Mao Ban 毛班, royal collateral } \\
\text { lineage head, high military } \\
\text { commander }\end{array}$ & Ji, Mao 毛 lineage & Ban $g u i$ 班筫 & 1 & 195 & 1 & & & & & \\
\hline 17 & $\begin{array}{l}\text { Guai bo 乘伯, leader of an } \\
\text { external polity, possibly, } \\
\text { affinal relative }\end{array}$ & $\begin{array}{l}\text { non-Ji, Guai 我 } \\
\text { lineage }\end{array}$ & $\begin{array}{l}\text { Guai bo gui } \\
\text { 我伯笽 }\end{array}$ & 1 & 149 & 1 & 1 & & & & \\
\hline \multirow[t]{2}{*}{18} & $\begin{array}{l}\text { Shi Xun 師訇, royal affinal } \\
\text { relative, high-ranked } \\
\text { military commander }\end{array}$ & $\begin{array}{l}\text { non-Ji (possibly, } \\
\text { Mi 密, Si } \\
\text { 姒-surnamed }\end{array}$ & Xun $g u i$ 訇篮 & 1 & 131 & & & 1 & & & \\
\hline & & lineage) & $\begin{array}{l}\text { Shi Xun } g u i \\
\text { 師訇篮 }\end{array}$ & 1 & 210 & & & 1 & & & \\
\hline 19 & $\begin{array}{l}\text { Wei shi Qiang 微史牆, } \\
\text { member of royal retinue, } \\
\text { ritual specialist, member of } \\
\text { an old "Shang" lineage }\end{array}$ & $\begin{array}{l}\text { non-Ji, Wei 微 } \\
\text { lineage }\end{array}$ & $\begin{array}{l}\text { Shi Qiangpan } \\
\text { 史牆盤 }\end{array}$ & 1 & 276 & 1 & 1 & 1 & 1 & & 1 \\
\hline 20 & $\begin{array}{l}\text { Wei bo Xing 微伯瘨, member } \\
\text { of royal retinue }\end{array}$ & & $\begin{array}{l}\text { Xing zhong } \\
\text { 瘨鐘 }\end{array}$ & 1 & 115 & 1 & 1 & & & & 1 \\
\hline \multirow[t]{2}{*}{21} & King Li & $\mathrm{Ji}$, royal lineage & Hu zhong 踟鐘 & 1 & 111 & & & 1 & & & \\
\hline & & & $\begin{array}{l}\text { 5th year } \\
\text { Huzhong } \\
\text { 五祀踟鐘 }\end{array}$ & 1 & 89 & 1 & & & & & \\
\hline 22 & $\begin{array}{l}\text { Mao Yin 毛音, royal collateral } \\
\text { lineage head }\end{array}$ & Ji, Mao 毛 lineage & $\begin{array}{l}\text { Mao gong ding } \\
\text { 毛公鼎 }\end{array}$ & 1 & 479 & & & 1 & & & \\
\hline 22 & $\begin{array}{l}\text { Shi Ke 師克 (a.k.a. Shanfu Ke } \\
\text { 膳夫克), possibly royal col- } \\
\text { lateral lineage head, official }\end{array}$ & $\begin{array}{l}\mathrm{Ji} \text {, probably Jing } \\
\text { 井 lineage }\end{array}$ & $\begin{array}{l}\text { Shi Ke } x u \\
\text { 師克嬃 }\end{array}$ & 2 & 151 & & & 1 & & & \\
\hline \multirow[t]{3}{*}{23} & Shan Qiu 單述, high- ranked & Ji, Shan 單 & Qiu pan 逑盤 & 1 & 372 & 1 & 1 & 1 & & & 1 \\
\hline & $\begin{array}{l}\text { member of a royal collateral } \\
\text { lineage, official }\end{array}$ & lineage & $\begin{array}{l}\text { 42nd year Qiu } \\
\text { ding 四十二 } \\
\text { 年㟈鼎 }\end{array}$ & 2 & 292 & & & 1 & & & \\
\hline & & & $\begin{array}{l}\text { 43nd year Qiu } \\
\text { ding 四十三 } \\
\text { 年逑鼎 }\end{array}$ & 10 & 320 & & & 1 & & & \\
\hline
\end{tabular}




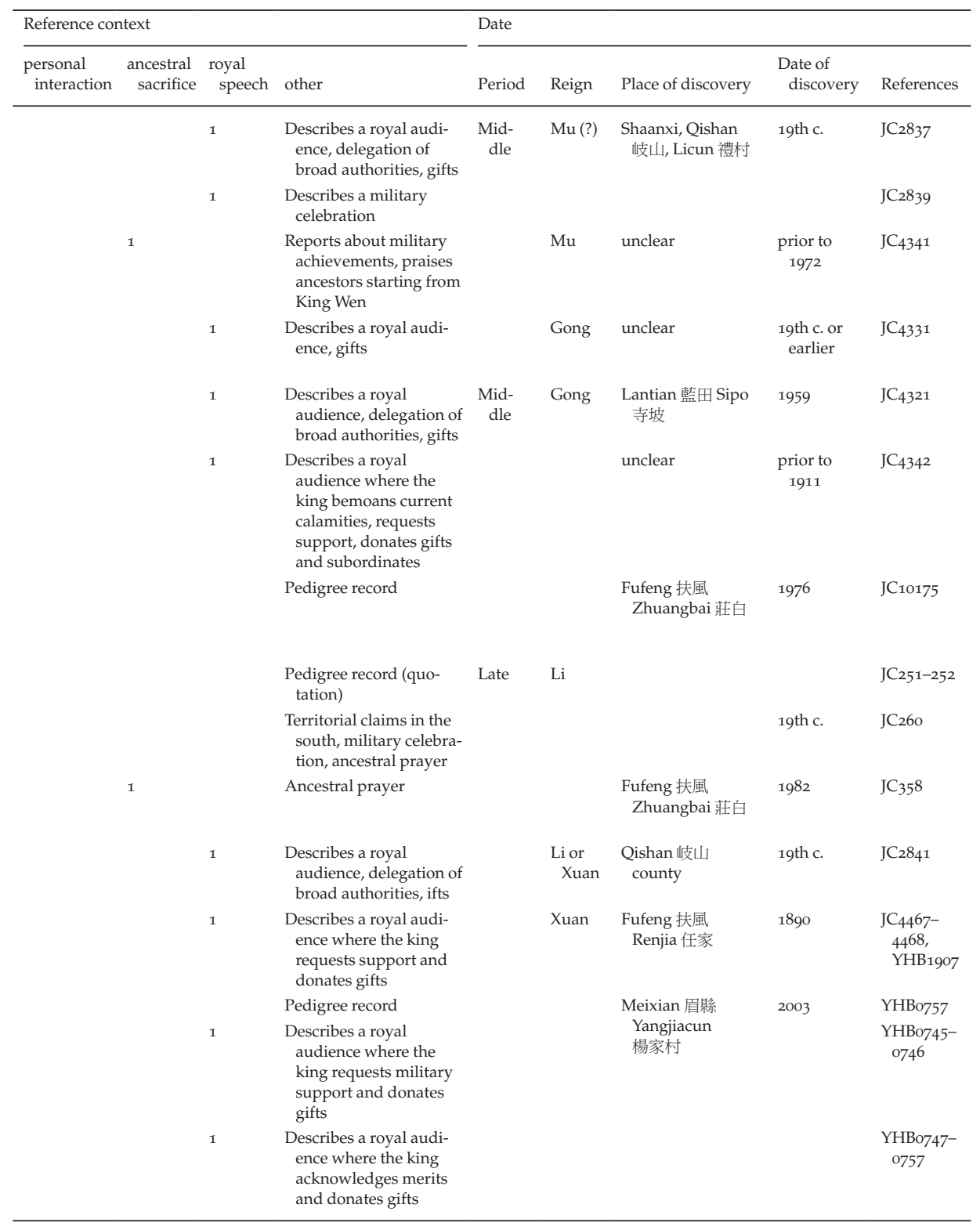




\section{中國文化記憶創造的開端與西周王室的記憶政策}

\section{夏玉婷}

提要

周克商及早期周王的記憶乃古代中國歷史與文化傳統的關鍵部分之一。 本文從 “社會記憶” 及 “文化記憶”理論的角度, 探索此記憶的早期傳承 過程。從本文針對西周（公元前 11 世紀中葉到公元前 8 世紀初）青銅 器銘文的分析可以顯示出, 約在公元前 10 世紀前半葉左右, 周王朝對 “奠基式的往事” 的紀念已成為周王室意圖推動的政策之一。而從公元前 10 世紀中葉開始, 官方敘事已將文王及武王結合為建邦之父, 同時抹鞄 成王的角色。筆者認為, 成王被西周官方敘事遺忘的原因可能在於宗族 結構中固有的邏輯: 宗族總是通過崇拜最早的共同祖先而保持父系親屬 網絡中的群體完整性。成王即位以後, 周王族停止化分支系, 成王的庶 子未成為權力氏族的先祖, 所以成王在西周以親屬為重點的社會及文化 記憶中所扮演的角色相對較為微弱。本文顯示, 大部分出現在這類紀念 文中的器主多屬於姬姓的親屬網絡, 而且在此網絡中多占尊貴的地位。 此外, 本文列示周王室培育維護文、武王記憶的方法包括禮儀, 禮器, 王言及銘文的應用。筆者的分析表明，周朝的 “鞏固根基式的回憶” 經 常被引述在政治協商的過程中, 包括籠絡異姓貴族等。西周奠基式的敘 事並非一成不變。相反地, 三百年間, 周王朝及其住在中心地區的屬下 貴族常將此敘事依照他們當時的需求而作修改。根據上述分析, 本文有 助於理解早期中國歷史傳統的根源及特定社會中文化記憶的創造過程。

Keywords: Western Zhou, Conquest of Shang, first Zhou kings, cultural memory, social memory, bronze inscriptions, kinship, Da Yu ding, He zun 西周, 周克商, 文王, 武王, 文化記憶, 社會記憶, 青銅器銘文, 親屬, 大 孟鼎, 何尊 